\title{
MACHINE-LEARNING THE SKILL OF MUTUAL FUND MANAGERS
}

\author{
Ron Kaniel \\ Zihan Lin \\ Markus Pelger \\ Stijn Van Nieuwerburgh \\ Working Paper 29723 \\ http://www.nber.org/papers/w29723 \\ NATIONAL BUREAU OF ECONOMIC RESEARCH \\ 1050 Massachusetts Avenue \\ Cambridge, MA 02138 \\ February 2022
}

The authors have no conflicts of interest to disclose. The views expressed herein are those of the authors and do not necessarily reflect the views of the National Bureau of Economic Research.

NBER working papers are circulated for discussion and comment purposes. They have not been peer-reviewed or been subject to the review by the NBER Board of Directors that accompanies official NBER publications.

(C) 2022 by Ron Kaniel, Zihan Lin, Markus Pelger, and Stijn Van Nieuwerburgh. All rights reserved. Short sections of text, not to exceed two paragraphs, may be quoted without explicit permission provided that full credit, including (C) notice, is given to the source. 
Machine-Learning the Skill of Mutual Fund Managers

Ron Kaniel, Zihan Lin, Markus Pelger, and Stijn Van Nieuwerburgh

NBER Working Paper No. 29723

February 2022

JEL No. G0,G11,G23,G5

\section{ABSTRACT}

We show, using machine learning, that fund characteristics can consistently differentiate high from low-performing mutual funds, as well as identify funds with net-of-fees abnormal returns. Fund momentum and fund flow are the most important predictors of future risk-adjusted fund performance, while characteristics of the stocks that funds hold are not predictive. Returns of predictive long-short portfolios are higher following a period of high sentiment or a good state of the macro-economy. Our estimation with neural networks enables us to uncover novel and substantial interaction effects between sentiment and both fund flow and fund momentum.

\author{
Ron Kaniel \\ University of Rochester \\ Simon School of Business \\ 500 Wilson BLVD \\ Carol Simon Hall \\ Box 270100 (Room CS3-312) \\ ron.kaniel@simon.rochester.edu \\ Zihan Lin \\ Stanford University \\ 475 Via Ortega \\ Suite B060 \\ Stanford, CA 94305 \\ zihanl@stanford.edu
}

\author{
Markus Pelger \\ Stanford University \\ Department of Management Science \\ \& Engineering \\ 312 Huang Engineering Center \\ Stanford, CA 94305 \\ mpelger@stanford.edu \\ Stijn Van Nieuwerburgh \\ Columbia University \\ Graduate school of Business \\ Uris Hall, office 809 \\ 3022 Broadway \\ New York, NY 10027 \\ and NBER \\ svnieuwe@gsb.columbia.edu
}




\section{Introduction}

The asset management industry is enormous and growing rapidly. U.S. mutual funds had \$24 trillion in assets under management at the end of 2020, more than half of which were in equity mutual funds. Over 100 million Americans rely on such funds to save for retirement and meet other financial objectives. Many of these mutual funds actively trade stocks in an effort to out-perform their benchmarks and create value for their investors. The literature has found mixed results in terms of the investment performance of actively-traded equity mutual funds. We revisit the evidence using modern techniques, and ask which-if any-characteristics of mutual funds and of the stocks they hold can help separate the corn from the chaff. We uncover new evidence that fund flows and fund return momentum are the only two characteristics that can meaningfully and robustly help distinguish funds that outperform from those that under-perform. The relative performance of top and bottom performers is particularly large in times of high investor sentiment.

Specifically, we study the universe of actively-traded U.S. equity mutual funds between 1980 and 2019 and the stocks that they hold. The object we predict is the abnormal fund return, defined as the four-factor alpha of the mutual fund. The predictors are a long list of 46 stock characteristics weighted by the funds' holdings and 13 fund and fund-family characteristics. Fund characteristics include fund return momentum and fund flow. We also include a variable that summarizes the overall state of the market, either proxied by investor sentiment or by a comprehensive measure of macro-economic activity. Our main method is an artificial neural network model, namely a feedforward neural network, which can reliably estimate a complex functional relationship among a large set of variables. It is trained and tuned on one subset of the data and evaluated on another subset of the data. Hence, all of our predictions are out-of-sample. It identifies fund characteristic information, and specifically fund flow and fund momentum, as the key predictors of mutual fund out-performance. Moreover, these two fund characteristics matter much more when investor sentiment is high. That is, there is an important interaction effect, which linear models fail to pick up.

The model predictions generate a large difference in performance out-of-sample. Buying the ten percent of mutual funds with the best predicted performance each month, and using the model not only to select but also to weight the funds within the top decile, generates a cumulative abnormal return of $72 \%$ over our sample period. Buying the ten percent of mutual funds with the worst predicted performance each month produces a cumulative abnormal return of $-119 \%$. The $191 \%$ difference in out-of-sample performance based on the model's predictions is economically large and statistically significant. Since the best and the worst funds have similar fees, it holds for both before- and after-fee abnormal returns. Moreover, top performing funds exhibit positive abnormal performance net-of-fees as well. This performance improves further when we use a model that directly predicts net-of-fees performance 
The performance differential is nearly identical if we constrain the model by removing all stock characteristic information. In fact, we can also remove most fund and fund family characteristics. The predictions of a model that are only fed fund flow, fund momentum, and sentiment are nearly as good as those of the full model. They deliver out-performance of nearly 50 basis points per month for the top relative to the bottom deciles of predicted performers. The Sharpe ratio on this strategy is 0.25 per month.

Having uncovered flow and fund momentum as the key predictors, we show that they each predict fund performance in a univariate analysis. However, such a univariate analysis fails to account for the non-linear interaction effects of these two characteristics with investor sentiment. The state of the macro-economy, measured by the Chicago Fed National Activity Index (CFNAI), predicts the best and worst fund performers as well as sentiment does when combined with fund characteristics. However, CFNAI is not as good at predicting the relative returns within the top and bottom deciles as sentiment. We trace back this difference to a lack of interaction effects between CFNAI and fund characteristics.

We decompose the fund abnormal return into a between-disclosure component, which holds fixed the funds' stock holdings at their previous quarter-end values, and a within-disclosure component, which accounts for mutual fund trades during the quarter. The latter is the sum of the return gap and a risk exposure differential. ${ }^{1}$ We find that about half of the outperformance comes from the model's ability to predict between-disclosure abnormal returns and the other half from predicting within-disclosure abnormal returns. Both fund flow and fund momentum predict the return gap and the risk exposure differential, while most stock characteristics that predict the return gap do so by taking on more systematic risk resulting in little within-disclosure abnormal return. These results shed additional light on the sources and persistence of out-performance .

In sum, mutual fund returns are predictable in real time. The predictability lasts for three years, and is economically meaningful. About $10-20 \%$ of funds generate positive abnormal returns even after fees. Most of the benefits accrue from avoiding the worst-performing funds.

The salience of flow and fund return momentum as the key predictors suggests that some investors can detect skill and (re)allocate their investment towards such skilled managers. This reallocation of investment flows is not as strong as the frictionless model of Berk and Green (2004) predicts. Skill leaves a trail in the form of fund return momentum for investors to exploit in the next period. Put differently, the flows are gradual and small enough that it takes several periods until the fund runs into zero marginal abnormal returns.

The results are potentially also consistent with funds and fund families attracting flows through marketing rather than-or in addition to-through investment skill (Ibert, Kaniel, Van Nieuwerburgh, and Vestman, 2018; Roussanov, Ruan, and Wei, 2021). Marketing-induced inflows create

\footnotetext{
${ }^{1}$ The return gap is the difference between the fund's actual returns over the period and the hypothetical returns generated by keeping the fund's portfolio holdings constant.
} 
buying pressure for stocks that the fund typically invests in. In a world with downward-sloping demand curves (Coval and Stafford, 2007; Koijen and Yogo, 2019; Gabaix and Koijen, 2021), this raises prices and lifts fund returns. Through the flow-performance relationship, as well as through persistence in marketing-driven flows, the out-performance creates more inflows in the next period. The demand pressure increases prices further, generating momentum in fund returns. The fact that flows and fund momentum have a much stronger association with fund performance in high-sentiment periods lends further credence to this marketing-driven channel.

Our paper makes several methodological contributions adding to the protocol of how to use machine learning models for asset pricing. First, we contribute to relative performance prediction. We show that abnormal returns, obtained as residuals to a factor model, are not only an economically motivated, but also the statistically better target for prediction. In contrast, the level of fund (and stock) returns is extremely hard to predict. Abnormal returns remove the level effect of market and other risk factors, which makes the prediction of abnormal returns a relative objective. The commonly-used machine learning prediction of returns can be dominated by the prediction error in the common component in return levels, resulting in suboptimal use of cross-sectional information relevant to relative performance. Indeed, we show that using the same flexible methods for predicting abnormal returns instead of returns results in higher accuracy and better portfolio performance.

Second, we show how to measure the dependencies on macroeconomic states. Specifically, we propose a cross-out-of-sample evaluation of conditional models using the full time-series. Importantly, the data points for estimating and evaluating the model have to be sampled such that all relevant economic conditions are represented in all subsamples, which can be achieved by random sampling over time. This is particularly important for measuring the dependencies on macro-economic states which are only available in a subset of the data and might be neglected in the estimation or evaluation with a conventional chronological data split. Our evaluation approach allows us to take advantage of all data for the out-of-sample analysis, diminishing the effect of particular subperiods.

Third, we quantify the economic benefit of different information sets. We suggest to compare the prediction and trading benefits by varying the information set available to the same flexible machine-learning algorithm. The focus is the comparison of information sets instead of a horse race of model specifications.

Fourth, in order to better assess the investment benefits of prediction, we suggest predictionweighted portfolios. These portfolios result in the largest return spread as they take advantage not only of the ranking but also of the relative strength of the prediction signal. The predictionweighted portfolios dominate the widely-used equally-weighted portfolios based on prediction quantiles.

Last but not least, we propose a new measure for interaction effects in machine learning algo- 
rithms, which does not only measure a local slope, but a more informative global slope.

Related Literature An enormous literature in empirical asset pricing studies whether mutual fund managers outperform their benchmarks through stock picking and market timing. The seminal paper of Berk and Green (2004) suggests that a large fraction of fund managers outperforms before fees while Fama and French (2010) find no out-performance before fees. Kacperczyk, Nieuwerburgh, and Veldkamp $(2014 ; 2016)$ find that a modest fraction of managers displays enough skill to persistently outperform, through a strategy that switches between market timing in recessions and stock picking in expansions. The presence of uninformed mutual fund managers and retail traders makes this possible as an equilibrium phenomenon (Stambaugh, 2014).

While investors direct flows to funds that out-perform, at least as measured by the CAPM alpha (Berk and Van Binsbergen, 2016; Barber, Huang, and Odean, 2016), there is mounting evidence that other factors besides fees and before-fee performance determine fund flows. Roussanov, Ruan, and Wei (2021) argues that marketing is an important determinant of flows, necessary to understand the empirical joint distribution of fund size and performance. Consistent with this, Ibert, Kaniel, Van Nieuwerburgh, and Vestman (2018) shows that fund manager compensation is tied to the component of assets-under-management that is orthogonal to current and past fund performance.

The predictive role of flows to fund performance was first uncovered by Gruber (1996) and Zheng (1999), who identified a positive fairly short-lived and weak relationship. The "smart money" relation they found exists for small but not for large funds. Importantly, risk adjustment in these papers did not include adjusting for momentum. Using the Carhart (1997) 4-factor model, Sapp and Tiwari (2004) show the smart money effect is explained by a stock return momentum factor. Our machine learning approach revives the predictive role of flows, with a 4-factor riskadjustment. Furthermore, the predictive power of our method is long lived.

Carhart (1997) finds that persistence in fund net performance essentially disappears once a momentum factor is added, apart for the worst performing funds where it arises from persistently high expenses. With the aid of machine learning, we identify an important predictive role for fund past performance both gross and net of fees, and after controlling for stock momentum. Bollen and Jeffrey (2005) argue that part of the reason for the lack of performance persistence in Carhart (1997) is that he forms decile portfolios and considers the time series of performance of these decile portfolios, instead of computing an abnormal return at the stock level and averaging that across stocks in each subsequent period. Our predictive results, which find an important role for fund past performance, hold for long-short portfolios as well, highlighting that including fund past performance as part of a neural network prediction model is important.

Our paper more broadly relates to the fund return predictability literature. Cremers and Petajisto (2009)'s Active Share-funds with holdings that differ greatly from their benchmarks- 
predicts benchmark index-adjusted Carhart alphas. Kacperczyk, Sialm, and Zheng (2008a)'s Return Gap predicts 4-factor monthly alphas. The monthly abnormal return we identify is about twice as large as theirs. While they finds significance for the short but not the long leg, we find significance for both. ${ }^{2}$ More importantly, we show that the predictive power of fund momentum and fund flows are substantially amplified when investor sentiment is high at the time of forming portfolios.

There is fairly little evidence on the impact of macro-economic conditions on performance. Moskowitz (2000) and Kosowski (2011) find that risk-adjusted performance of mutual funds is better in recessions than in booms. Massa and Yadav (2015) show that a fund's level of exposure to high-sentiment beta stocks predicts lower future returns. Sentiment affects the out-performance of fund managers differently than long-short anomaly strategies. Similar to the findings in Stambaugh, Yu, and Yuan (2012) for stock return anomalies, we find that high sentiment periods coincide with more fund return predictability. While the effect for equity anomalies comes primarily from its short leg, the out- respectively under-performance of the best and worst fund managers in high sentiment periods is symmetric, suggesting a different economic channel. In contrast to the novel interaction effects between sentiment and fund characteristics there are no equivalent interaction effects with the state of the macro-economy, as proxied by CFNAI.

Our work connects to the growing Machine Learning (ML) literature in finance (see Karolyi and Van Nieuwerburgh, 2020, for a summary). This literature has focused on analyzing the crosssection of stock returns using a plethora of return predictors. ${ }^{3}$ Similar techniques are beginning to be used in other asset classes. ${ }^{4}$. Contemporaneous and independent work to ours by $\mathrm{Li}$ and Rossi (2020) and DeMiguel, Gil-Bazo, Nogales, and Santos (2022) study mutual fund performance with ML techniques, both providing a comparison study of predicting fund returns or abnormal returns, respectively, with machine learning methods similar to Gu, Kelly, and Xiu (2020). In addition to methodological innovations, we use a richer information set, which allows us to distill the economic value of holdings-based, fund-specific, and macroeconomic information. ${ }^{5}$ Our results emphasize the role of fund-specific characteristics and the interaction with the state of the economy, and make progress on understanding the economic mechanism.

The rest of the paper is organized as follows. Section 2 describes or data. Section 3 turns to a

\footnotetext{
${ }^{2}$ Some other predictive variables identified in the literature include, for example, Industry Concentration of holdings (Kacperczyk, Sialm, and Zheng (2005)) and fund $R^{2}$ (Amihud and Ruslan (2013).

${ }^{3}$ Important contributions include among others: return prediction with flexible and regularized models in Freyberger, Neuhierl, and Weber (2020) and Gu, Kelly, and Xiu (2020), robust stochastic discount factor construction with many characteristics in Kozak, Nagel, and Santosh (2020), Chen, Pelger, and Zhu (2020) and Bryzgalova, Pelger, and Zhu (2021) and estimation and evaluation of risk factors in Lettau and Pelger (2020), Kelly, Pruitt, and Su (2019), and Feng, Giglio, and Xiu (2020).

${ }^{4}$ Bianchi, Büchner, and Tamoni (2021); Bianchi, Büchner, Hoogteijling, and Tamoni (2021) study bonds, Filippou, Rapach, Taylor, and Zhou (2021) currencies, and Wu, Chen, Yang, and Tindall (2021) hedge fund strategies

${ }^{5}$ In particular, characteristics based on price trends of funds and sentiment information, which we find to be the most relevant, are not included in their contemporaneous studies.
} 
linear, univariate, in-sample analysis as a first pass on analyzing mutual fund performance. Section 4 describes our neural network model and our main results. Section 5 studies the mechanism by decomposing fund abnormal returns. Section 6 concludes. The appendix provides the details on data cleaning and imputation (A), robustness of our main results (B), and implementation (C).

\section{Data}

\subsection{Mutual Funds}

As is customary, we focus on actively-managed mutual funds holding mostly domestic equities. The mutual fund returns, expenses, total net assets (TNA), investment objectives and other fund characteristics are from the Center for Research in Security Prices (CRSP) Survivor Bias-Free Mutual Fund Database. Our analysis requires fund holdings, which we obtain by linking the database to the Thomson Financial Mutual Fund Holdings. Our cleaned data set includes 407,158 (mutual fund by month) observations for 3275 mutual funds spanning the period from January 1980 until January 2019. We restrict our study to mutual funds with raw returns observed at time $t$ and holdings data and total net assets observed at $t-1$, which guarantees that holding-based abnormal return returns at time $t$, as defined below, are observed. At each time $t$, mutual funds are also required to have at least 30 non-missing return observations in the last 36 months, which guarantees that the regression-based abnormal returns are well-defined. Appendix A contains more details and summary statistics.

\subsection{Abnormal Fund Returns}

Our main object of interest is the abnormal mutual fund return. It measures fund performance after subtracting compensation for systematic risk factor exposure. We construct the abnormal return for each fund-month observation relative to the Carhart (1997) model, following a similar procedure. First, factor loadings are estimated over the prior 36 months:

$$
R_{i, t-36: t-1}=\alpha_{i}+F_{t-36: t-1} \hat{\beta}_{i, t-1}+\eta_{i,-36: t-1}
$$

where $R_{i, t}$ is the gross (before-fee) return of fund $i$ in month $t$ in excess of a one-month T-bill yield. The rolling window regressions allow for time-varying factor exposures. Second, abnormal returns $\left(R_{i, t}^{a b n}\right)$ are computed:

$$
R_{i, t}^{a b n}=R_{i, t}-F_{t} \hat{\beta}_{i, t-1}
$$

Abnormal returns are not guaranteed have a mean of zero. Their mean and median is $-0.03 \%$ per month in our sample with a standard deviation of $2.00 \%$. Hence, mutual funds earn returns 
commensurate with the predictions of the Carhart model on average, but with substantial crosssectional dispersion. While there is some controversy over which return model actual mutual fund investors use (Berk and Van Binsbergen, 2015; Barber, Huang, and Odean, 2016; Jegadeesh and Mangipudi, 2021), the Carhart model arguably remains the main factor model in the mutual fund literature and hence a natural benchmark for our purposes. The main results are robust to using abnormal returns with respect to an eight-factor model. ${ }^{6}$

We will use machine-learning techniques to connect abnormal fund returns to the characteristics of mutual funds, including the characteristics of the stocks they hold, and to variables that capture the state of the economy.

\subsection{Holdings-based Characteristics}

Mutual funds hold stocks. The stock characteristics are from Chen, Pelger, and Zhu (2020) and cover 46 characteristics that have been shown to have predictive power for the cross-section of expected returns. They are listed in Table 1 in six subgroups.

There are 332,294 fund/time observations with fully observed fund characteristics. We impute the missing fund characteristics with a latent factor model in the characteristics space as described in Appendix A. Hence, we have a complete set of fund characteristics for all 407,158 fund/time observations. Our results are robust to the data imputation and are essentially identical on the subset of funds with fully observed data.

All stock characteristics are cross-sectionally normalized to range from - 0.5 to 0.5 based on stocks' rankings on that characteristic. We normalize the sign of the characteristic ranking of stocks such that the corresponding long-short factor has a positive risk premium. For example for size (LME), the largest stocks have negative rankings while small stocks have positive rankings. The stock-specific characteristics of each fund are weighted by the fund's holdings.

\subsection{Fund and Family Characteristics}

In addition to the 46 stock characteristics, we also form 13 fund characteristics sorted in the last three subgroups shown in Table 1: fund momentum, fund characteristics, and fund family characteristics. The three fund momentum characteristics are computed from fund returns as defined in Table 2. Following Brown and $\mathrm{Wu}$ (2016), fund family is identified by the management company code. The variables "Family_r12_2" and "Family flow" are the average of the fund-level counterparts, "F_r12_2" and "flow," weighted by TNA of all funds in the family, excluding the fund itself. "Family age" is the age of the oldest fund in the family, excluding the fund itself. "Fund no" is

\footnotetext{
${ }^{6}$ That model includes market, size, value, momentum, investment, profitability, short-term reversal, and long-term reversal factors. The results are available upon request.
} 
Table 1: Fund-specific and stock-specific characteristics by category

\begin{tabular}{|c|c|c|c|c|c|}
\hline & Past Returns & & (30) & CF2P & Cashflow to price \\
\hline (1) & $\overline{\mathrm{r} 2 \_1}$ & Short-term momentum & (31) & D2P & Dividend Yield \\
\hline (2) & r12_2 & Momentum & (32) & E2P & Earnings to price \\
\hline (3) & r12_7 & Intermediate momentum & (33) & $\mathrm{Q}$ & Tobin's Q \\
\hline (4) & r36_13 & Long-term momentum & (34) & S2P & Sales to price \\
\hline (5) & ST_Rev & Short-term reversal & (35) & Lev & Leverage \\
\hline \multirow[t]{3}{*}{ (6) } & LT_Rev & Long-term reversal & \multirow{2}{*}{\multicolumn{3}{|c|}{ Trading Frictions }} \\
\hline & & & & & \\
\hline & Investment & & (36) & AT & Total Assets \\
\hline (7) & $\overline{\text { Investment }}$ & Investment & (37) & Beta & CAPM Beta \\
\hline (8) & NOA & Net operating assets & (38) & IdioVol & Idiosyncratic volatility \\
\hline \multirow[t]{2}{*}{ (9) } & DPI2A & Change in property, plants, and & (39) & LME & Size \\
\hline & & equipment & (40) & LTurnover & Turnover \\
\hline \multirow[t]{3}{*}{ (10) } & NI & Net Share Issues & (41) & MktBeta & Market Beta \\
\hline & & & (42) & Rel2High & Closeness to past year high \\
\hline & Profitability & & (43) & Resid_Var & Residual Variance \\
\hline (11) & $\overline{\mathrm{PROF}}$ & Profitability & (44) & Spread & Bid-ask spread \\
\hline (12) & ATO & Net sales over lagged net operating assets & (45) & SUV & Standard unexplained volume \\
\hline (13) & СТO & Capital turnover & (46) & Variance & Variance \\
\hline (14) & FC2Y & Fixed costs to sales & & & \\
\hline (15) & OP & Operating profitability & & Fund Moment & \\
\hline (16) & PM & Profit margin & (47) & $\overline{\text { F_ST_Rev }}$ & $\overline{\text { Fund short-term momentum }}$ \\
\hline (17) & RNA & Return on net operating assets & $(48)$ & F_r2_1 & Fund short-term momentum \\
\hline (18) & ROA & Return on assets & (49) & F_r12_2 & Fund momentum \\
\hline (19) & ROE & Return on equity & & & \\
\hline \multirow[t]{2}{*}{ (20) } & SGA2S & Selling, general and administrative & & \multicolumn{2}{|c|}{ Fund Characteristics } \\
\hline & & expenses to sales & (50) & age & Fund age \\
\hline \multirow[t]{3}{*}{ (21) } & $\mathrm{D} 2 \mathrm{~A}$ & Capital intensity & $(51)$ & tna & Fund tna \\
\hline & & & $(52)$ & flow & Fund flow \\
\hline & Intangibles & & (53) & exp_ratio & fund expense ratio \\
\hline (22) & $\overline{\mathrm{AC}}$ & Accrual & $(54)$ & turnover ratio & turnover ratio \\
\hline (23) & OA & Operating accruals & & & \\
\hline (24) & OL & Operating leverage & & \multicolumn{2}{|c|}{ Fund Family Characteristics } \\
\hline (25) & PCM & Price to cost margin & (55) & family_tna & family tna \\
\hline & & & (56) & fund_no & number of funds in family \\
\hline & Value & & (57) & Family_r12_2 & family momentum \\
\hline (26) & $\overline{\mathrm{A} 2 \mathrm{ME}}$ & Assets to market cap & $(58)$ & Family_age & Family age \\
\hline (27) & BEME & Book to Market Ratio & (59) & Family_flow & Family flow \\
\hline (28) & C & Ratio of cash and short-term & & & \\
\hline (29) & $\mathrm{CF}$ & Free Cash Flow to Book Value & & & \\
\hline
\end{tabular}

This table shows all 59 characteristics sorted into nine categories. The first six categories represent stock-specific characteristics and the last three characteristic groups are fund-specific characteristics.

the number of funds in the family and "Family tna" is the sum of TNAs of all funds in the family excluding the fund itself. The fund and family characteristics are similarly normalized.

On average, mutual funds in our sample are 13.7 years old, manage \$1,153 million dollars in assets, and charge a monthly expense ratio of around $0.1 \%$. The fund's flow is defined as $\mathrm{flow}_{i, t}=$ $\frac{T N A_{i, t}-T N A_{i, t-1}\left(1+R_{i, t}\right)}{T N A_{i, t-1}}$. Throughout the sample period the mutual fund industry is growing; on average funds enjoy a $1.6 \%$ monthly inflow. 
Table 2: Fund momentum characteristics

\begin{tabular}{|c|c|c|c|}
\hline Acronym & Name & Definition & Reference \\
\hline F_r2_1 & Short-term momentum & Lagged one-month abnormal return & Jegadeesh and Titman (1993) \\
\hline F_r12_2 & Momentum & $\begin{array}{l}\text { Mean abnormal return from past } 12 \text { months before the } \\
\text { abnormal return prediction to two months before. Need } \\
\text { at least } 8 \text { non-missing samples to be included. }\end{array}$ & Fama and French (1996) \\
\hline F_ST_Rev & Short-term reversal & Prior month abnormal return & Jegadeesh and Titman (1993) \\
\hline
\end{tabular}

This table summarizes the fund momentum characteristics. We use a ' $F$ ' prefix to denote that these characteristics are based on mutual funds. It includes their acronym, name, definition and reference of their stock based counterpart. The fund momentum characteristics follow the same definition as their stock counterpart in Chen, Pelger, and Zhu (2020).

\subsection{Macro-economic Information}

Figure 1: Macroeconomic time series plots

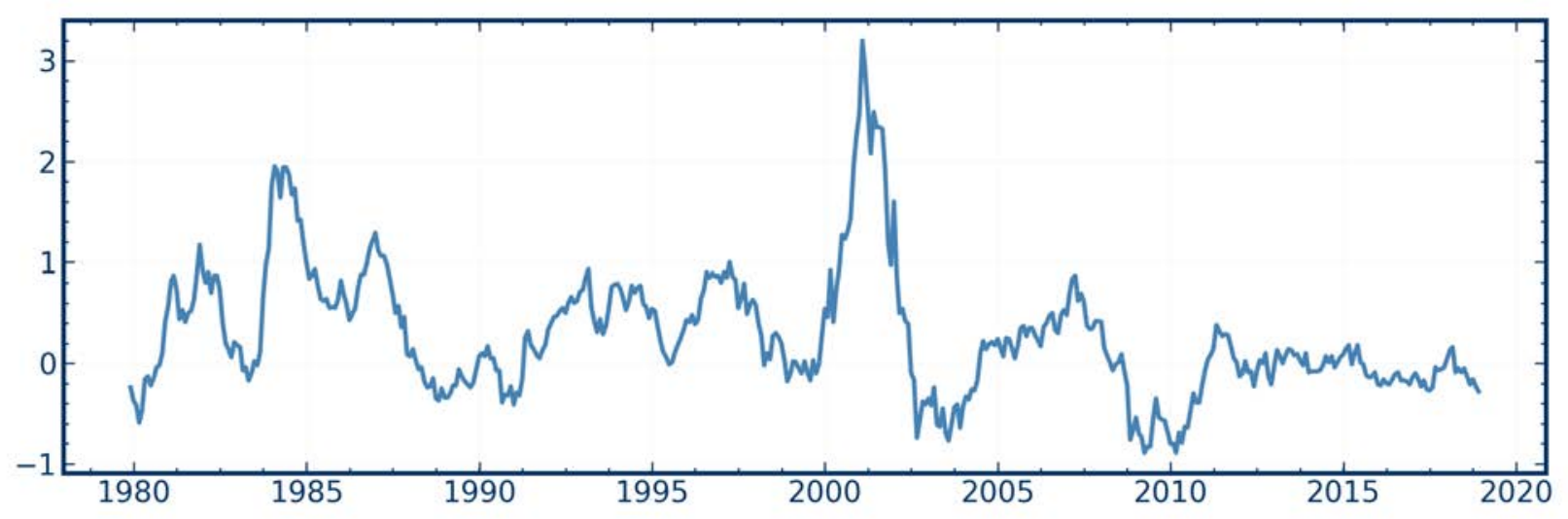

(a) Sentiment

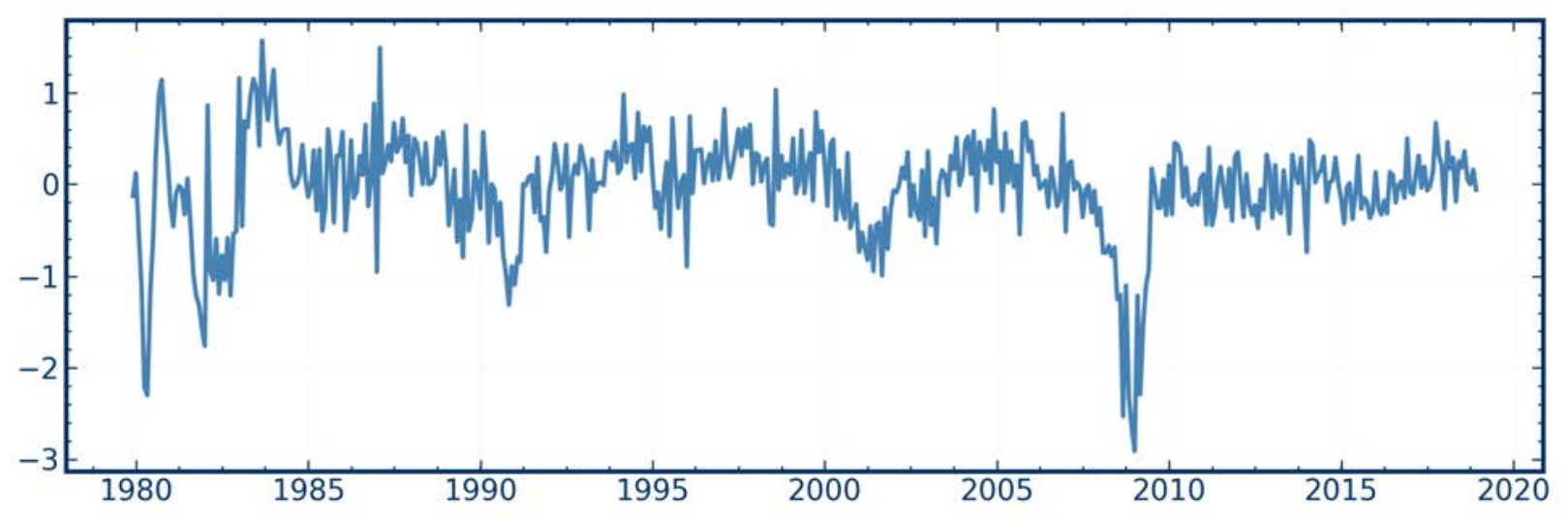

(b) CFNAI

These figures show the macroeconomic time series plot. Panel (a) plots the sentiment time series and panel (b) plots the CFNAI time series.

To study whether fund performance can be linked to the state of the economy, we include 
investor sentiment (Baker and Wurgler (2006)) and the Chicago Fed National Activity Index (CF$\mathrm{NAI}$ ), a series which captures the state of the macro economy and is itself an index of many macro time series. Figure 1 plots the time series plots of both macro variables. Kacperczyk, Nieuwerburgh, and Veldkamp (2014) shows that mutual fund performance depends on the second variable.

\section{In-Sample Fund Performance By Univariate Characteristic}

As an initial step before our main analysis, we explore which fund characteristics are associated with strong mutual fund performance. This analysis is not a substitute for our full analysis since it is (i) in-sample, rather than predictive, (ii) it ignores the possibility of important non-linearities in the relationship between fund characteristics and fund abnormal returns, and (iii) it ignores the possibility of important interaction effects between multiple characteristics or between characteristics and macro variables.

For each of the 59 characteristics, we sort fund abnormal returns into deciles based on the value of the characteristic. Then, we construct long-short portfolios as the difference between the top and bottom deciles. The first two columns of Table 3 report the mean and Sharpe ratio of these long-short portfolio returns, ranked from highest to lowest Sharpe ratio. The stars report the significance of a test that the mean of the long-short portfolio return is different from zero. The main finding, which foreshadows the results in our main analysis, is that portfolios based on fund characteristics, and in particular fund momentum and flow, are associated with the highest Sharpe ratios as well as a large and statistically significant mean abnormal fund return. Of the ten characteristics that are associated with a monthly Sharpe ratio above 0.10, seven are fundlevel variables and only three are stock characteristics. Most stock-specific characteristics cannot systematically differentiate between the performance of mutual funds. Put simply, little can be learned about fund abnormal returns from the stocks that they hold.

In Appendix Table B.1, we show that the pre-eminence of fund characteristics as (univariate) drivers of fund performance also emerges when we collapse characteristics by group (using the nine groups in Table 1). Group characteristics are formed as the equally-weighted average of the characteristics within each category, and then long-short portfolios of funds are formed based on the deciles of the group characteristics. Fund momentum rises to the top as the group characteristic that is associated most strongly with fund performance (Sharpe ratio of 0.22 ), followed by Family characteristics (SR of 0.16), and Fund characteristics (0.13). The holdings-based characteristics Value (0.16) and Profitability (0.11) are in third and fifth place. Thus, the last five places out of nine are reserved for stock characteristics. 
Interaction Effects with Macro Variables The univariate analysis also foreshadows a second main result of the paper, which is that fund characteristics exercise a different influence on fund performance depending on the state of the economy. The last six columns of Table 3 report Sharpe ratios and mean returns of the same univariate long-short portfolios, but conditional on the level of investor sentiment. The sample is split into terciles based on the value of the sentiment index in the prior month. ${ }^{7}$ We find that the strong association between abnormal performance and fund characteristics such as fund momentum, fund short-run reversal, and flow is driven by aboveaverage sentiment periods. This is an early hint at important interaction effects between macro variables and (fund) characteristics. ${ }^{8}$

\footnotetext{
${ }^{7}$ We obtain similar results obtain when using the economic activity variable CFNAI; see Table B.5 in Appendix B.

${ }^{8}$ Appendix Table B.1 shows that this result also applies to the group-averaged characteristics.
} 
Table 3: Univariate long-short portfolios from mutual fund abnormal returns

\begin{tabular}{|c|c|c|c|c|c|c|c|c|}
\hline & \multicolumn{2}{|c|}{ Full sample } & \multicolumn{2}{|c|}{ Low sentiment } & \multicolumn{2}{|c|}{ Medium sentiment } & \multicolumn{2}{|c|}{ High sentiment } \\
\hline & SR & mean $(\%)$ & SR & mean $(\%)$ & SR & & & \\
\hline F_r12_2 & 0.28 & $0.36^{* * *}$ & 0.16 & $0.19^{*}$ & 0.46 & $0.50^{* * *}$ & 0.25 & $0.40^{* * *}$ \\
\hline F_ST_Rev & 0.20 & $0.30^{* * *}$ & 0.11 & 0.15 & 0.22 & $0.28^{* * *}$ & 0.26 & $0.49^{* * *}$ \\
\hline Family_r12_2 & 0.19 & $0.13^{* * *}$ & 0.24 & $0.13^{* * *}$ & 0.31 & $0.21^{* * *}$ & 0.06 & 0.05 \\
\hline Beta & 0.15 & $0.18^{* * *}$ & 0.17 & $0.19^{* *}$ & 0.06 & 0.06 & 0.23 & $0.31^{* * *}$ \\
\hline Rel2High & 0.14 & $0.20^{* * *}$ & 0.06 & 0.08 & 0.20 & $0.24^{* *}$ & 0.18 & $0.31^{* *}$ \\
\hline RNA & 0.13 & $0.13^{* * *}$ & 0.16 & $0.14^{*}$ & 0.14 & $0.11^{*}$ & 0.10 & 0.13 \\
\hline Family_TNA & 0.13 & $0.09^{* * * *}$ & 0.01 & 0.01 & 0.24 & $0.15^{* * *}$ & 0.13 & 0.12 \\
\hline fund_no & 0.13 & $0.10^{* * *}$ & 0.03 & 0.01 & 0.24 & $0.17^{* * *}$ & 0.11 & 0.11 \\
\hline flow & 0.12 & $0.11^{* *}$ & 0.21 & $0.15^{* *}$ & 0.11 & 0.09 & 0.08 & 0.09 \\
\hline Family_age & 0.11 & $0.09^{* *}$ & 0.01 & 0.01 & 0.27 & $0.17^{* * *}$ & 0.08 & 0.08 \\
\hline ROA & 0.10 & $0.10^{* *}$ & 0.16 & $0.15^{*}$ & 0.05 & 0.04 & 0.11 & 0.13 \\
\hline PM & 0.10 & $0.10^{* *}$ & 0.11 & 0.10 & 0.19 & $0.13^{* *}$ & 0.07 & 0.09 \\
\hline ROE & 0.10 & $0.11^{* *}$ & 0.13 & 0.12 & 0.04 & 0.04 & 0.13 & 0.18 \\
\hline ST_Rev & 0.09 & $0.13^{* *}$ & 0.04 & 0.06 & 0.09 & 0.11 & 0.15 & $0.24^{*}$ \\
\hline CF & 0.09 & $0.09^{* *}$ & 0.08 & 0.07 & 0.02 & 0.01 & 0.15 & $0.21^{*}$ \\
\hline Resid_Var & 0.09 & $0.14^{* *}$ & 0.11 & 0.15 & 0.10 & 0.13 & 0.09 & 0.18 \\
\hline ages & 0.09 & $0.05^{* *}$ & 0.10 & 0.05 & 0.10 & 0.04 & 0.09 & 0.07 \\
\hline MktBeta & 0.08 & $0.14^{* *}$ & 0.09 & 0.16 & 0.13 & 0.16 & 0.06 & 0.12 \\
\hline r12_2 & 0.08 & $0.11^{* *}$ & 0.02 & 0.02 & 0.17 & $0.18^{* *}$ & 0.06 & 0.11 \\
\hline Spread & 0.08 & $0.13^{* *}$ & 0.11 & 0.16 & 0.06 & 0.07 & 0.10 & 0.21 \\
\hline $\mathrm{D} 2 \mathrm{P}$ & 0.08 & $0.12^{* *}$ & 0.04 & 0.06 & -0.04 & -0.05 & 0.19 & $0.32^{* *}$ \\
\hline r12_7 & 0.08 & $0.11^{* *}$ & 0.08 & 0.11 & 0.10 & 0.10 & 0.05 & 0.10 \\
\hline F_r2_1 & 0.08 & 0.11 & 0.02 & 0.02 & 0.23 & $0.27^{* * *}$ & 0.02 & 0.04 \\
\hline LTurnover & 0.07 & 0.13 & 0.13 & 0.24 & -0.00 & -0.00 & 0.09 & 0.20 \\
\hline Variance & 0.07 & 0.13 & 0.11 & 0.17 & 0.03 & 0.04 & 0.10 & 0.21 \\
\hline IdioVol & 0.07 & 0.12 & 0.09 & 0.13 & 0.09 & 0.11 & 0.07 & 0.15 \\
\hline C & 0.07 & 0.09 & 0.03 & 0.04 & 0.11 & 0.11 & 0.06 & 0.08 \\
\hline Lev & 0.07 & 0.08 & 0.08 & 0.09 & 0.05 & 0.05 & 0.05 & 0.07 \\
\hline Family_flow & 0.07 & 0.04 & 0.09 & 0.04 & 0.06 & 0.03 & 0.07 & 0.06 \\
\hline ATO & 0.07 & 0.07 & 0.02 & 0.01 & 0.01 & 0.01 & 0.12 & 0.16 \\
\hline exp_ratio & 0.07 & 0.04 & 0.12 & 0.06 & 0.01 & 0.01 & 0.07 & 0.06 \\
\hline CTO & 0.06 & 0.07 & 0.03 & 0.02 & 0.05 & 0.04 & 0.08 & 0.11 \\
\hline tha & -0.06 & -0.04 & -0.03 & -0.02 & -0.19 & $-0.11^{* *}$ & -0.00 & -0.00 \\
\hline SUV & 0.06 & 0.06 & 0.15 & $0.14^{*}$ & -0.06 & -0.05 & 0.08 & 0.10 \\
\hline SGA2S & 0.05 & 0.06 & 0.11 & 0.12 & 0.04 & 0.04 & -0.01 & -0.01 \\
\hline OL & 0.05 & 0.05 & 0.02 & 0.01 & 0.02 & 0.02 & 0.07 & 0.08 \\
\hline PCM & 0.05 & 0.05 & 0.15 & $0.14^{*}$ & 0.05 & 0.04 & -0.04 & -0.05 \\
\hline r2_1 & 0.05 & 0.06 & 0.02 & 0.02 & 0.06 & 0.07 & 0.07 & 0.13 \\
\hline CF2P & 0.04 & 0.06 & 0.03 & 0.05 & 0.09 & 0.10 & -0.00 & -0.01 \\
\hline NI & 0.04 & 0.05 & 0.12 & 0.17 & -0.06 & -0.05 & 0.05 & 0.08 \\
\hline Q & 0.04 & 0.05 & 0.05 & 0.07 & 0.01 & 0.01 & 0.03 & 0.04 \\
\hline FC2 $Y$ & 0.04 & 0.05 & 0.10 & 0.12 & 0.04 & 0.03 & -0.02 & -0.03 \\
\hline PROF & 0.04 & 0.04 & 0.11 & 0.08 & 0.01 & 0.01 & 0.01 & 0.02 \\
\hline LME & 0.04 & 0.03 & 0.01 & 0.01 & -0.03 & -0.02 & 0.11 & 0.11 \\
\hline D2A & 0.03 & 0.03 & -0.05 & -0.04 & 0.03 & 0.02 & 0.10 & 0.10 \\
\hline turnover & 0.03 & 0.03 & 0.03 & 0.02 & -0.03 & -0.02 & 0.08 & 0.08 \\
\hline AT & 0.03 & 0.04 & 0.02 & 0.02 & -0.04 & -0.03 & 0.06 & 0.09 \\
\hline OA & 0.03 & 0.03 & -0.02 & -0.01 & 0.08 & 0.06 & 0.05 & 0.06 \\
\hline r36_13 & -0.03 & -0.04 & 0.02 & 0.03 & 0.01 & 0.01 & -0.09 & -0.13 \\
\hline $\mathrm{AC}$ & 0.03 & 0.02 & -0.01 & -0.01 & 0.08 & 0.06 & 0.04 & 0.04 \\
\hline E2P & -0.03 & -0.04 & 0.05 & 0.06 & -0.05 & -0.06 & -0.04 & -0.07 \\
\hline OP & 0.02 & 0.03 & 0.12 & 0.10 & -0.02 & -0.02 & 0.01 & 0.02 \\
\hline NOA & 0.02 & 0.02 & -0.03 & -0.02 & 0.18 & $0.13^{* *}$ & -0.03 & -0.04 \\
\hline DPI2A & 0.01 & 0.01 & 0.00 & 0.00 & 0.19 & $0.14^{* *}$ & -0.08 & -0.09 \\
\hline $\mathrm{A} 2 \mathrm{ME}$ & 0.01 & 0.02 & 0.07 & 0.11 & 0.03 & 0.03 & -0.07 & -0.12 \\
\hline S2P & -0.01 & -0.02 & -0.07 & -0.10 & -0.07 & -0.07 & 0.10 & 0.16 \\
\hline Investment & 0.01 & 0.01 & -0.01 & -0.01 & 0.12 & 0.09 & -0.05 & -0.06 \\
\hline LT_Rev & 0.01 & 0.01 & 0.08 & 0.08 & 0.03 & 0.03 & -0.04 & -0.06 \\
\hline BEME & -0.00 & -0.00 & -0.07 & -0.09 & -0.03 & -0.02 & 0.09 & 0.13 \\
\hline
\end{tabular}

This table reports summary statistics for univariate long-short portfolios in the full sample and in different sentiment terciles. The results are sorted according to the Sharpe ratio of univariate long-short factors. For each of the 59 characteristics, we construct ten sorted decile portfolios. The long-short factors are the differences between the top decile and the bottom decile. We split the time-series into $T^{H}, T^{M}$ and $T^{L}$, which denotes the high, medium and low sentiment terciles based on the previous months. For each of these time periods we separately estimate "Mean" and "Sharpe ratio", which report the mean and Sharpe ratio of this factor conditional on a sentiment tercile. The stars are the signifance of $t$-statistics for the test that the factor mean is different from 0 . The sample period is $1980 / 01$ to $2019 / 01$ with monthly rebalancing. 
Spanning Next, we show that the long-short portfolios that are most strongly associated with fund outperformance do not simply reflect compensation for exposure to standard risk factors. To that end, we estimate multivariate regressions of the long-short portfolios based on fund characteristics on the four Carhart factors and an intercept. The results are in Table 4. All $R^{2}$ are small (below 10\%) except for fund momentum (23\%). Most of the factor loadings are also insignificant. Importantly, a vast majority of alphas are highly significant, meaning that the returns on long-short portfolios are not spanned by the equity asset pricing factors. We also report the mean return on the long-short portfolios. In the few cases where the alpha is not significant, the risk premium of the portfolios is typically not significant. For most fund variables, the mean return and the mean intercept are similar in magnitude, which implies that the Carhart factor exposure explains little of the abnormal returns of fund characteristic portfolios. ${ }^{9}$

Holding Period Before we turn to the main analysis, we note that these results are robust to alternative holding period assumptions. This is germane, as mutual funds tend to be held by investors for longer periods than one month. We consider three robustness tests: (1) we update characteristics annually, (2) we hold each fund investment for one year with overlapping returns, and (3) we consider quarterly returns of quarterly updated positions. For all three, as for monthly returns, portfolios sorted on fund-specific characteristics, in particular flow and fund momentum, have the highest Sharpe ratio and a statistically significant mean, while most stock-specific characteristics cannot systematically differentiate the performance of funds. Appendix B.3 contains the details. These results show that monthly rebalancing of mutual funds is not crucial to earning the high abnormal returns associated with strongly-performing funds. We study even longer holding periods in our main analysis below.

\section{Main Analysis}

Our main analysis aims to predict mutual fund abnormal returns. In contrast to the preceding analysis, this analysis is an out-of-sample prediction analysis with many conditioning variables. It allows for interactions of characteristics (the 59 characteristics in Table 1 plus sentiment), as well as for non-linearities in the relationship between characteristics and future fund outperformance. To that end, we use an artificial neural network, similar to Gu, Kelly, and Xiu (2020). In their extensive comparison study, they show that this method dominates other ML techniques for predicting stock

\footnotetext{
${ }^{9}$ Appendix Table B.3 shows that these results are robust to using alternative factor models: the Fama-French threefactor model, the Fama-French five-factor model (with investment and profitability factors), a six-factor model that adds momentum to the Fama-French five factors, and an eight-factor model that adds short-term reversal, long-term reversal, and momentum to the Fama-French five factors.
} 
Table 4: Spanning of univariate long-short portfolios with FFC-4 factors.

\begin{tabular}{|c|c|c|c|c|c|c|c|}
\hline & $\mathrm{Mkr}$ & $\mathrm{SMB}$ & HML & Mom & $\alpha$ & Factor mean & $R^{2}$ \\
\hline \multirow[t]{2}{*}{ F_ST_Rev } & $-0.09 *$ & 0.07 & $0.08^{*}$ & $0.13^{* * *}$ & $0.18^{* * *}$ & $0.20^{* * *}$ & 0.04 \\
\hline & $(0.05)$ & $(0.05)$ & $(0.05)$ & $(0.05)$ & $(0.05)$ & $(0.05)$ & \\
\hline \multirow[t]{2}{*}{ F_r2_1 } & $0.10^{* *}$ & -0.05 & 0.05 & $0.34^{* * *}$ & 0.01 & 0.08 & 0.11 \\
\hline & $(0.05)$ & $(0.04)$ & $(0.05)$ & $(0.05)$ & $(0.05)$ & $(0.05)$ & \\
\hline \multirow[t]{2}{*}{ F_r12_2 } & $0.29 * * *$ & 0.04 & $0.11^{* *}$ & $0.44^{* * *}$ & $0.17^{* * *}$ & $0.28^{* * *}$ & 0.23 \\
\hline & $(0.04)$ & $(0.04)$ & $(0.04)$ & $(0.04)$ & $(0.04)$ & $(0.05)$ & \\
\hline \multirow[t]{2}{*}{ ages } & -0.00 & $-0.11^{* *}$ & 0.07 & 0.06 & 0.08 & $0.09^{*}$ & 0.02 \\
\hline & $(0.05)$ & $(0.05)$ & $(0.05)$ & $(0.05)$ & $(0.05)$ & $(0.05)$ & \\
\hline \multirow[t]{2}{*}{ flow } & $0.12^{* *}$ & $-0.10^{* *}$ & 0.03 & 0.03 & $0.10^{* *}$ & $0.12^{* *}$ & 0.02 \\
\hline & $(0.05)$ & $(0.05)$ & $(0.05)$ & $(0.05)$ & $(0.05)$ & $(0.05)$ & \\
\hline \multirow[t]{2}{*}{ exp_ratio } & -0.07 & 0.02 & $-0.08^{*}$ & $-0.20^{* * *}$ & $0.11^{* *}$ & 0.07 & 0.04 \\
\hline & $(0.05)$ & $(0.05)$ & $(0.05)$ & $(0.05)$ & $(0.05)$ & $(0.05)$ & \\
\hline \multirow[t]{2}{*}{ tna } & $-0.09^{*}$ & -0.03 & 0.03 & 0.05 & -0.05 & -0.06 & 0.02 \\
\hline & $(0.05)$ & $(0.05)$ & $(0.05)$ & $(0.05)$ & $(0.05)$ & $(0.05)$ & \\
\hline \multirow[t]{2}{*}{ turnover } & -0.00 & 0.04 & 0.03 & 0.06 & 0.02 & 0.03 & 0.01 \\
\hline & $(0.05)$ & $(0.05)$ & $(0.05)$ & $(0.05)$ & $(0.05)$ & $(0.05)$ & \\
\hline \multirow[t]{2}{*}{ Family_TNA } & $0.11^{* *}$ & -0.03 & -0.06 & -0.07 & $0.13^{* * *}$ & $0.13^{* * *}$ & 0.02 \\
\hline & $(0.05)$ & $(0.05)$ & $(0.05)$ & $(0.05)$ & $(0.05)$ & $(0.05)$ & \\
\hline \multirow[t]{2}{*}{ fund_no } & $0.17^{* * *}$ & 0.02 & 0.03 & 0.08 & $0.09^{*}$ & $0.13^{* * *}$ & 0.03 \\
\hline & $(0.05)$ & $(0.05)$ & $(0.05)$ & $(0.05)$ & $(0.05)$ & $(0.05)$ & \\
\hline \multirow[t]{2}{*}{ Family_r12_2 } & $0.10^{*}$ & 0.04 & $0.10^{* *}$ & $0.21^{* * *}$ & $0.14^{* * *}$ & $0.19^{* * *}$ & 0.04 \\
\hline & $(0.05)$ & $(0.05)$ & $(0.05)$ & $(0.05)$ & $(0.05)$ & $(0.05)$ & \\
\hline \multirow[t]{2}{*}{ Family_age } & $0.18^{* * *}$ & 0.01 & 0.00 & 0.07 & 0.08 & $0.11^{* *}$ & 0.03 \\
\hline & $(0.05)$ & $(0.05)$ & $(0.05)$ & $(0.05)$ & $(0.05)$ & $(0.05)$ & \\
\hline \multirow[t]{2}{*}{ Family_flow } & -0.04 & 0.04 & -0.01 & -0.06 & $0.08^{*}$ & 0.07 & 0.01 \\
\hline & $(0.05)$ & $(0.05)$ & $(0.05)$ & $(0.05)$ & $(0.05)$ & $(0.05)$ & \\
\hline
\end{tabular}

This table reports the multivariate time-series regression results of univariate long-short abnormal return portfolios on the four Fama-French-Carhart factors. The first four columns report the slope coefficient on the FFC-4 factors in the regression and the fifth column, $\alpha$ reports the time-series pricing error of the regression. The last two columns report the mean of the univariate long-short decile portfolios and the $R^{2}$ of the regression. Both, the univariate long-short abnormal return portfolios and FFC-4 factors, are normalized to have a standard deviation of 1.

returns. We predict fund abnormal returns with a neural network of lagged predictors:

$$
R_{i, t+1}^{a b n}=g\left(z_{i t}, z_{t}\right)+\epsilon_{i, t+1}
$$

The structure of the neural network $g(\cdot)$ is selected based on a validation sample. It uses as its inputs the characteristics $z_{i, t}$ specific to mutual funds, and macro-economic variables $z_{t}$ (sentiment or CFNAI) to build the best predictors of fund abnormal returns.

We use a cross-out-of-sample analysis to evaluate the performance of the neural network model. Following Kozak, Nagel, and Santosh (2020), Lettau and Pelger (2020) and Bryzgalova, Pelger, and Zhu (2021), we split the full sample into three periods of the same length but select the dates randomly. We use two of the periods to estimate the model and select the tuning parameters, and evaluate the prediction out-of-sample on the remaining third of the sample. We repeat the estimation on three different combinations of the three time periods and report the average results. 
The estimation and validation time period is split into $3 / 4$ used for training (estimation) and $1 / 4$ used for validation (to select the tuning parameters). The random sampling of the dates assumes that the functional relationship between abnormal returns and the conditioning information is independent over time. The details of the hyperparameter tuning are in Appendix C.

Our cross-out-of-sample evaluation is important for two reasons. First, the random sampling is crucial for measuring the dependencies on macroeconomic states. Some states, such as highly elevated sentiment, are only available in a subset of the data and might be neglected in the estimation or evaluation with a conventional chronological data split. Figure C.1 depicts the time-series information used in the three folds and how they relate to sentiment. Second, the cross-out-ofsample evaluation allows us to use all data for the out-of-sample analysis and diminishes the effect of particular subperiods. In other words, we have an out-of-sample prediction for each data point in our sample. We have confirmed that our results are qualitatively robust to multiple alternative out-of-sample evaluations. We have implemented the conventional chronological split into training and test data, where the first part of the data serves as training data, the middle portion is used for tuning parameter selection, and the last part for the out-of-sample analysis. As described above, this split focuses the evaluation only on the shorter last part of the data. We have also implemented the cross-out-of-sample analysis, which generalizes the chronological split. In this case we split the data into the three folds chronologically, and then apply the same type of crossanalysis as above, but respect the chronological order within each fold. One of the three possible fold evaluations is exactly the conventional out-of-sample analysis. We note that our cross-outof-sample analysis is different from a conventional cross-validation, which would use all but one fold for estimation and the remaining fold for evaluation and the tuning parameter selection, that is, there would be no complete out-of-sample evaluation.

\subsection{Neural Network}

A feedforward network (FFN $)^{10}$ is a flexible non-parametric estimator that can learn any functional relationship $y=f(x)$ between an input $x$ and output variable $y$ with sufficient data.

Our best model structure is a one-layer neural network. It combines the raw predictor variables (or features) $z=z^{(0)} \in \mathbb{R}^{K^{(0)}}$ linearly and applies a non-linear transformation. This non-linear transformation is based on an element-wise operating activation function. We choose the popular function known as the rectified linear unit $(\operatorname{ReLU})^{11}$, which component-wise thresholds the inputs

\footnotetext{
${ }^{10} \mathrm{FFN}$ are among the simplest neural networks and treated in detail in standard machine learning textbooks, e.g. Goodfellow, Bengio, and Courville (2016).

${ }^{11}$ ReLU activation functions have a number of advantages including the non-saturation of its gradient, which greatly accelerates the convergence of stochastic gradient descent compared to the sigmoid/hyperbolic functions and fast calculations of expensive operations.
} 
Figure 2: Illustration of Feedforward Network with Single Hidden Layer

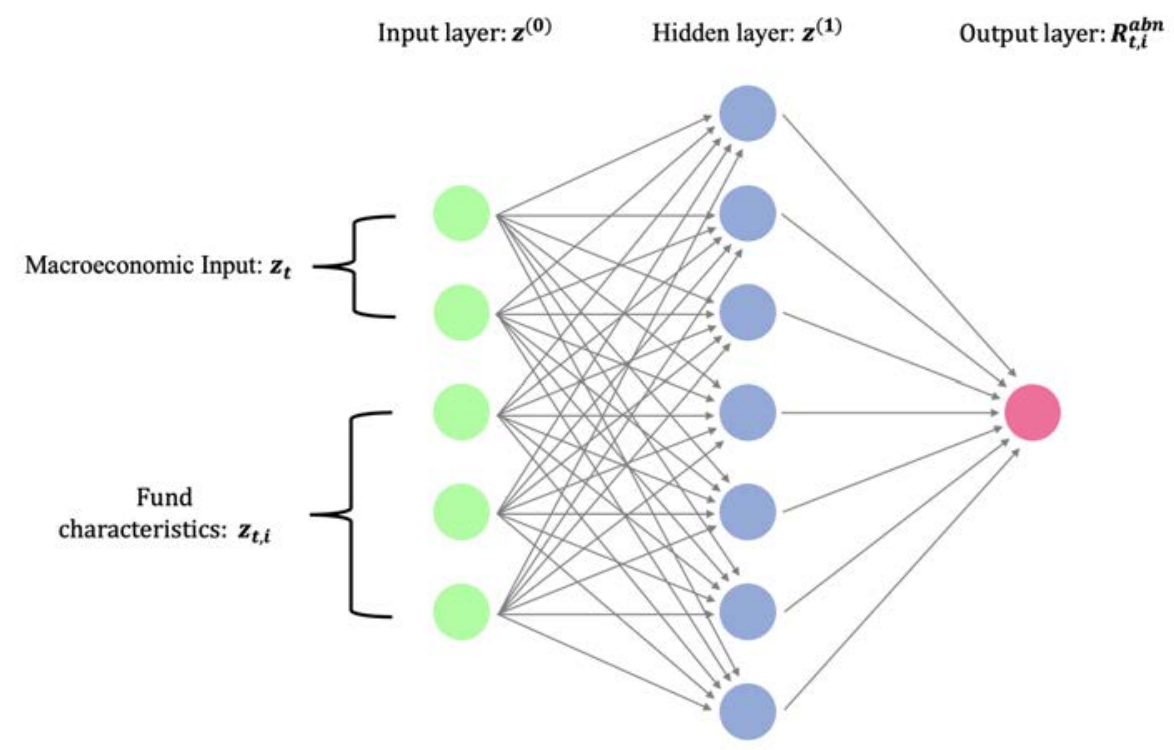

and is defined as

$$
\operatorname{ReLU}\left(z_{k}\right)=\max \left(z_{k}, 0\right)
$$

The result is the hidden layer $z^{(1)}=\left(z_{1}^{(1)}, \ldots, z_{K^{(1)}}^{(1)}\right)$ of dimension $K^{(1)}$ which depends on the parameters $W^{(0)}=\left(w_{1}^{(0)}, \ldots, w_{K^{(0)}}^{(0)}\right)$ and the bias term $w_{0}^{(0)}$. The output layer is simply a linear transformation of the output from the hidden layer.

$$
\begin{aligned}
& z^{(1)}=\operatorname{ReLU}\left(W^{(0) \top} z^{(0)}+w_{0}^{(0)}\right)=\operatorname{ReLU}\left(w_{0}^{(0)}+\sum_{k=1}^{K^{(0)}} w_{k}^{(0)} z_{k}^{(0)}\right) \\
& R^{a b n}=W^{(1) \top} z^{(1)}+w_{0}^{(1)} \quad \text { with } z^{(1)} \in \mathbb{R}^{K^{(1)}}, W^{(0)} \in \mathbb{R}^{K^{(1)} \times K^{(0)}}, W^{(1)} \in \mathbb{R}^{K^{(1)}} .
\end{aligned}
$$

Note that without the non-linearity in the hidden layer, the one-layer network would reduce to a generalized linear model. A deep neural network combines several layers by using the output of one hidden layer as an input to the next hidden layer. Our optimal network has 64 nodes in the hiden layer, which can be interpreted as representing the information set with 64 basis functions which are non-linear transformations of the original characteristics and macroeconomic variables and which are linearly combined to predict the abnormal return.

Our results are extremely robust to the choice of tuning parameters. Networks with more layers and nodes result in a very similar performance and estimated functional form as our optimal network. This is consistent with the findings in Chen, Pelger, and Zhu (2020) and Gu, Kelly, and Xiu (2020). Hence, it matters primarily to allow for the flexible functional form and interaction effects, which can be achieved with many model specifications. 
We quantify the economic benefit of different information sets by comparing the prediction and trading benefits of varying the information set available to the neural network. As appropriately tuned neural networks can approximate any functional relationship, they allow us to understand what the best possible prediction is for a given information set.

\subsection{Optimal Prediction}

Having estimated the neural network model, we form the model's prediction of fund abnormal returns for each fund-month using all 59 characteristics listed in Table 1 and investor sentiment. We sort funds in deciles based on their predicted abnormal return for the next month. Within the deciles we weight the funds either equally or by their predicted value. Figure 3 illustrates the two weighting schemes in the extreme deciles for a representative month. The prediction weights exploits the heterogeneity in the prediction and assigns a higher relative weight to predictions that deviate from the center of the decile. ${ }^{12}$

Figure 4 plots the cumulative abnormal return from investing in each of these $10 \%$ of funds. The right panel equally-weights the abnormal returns of the funds within each decile, using the neural network model only to sort funds into deciles. The left panel additionally uses the neural network model prediction to form portfolio weights; we refer to this as the prediction-weighted return. A prediction-weighted approach uses more information resulting in a larger spread in the prediction portfolios. Therefore, our baseline model is prediction-weighted. ${ }^{13}$ An investor who had followed an investment strategy that invests in the $10 \%$ best mutual funds based on the neural network model's predictions would have earned a cumulative abnormal return of $72 \%$ predictionweighted and $48 \%$ equally-weighted. The difference between these two numbers shows that the neural net is not only good at predicting which funds are likely to be in the top performance decile, but also at how good some of the funds in the top decile are relative to other top-performing funds.

At the other end of the spectrum, the $10 \%$ worst funds according to the out-of-sample prediction of the neural network model generate cumulative abnormal returns of $-119 \%$ prediction-

${ }^{12}$ The prediction based weights are defined as the following shifted and scaled weights:

$$
\begin{aligned}
\text { For top portfolio: } \tilde{\mu}_{i, t} & =\hat{\mu}_{i, t}-\min _{i \in \operatorname{Top}}\left(\hat{\mu}_{i, t}\right) \\
\text { For bottom portfolio: } \tilde{\mu}_{i, t} & =\hat{\mu}_{i, t}-\max _{i \in \operatorname{Bottom}}\left(\hat{\mu}_{i, t}\right) \\
w_{i, t}^{\text {pred }} & =\frac{\tilde{\mu}_{i, t}}{\sum_{i=1}^{N} \tilde{\mu}_{i, t}}
\end{aligned}
$$

where $\hat{\mu}_{i, t}$ are the predictions of neural network models. For top-performing funds, we subtract the smallest model prediction within the group in equation (4) to ensure that the top portfolio is a long-only portfolio. For bottom-performing funds, we subtract the largest model prediction within the group in equation (5) to ensure that the bottom portfolio is a short-only portfolio. We then standardize the normalized predictions to sum up to 1 per equation (6). The prediction weights are similar for the other deciles. The results for quintiles and 20 quantiles are very similar and available upon request. An alternative to the prediction weights within the quantiles are rank weights. The results are very similar to the prediction weights and hence omitted.

${ }^{13}$ The results for the equally-weighted approach are qualitatively similar and presented in Appendix B.5. 
Figure 3: Equally and prediction-weighted portfolio weights within deciles

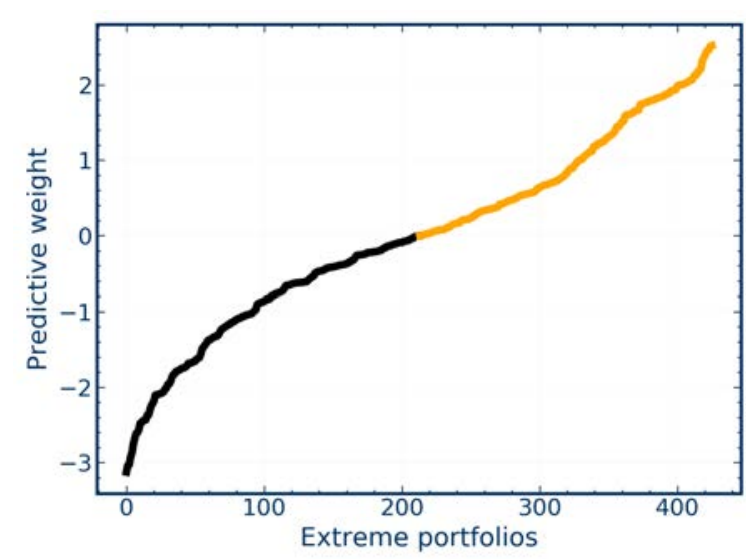

(a) Prediction weights

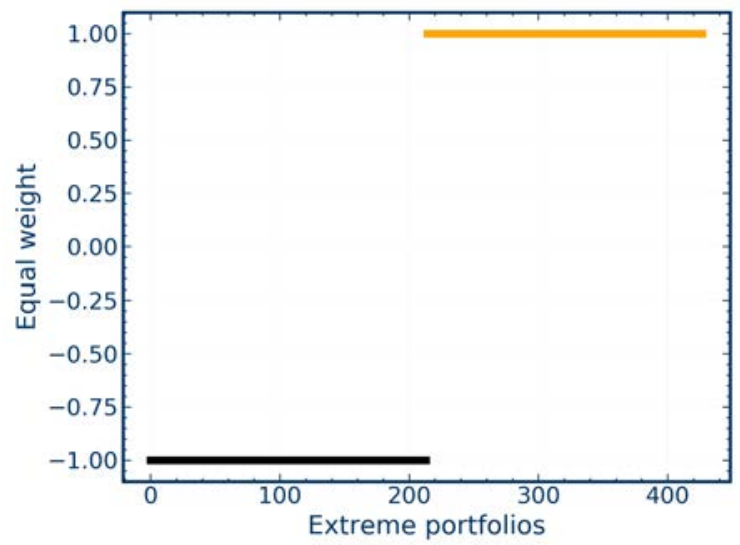

(b) Equal weights

These figures show the equal and prediction-weighted portfolio weights for the first and tenth decile in a long-short portfolio for the representative example month 2000/01.

weighted and $-93 \%$ equally-weighted. Hence, avoiding the worst mutual funds is even more valuable than investing in the best $10 \%$ of mutual funds.

The main conclusion is that abnormal mutual fund returns are predictable and the extent of predictability over the past 40 years is economically large. The cumulative abnormal return translates into a monthly out-performance of 15 (10) basis points for the $10 \%$ best funds predictionweighted (equally-weighted).

Panel (a) of Figure 5 shows the average fees for the different prediction based decile portfolios. While those funds with higher predicted and realized abnormal returns charge a higher fee, the spread in fees does not explain the spread in expected returns. In fact, the worst and best $10 \%$ of funds both have a cumulative expense ratio of around 50\%, which are higher than the expense ratios of the funds in the middle of the predicted performance distribution. Given that the $10 \%$ best and $10 \%$ worst funds have the same fees, fees can explain nothing of their relative performance. The $10 \%$ best funds earn cumulative abnormal gross returns of $72 \%$, exceeding cumulative fees. Indeed, Panel (b) of Figure 5 shows that the funds in the top two prediction deciles still earn a positive abnormal return after fees. Note that these are lower bounds as predicting abnormal returns after fees (rather than before fees) could improve the predicted after fee performance. Indeed, in Figure B.1 we show performance for predicting abnormal net returns which improves the results. The 9th decile based on predicting abnormal gross returns has a lower expense ratio than the 10th decile, which is taken into account in the prediction of abnormal net returns. In fact, the $10 \%$ best funds achieve a cumulative abnormal return after fees of $37 \%$. On the other hand, the $10 \%$ worst funds earn cumulative abnormal returns after fees of around $-170 \%$, further highlighting the usefulness of the neural network in identifying which funds to avoid. 
Figure 4: Cumulative abnormal returns of prediction deciles for all characteristics.

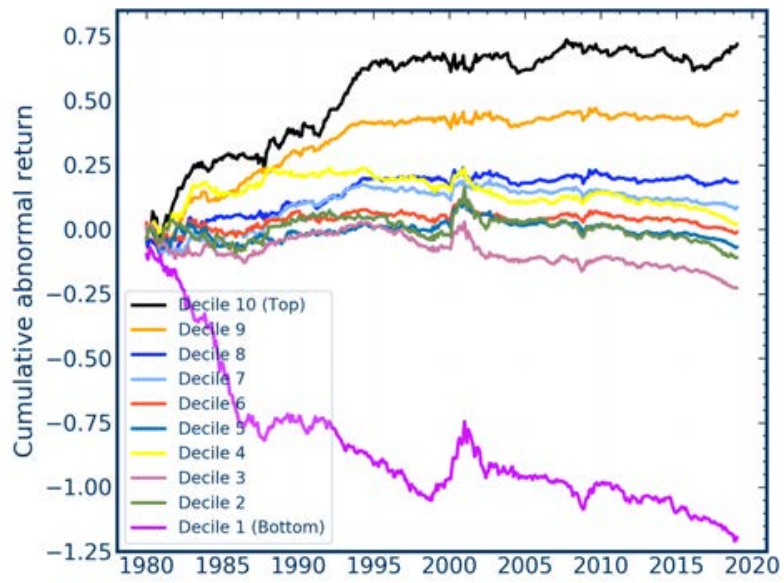

(a) Prediction-weighted abnormal returns.

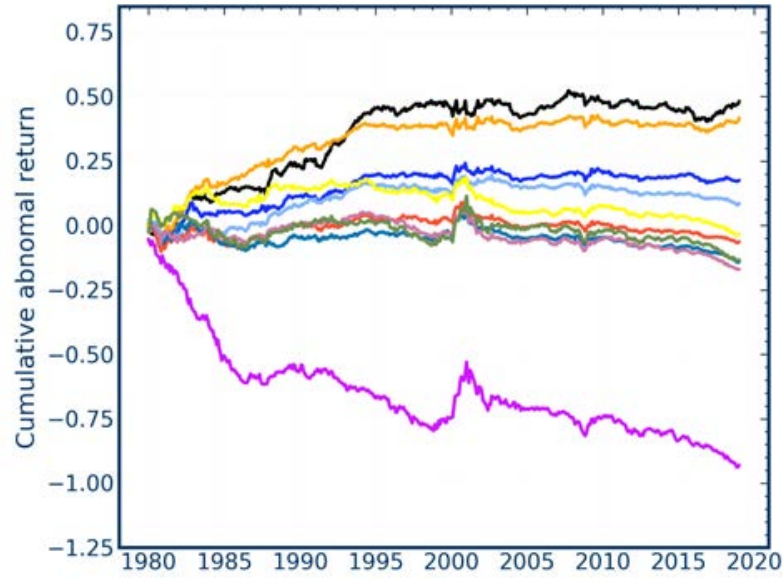

(b) Equally-weighted abnormal returns.

These figures show the cumulative abnormal returns sorted into prediction deciles when considering the complete information set (fund-specific and stock-specific characteristics + sentiment) to predict abnormal returns.

Figure 5: Cumulative expense ratios and abnormal net return.

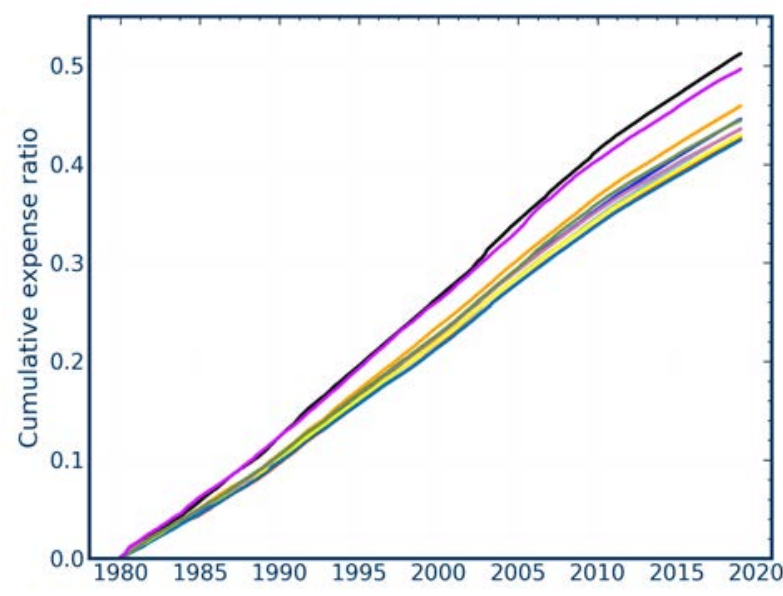

(a) Cumulative prediction-weighted expense ratios

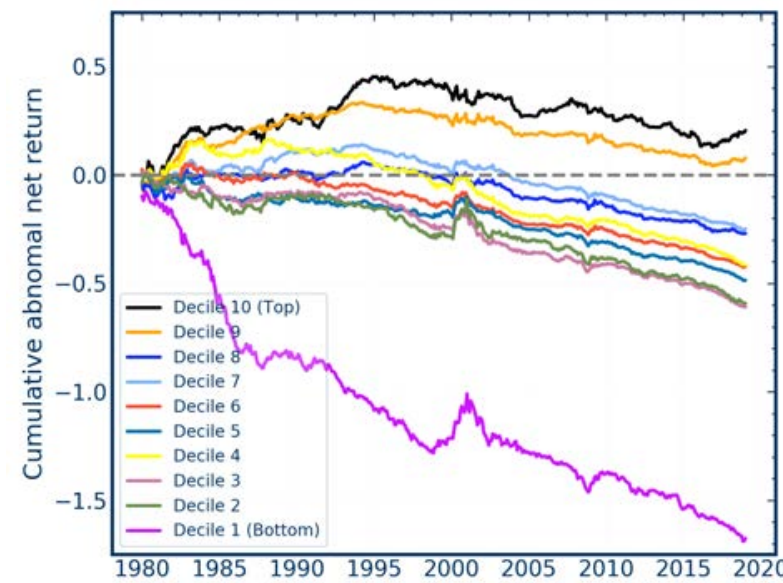

(b) Cumulative abnormal net returns

The left figure shows the cumulative expense ratios of prediction-weighted deciles based on the full information set (fund-specific and stock-specific characteristics + sentiment). The right figures shows the abnormal net returns for the prediction-weighted deciles, that is, the abnormal returns minus the fees.

\subsection{Which Information Most Useful When Predicting Fund Abnormal Returns?}

To assess the importance of stock-specific characteristics (labeled 1-46 in Table 1), fund momentum (47-49), fund characteristics (50-54), family characteristics (55-59), and sentiment for the prediction of fund abnormal performance, we estimate neural network models that are given subsets of predictors. Our main finding is that the combination of fund-level variables and sentiment results in the best performance. 
Figure 6: Cumulative abnormal returns for different information sets.

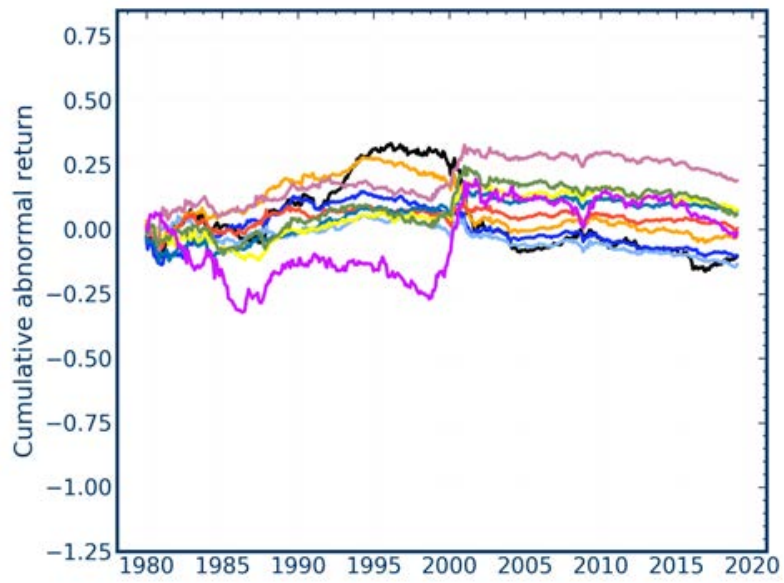

(a) Stock-specific characteristics

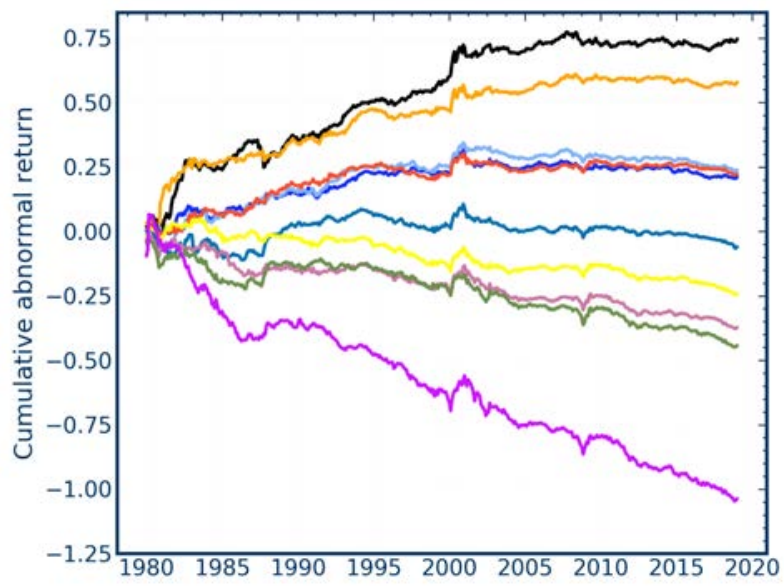

(c) Fund-specific characteristics

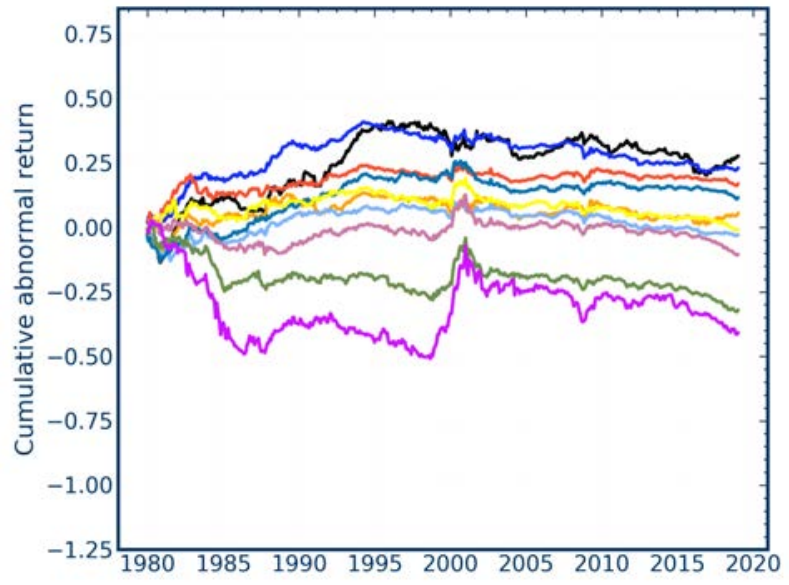

(b) Stocks-specific characteristics + sentiment

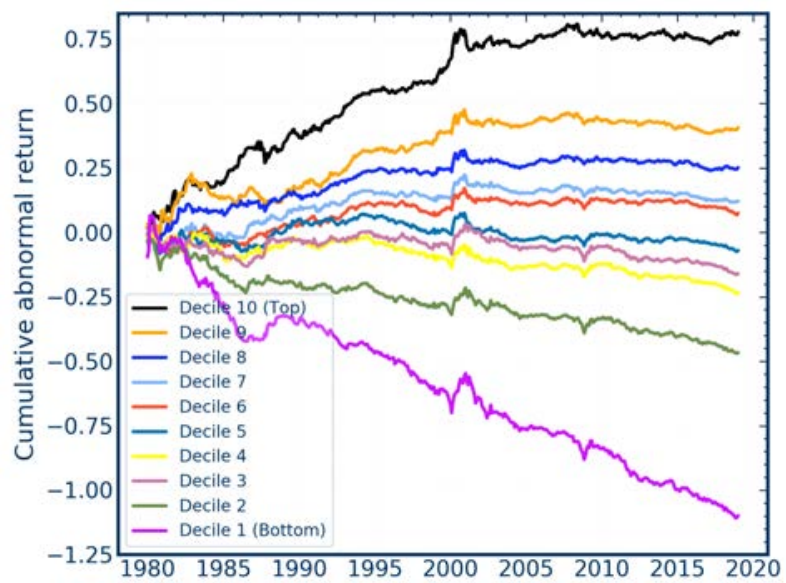

(d) Fund-specific characteristics + sentiment

These figures show the cumulative abnormal returns sorted into prediction deciles for different information sets. The returns are prediction-weighted within deciles. We consider fund-specific characteristics + sentiment, stock-specific characteristics+ sentiment, fund-specific characteristics or stock-specific characteristics to predict abnormal returns.

Figure 6 shows the cumulative abnormal returns for the fund deciles when using stock characteristics 1-46 only (Panel A), stock characteristics and sentiment (Panel B), fund characteristics 47-59 (Panel C), and fund characteristics and sentiment (Panel D). Fund abnormal returns within each decile are prediction-weighted. The best model for predicting fund abnormal returns ignores stock characteristics entirely. Fund characteristics, in sharp contrast to stock characteristics, are extremely useful for prediction, as is sentiment. We note the monotone (almost monotone) pattern in Panel D (C). As we will see shortly, fund characteristics interact with sentiment in important ways.

Figure 7 shows that the portfolio that goes long in the (predicted) best $10 \%$ of funds and short in the (predicted) worst $10 \%$ of funds earns cumulative returns of $-9 \%$ out-of-sample when only 
Figure 7: Cumulative abnormal returns of long-short prediction portfolios

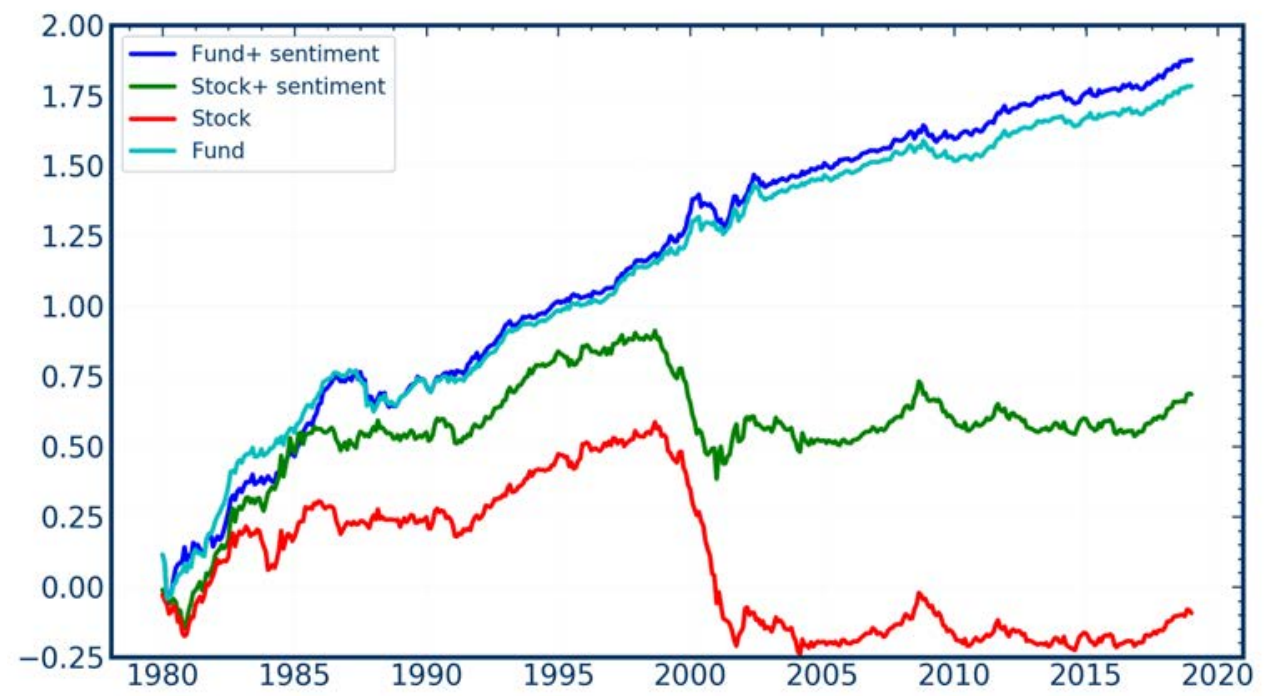

This figure plots the cumulative abnormal returns of prediction-weighted long-short decile portfolios that use different information sets for prediction. We consider fund-specific and stock-specific characteristics combined with sentiment.

stock information is used, $69 \%$ when using stock plus sentiment information, $178 \%$ when using fund information, $188 \%$ when using fund plus sentiment information, and 191\% when using stock plus fund plus sentiment information. The results are qualitatively the same for equally-weighted portfolios as shown in Appendix B.5.

Table 5: Performance of long-short abnormal return portfolios for different information sets.

\begin{tabular}{rrrrr}
\hline Information set & mean $(\%)$ & t-stat & SR & $R_{F}^{2}(\%)$ \\
\hline Stock & -0.02 & -0.2 & -0.01 & -1.60 \\
Stock+ sentiment & 0.15 & 1.6 & 0.07 & 1.27 \\
Stock+ fund & 0.28 & $3.3^{* * *}$ & 0.15 & 2.30 \\
Stock+ fund+ sentiment & 0.41 & $4.5^{* * *}$ & 0.21 & 5.00 \\
Fund & 0.38 & $5.5^{* * *}$ & 0.25 & 0.19 \\
Fund+ sentiment & 0.40 & $5.4^{* * *}$ & 0.25 & 2.73 \\
Fund momentum + sentiment & 0.35 & $4.4^{* * *}$ & 0.21 & 0.29 \\
Fund momentum + Flow + sentiment & 0.48 & $5.2^{* * *}$ & 0.24 & 0.92 \\
Fund excl. fund momentum and flow & 0.06 & 1.5 & 0.07 & 0.12 \\
\hline
\end{tabular}

This table reports the Sharpe ratio, mean and factor $R^{2}$ of long-short prediction-weighted decile portfolios that use different information sets for the prediction. We consider nine different information sets which combine fund-specific and stock-specific characteristics and sentiment. We also include flow and fund momentum individually.

To assess whether these different long-short investment strategies incur different amounts of risk, we also compute the Sharpe Ratio on the long-short decile portfolio, which Table 5 reports alongside the mean return. Consistent with the prior results, the highest Sharpe-ratio strategy ignores stock-specific information. Using fund information and sentiment to select the best and 
worst $10 \%$ of funds results in a monthly long-short return of 40 basis points with a monthly Sharpe ratio of 0.25 .

The last three rows show that when one only uses two out of the 13 fund characteristics, namely fund momentum (F_r12_2) and flow, combined with sentiment, the resulting long-short portfolio has a similar Sharpe ratio and return to the portfolio based on all fund information. Using all fund characteristics except for these two results in substantially worse performance. In summary, fund momentum and flow, interacted with sentiment, are the key variables for predicting fund abnormal returns.

Table 5 also reports the $R_{F}^{2}$ statistic, which measures how well the realized long-short portfolio return is predicted by the neural network model. ${ }^{14}$ If the realized long-short abnormal return factor is predicted more accurately, then an investor knows better by how much funds in the top decile will outperform funds in the bottom decile in the next period. ${ }^{15}$ The highest $R_{F}^{2}$ of $5.00 \%$ monthly, which is substantial, is obtained for the model with fund, sentiment, and stock information. Dropping sentiment information results in a large decline in $R_{F}^{2}$, which suggests that sentiment is crucial for predicting the high-minus-low abnormal fund return. The conditional mean of the long-short portfolio is higher in high sentiment periods, consistent with the results in Section 3. Replacing fund- with stock-level information also results in a large drop in $R_{F}^{2}$. Note that the $R_{F}^{2}$ measures accuracy of both the relative cross-sectional prediction of funds (the fund ranking) and the level of the abnormal returns. The prediction based only on fund information correctly predicts the ranking of future abnormal fund returns, but not their magnitude as suggested by the low $R_{F}^{2}$. Including sentiment slightly improves the relative prediction, due to the interaction effects studied in Section 4.4, but substantially improves the level prediction of abnormal returns.

Table 6: Performance of long-short return portfolios for different information sets.

\begin{tabular}{rrrrr}
\hline Data & mean $(\%)$ & t-stat & SR & $R_{F}^{2}(\%)$ \\
\hline Fund+ sentiment & 0.49 & $3.0^{* * *}$ & 0.14 & 0.97 \\
Fund & 0.53 & $3.5^{* * *}$ & 0.16 & 0.97 \\
Stock+ sentiment & 0.44 & $3.1^{* * *}$ & 0.14 & -20.03 \\
Stock & 0.11 & 1.1 & 0.05 & -53.21 \\
Stock+ fund+ sentiment & 0.45 & $3.1^{* * *}$ & 0.14 & -26.54 \\
\hline
\end{tabular}

This table reports the Sharpe ratio, mean and factor $R^{2}$ of long-short prediction-weighted decile portfolios based on predicting returns instead of abnormal returns with different information sets. We consider five different information sets which combine fund-specific and stock-specific characteristics and sentiment to predict returns instead of abnormal returns.

\footnotetext{
${ }^{14}$ We denote by $F_{t}$ the realized return and by $\hat{F}_{t}$ the predicted return of the long-short portfolio based on predictionsorted deciles. The normalized time-series prediction error is measured by $R_{F}^{2}=1-\frac{\sum_{t=1}^{T}\left(\hat{F}_{t}-F_{t}\right)^{2}}{\sum_{t=1}^{T} F_{t}^{2}}$.

${ }^{15}$ This information could be used for timing the portfolio investment in the spirit of Haddad, Kozak, and Santosh (2020).
} 
Figure 8: Cumulative returns of prediction-weighted return deciles for different information sets.

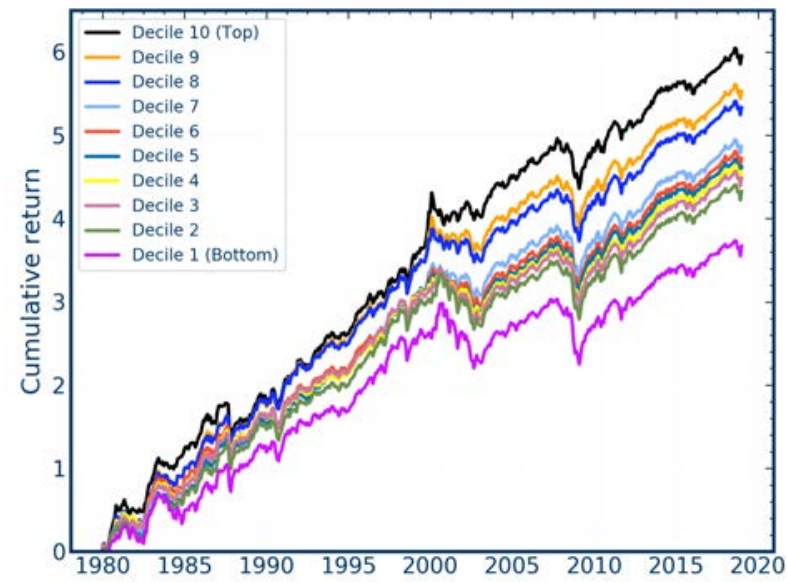

(a) Fund-specific characteristics+sentiment

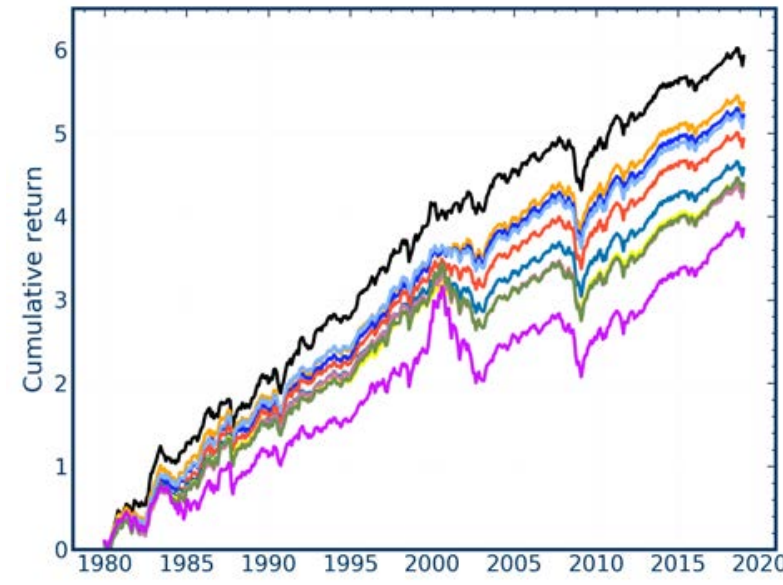

(b) Stock-specific characteristics+ sentiment

This figure plots the cumulative returns sorted into prediction deciles for different information sets. The returns are prediction-weighted within deciles. We consider information sets which combine fund-specific and stock-specific characteristics and sentiment to predict returns instead of abnormal returns.

Abnormal versus Total Return Prediction Abnormal returns are the appropriate prediction target because they measure the returns managers earn in excess of risk compensation. But for comparison, Figure 8 and Table 6 report the results for predicting the total returns of mutual funds (rather than abnormal returns). First, stock characteristics are substantially more predictive for total fund returns than for their abnormal returns. In other words, the stock characteristics seem to be able to predict the systematic factor component in fund returns. As we have established above, once this factor component is taken out, the stock characteristics lose most of their predictability. Second, the Sharpe ratio of long-short portfolios based on return prediction is lower than from predicting abnormal returns. This points to an important methodological contribution of this paper. The level of fund returns (and also stock returns) is extremely hard to predict, while the relative performance is more predictable. Abnormal returns remove the level effect of market and other risk factors. Hence, an abnormal return prediction objective is mainly a relative objective. In contrast, a machine learning prediction for returns might not select a model with a correct relative cross-sectional ranking of funds if it has a high prediction error in the level (which is largely irrelevant for relative trading). In summary, abnormal returns might be a better objective for machine learning prediction in general, and for our question in particular.

Spanning Revisited Do the long-short portfolio returns formed from the neural network model's prediction reflect compensation for risk or a true abnormal return? We estimate a multivariate regression of long-short portfolio returns on the four factors in the Carhart model. We find low $R^{2}$ and large and highly significant intercepts. Appendix Table B.6 shows the details. It also shows 
that these results are robust to richer factor models, and reflect abnormal returns.

Longer Holding Periods The monthly rebalancing of mutual funds is not crucial to earning the high abnormal returns associated with the relative performance of funds. Figure 9 shows the abnormal returns on a long-short prediction portfolio for holding periods ranging from 1 month to 3 years. Fund investments are made every month based on a one-month ahead prediction, but investments are held for a longer holding period (ranging from 1 to 36 months with overlapping returns). As expected, the mean return decreases over time but it stays significant for all holding periods. At the same time, the longer holding periods decrease the variance. A quarterly holding period actually reduces the standard deviation more than the mean, and hence results in a higher Sharpe ratio than the one-month holding period. Trading based on the most important predictors (flow, fund momentum and sentiment) results in the same holding-period patterns as using the full information set. In sum, while price-based fund characteristics such as fund momentum are changing relatively quickly, they contain predictive information that remains relevant for a longer horizon.

\subsection{Variable Importance and Interaction Effects}

Importance of Predictors In order to visualize which variables are the most important for prediction, we construct a metric based on the average absolute gradient of the abnormal return prediction to a characteristic, following Sadhwani, Giesecke, and Sirignano (2020) and Horel and Giesecke (2020):

$$
\operatorname{Sensitivity}\left(z_{k}\right)=\frac{1}{T} \sum_{t=1}^{T} \frac{1}{N_{t}} \sum_{i=1}^{N_{t}}\left|\frac{\partial \hat{R}_{i, t}^{a b n}}{\partial z_{i, k, t}}\right|
$$

The partial derivatives are evaluated at the observed characteristics and are approximated with numerical derivatives. $T$ is the number of periods and $N_{t}$ is the number of funds available at time $t$. The Sensitivity $\left(z_{k}\right)$ is then averaged over the three cross-out-of-sample folds and normalized to sum up to 1 . This sensitivity measure simplifies to the standard slope coefficient in the special case of a linear regression framework. A larger sensitivity means that a variable has a larger effect on the neural network prediction.

The left panel of Figure 10 shows the sensitivities for the neural network model with fund-level information and sentiment. Sentiment is the most important variable, followed by fund momen-

tum, fund reversal, turnover, and flow. In the right panel, we define the variable importance measure of a group by taking the average of the sensitivity measures within that group. The most important fund-specific characteristics group is still fund momentum characteristics. 
Figure 9: Performance for Different Holding Periods

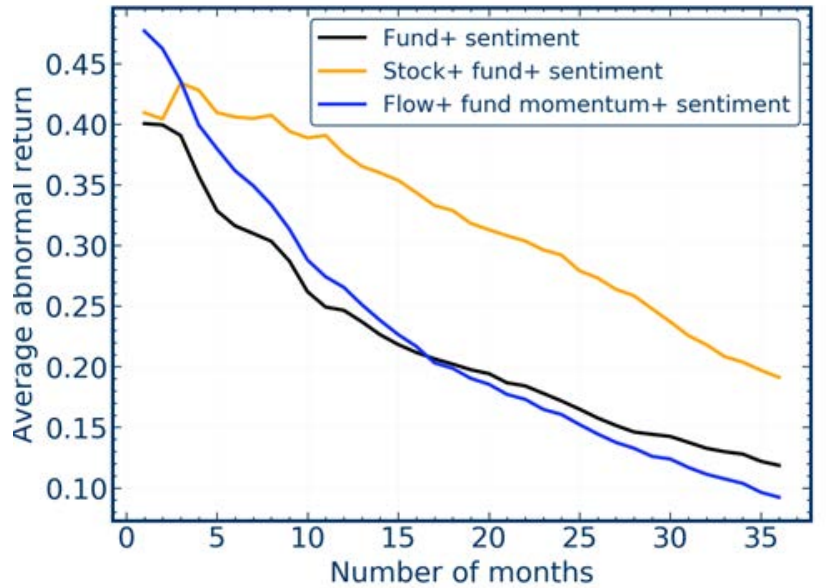

(a) Mean of abnormal returns

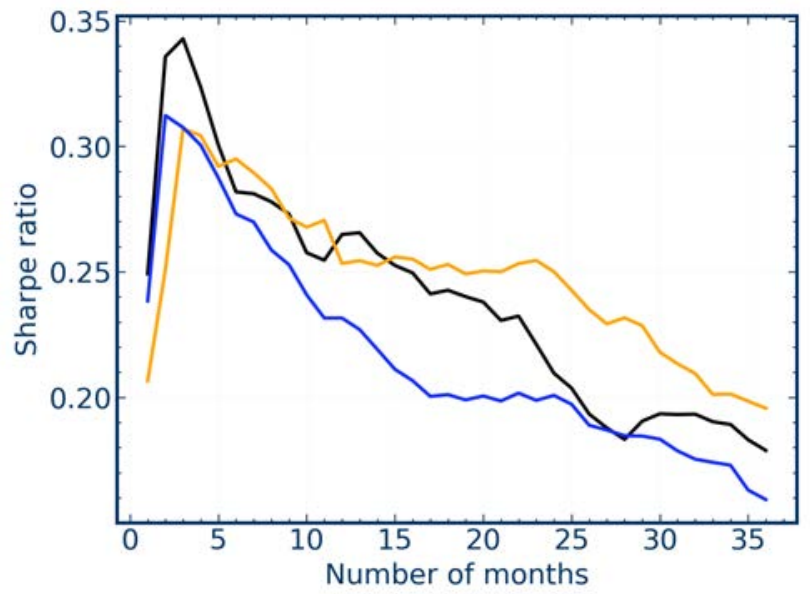

(c) Sharpe ratio

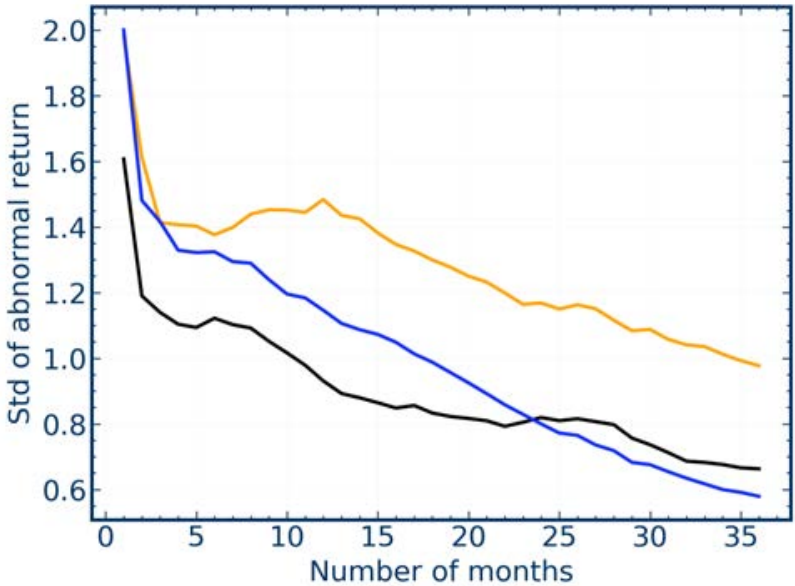

(b) Standard deviation

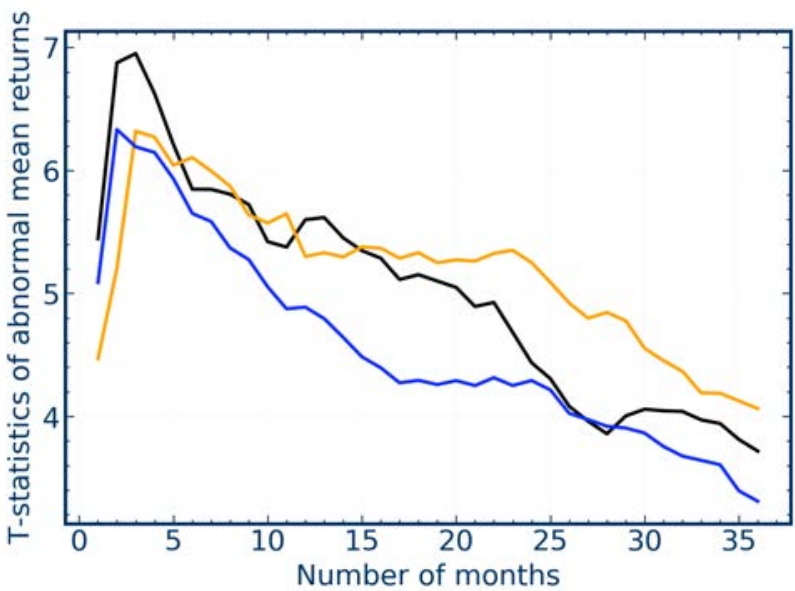

(d) T-statistics of abnormal mean returns

This figure shows the results for long-short prediction-weighted portfolios for different holding periods. At each time $t$, we sort funds based on the one-month prediction into deciles and hold the long-short prediction portfolio for $s$ months with overlapping returns. We calculate the mean, Sharpe ratio, standard deviation, and $t$-statistics of the overlapping abnormal returns. The one-month prediction uses either fund+sentiment, stock+fund+sentiment or flow+fund+sentiment.

Interaction Effects We now analyze the interactions between sentiment and fund characteristics that are implied by the neural network model. Table 3 suggested that fund-specific characteristics have the most predictive power in times of high sentiment, while Table 5 indicated that sentiment information is important to predict the skill of mutual fund managers. Figure 11 plots the predicted abnormal fund return (on the y-axis) as a function of one fund-level variable (on the $x$-axis), keeping all the other variables at their median level. The function is averaged over three cross-out-of-sample folds. In order to study the interaction effects with sentiment, we plot this one-dimensional function for different quantiles of the sentiment distribution. Hence, the plots 
Figure 10: Top variable importance for explaining abnormal returns.

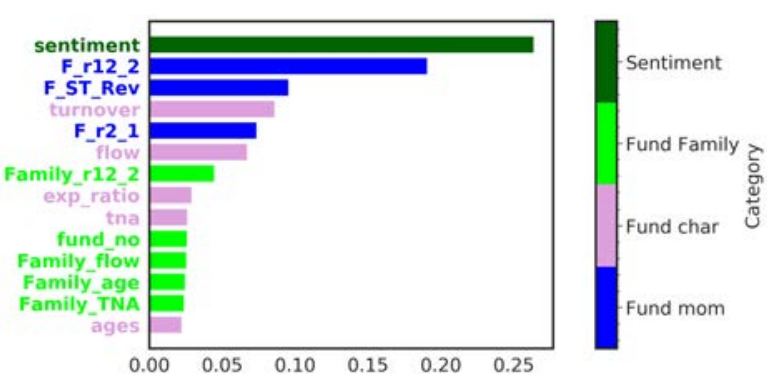

(a) Top variable importance.

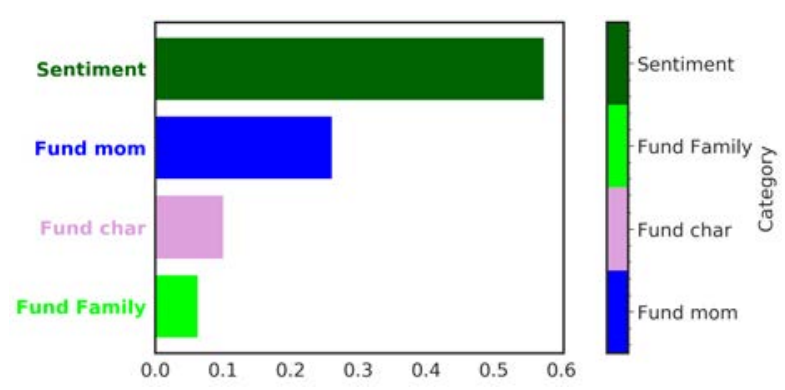

(b) Top variable group importance.

This figure shows the importance ranking for individual variables and variable groups. The ranking is the average of the absolute gradient for the eight ensemble fits. The variable importance measures are evaluated on the test data and averaged across three cross-out-of-sample folds. Fund-specific characteristics and sentiment are used as network input.

show the mean of abnormal fund returns conditional on the values of one fund variable and sentiment.

There are clear interaction effects between sentiment and fund-level variables. Predicted abnormal returns are almost linear in fund-specific variables, but the slope of that relationship is substantially higher in times of high sentiment. Note that without interaction effects between sentiment and the flow variable, the different curves in each panel would be parallel shifts. They clearly are not. The interaction effect with sentiment is particularly strong for fund momentum in panel (a). In contrast, there is no interaction effect for family momentum.

Why is our neural network structure able to generate such an interaction effect between sentiment and fund-level characteristics? The first hidden layer of the neural network performs a nonlinear transformation of original characteristics into new characteristics: $z(1)=\operatorname{ReLU}\left(\sum_{k=1}^{K} w_{k}^{(0)} z_{k}^{(0)}+\right.$

$\left.w_{0}^{(0)}\right)$. There are some hidden-layer neurons that get activated only when sentiment is high $\left(z_{t}\right.$ is large), which changes the dependency of the abnormal return prediction on fund-level characteristics. When the neuron gets activated, the slope of this dependency gets higher, which is exactly what we see in Figure 11. While the interaction effects with sentiment are the strongest, there are also interaction effects between the fund specific variables as shown in Appendix B.7.

\subsection{Which Macro-economic Variable?}

Having shown the importance of sentiment and its interaction effects with fund characteristics, it is reasonable to ask whether other variables like CFNAI might play a similarly important role in predicting mutual fund out-performance. Or maybe they add a useful piece of macro-economic information that is not contained in sentiment? To answer these questions, we estimate several additional neural network models which combine fund-level information with the following macro variables: sentiment (benchmark), CFNAI, sentiment orthogonalized to CFNAI, CFNAI orthogo- 
Figure 11: Conditional mean as a function of fund characteristics and sentiment.

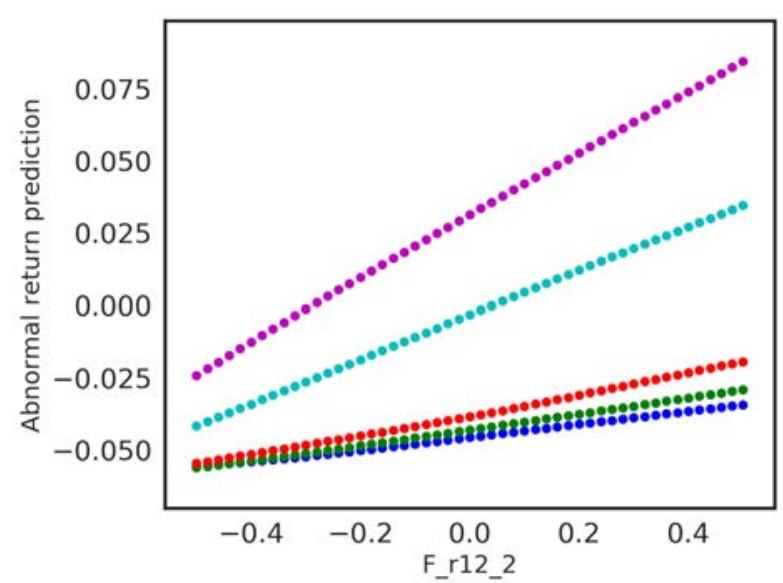

(a) Predicted abnormal returns as function of $F \_r 12 \_$

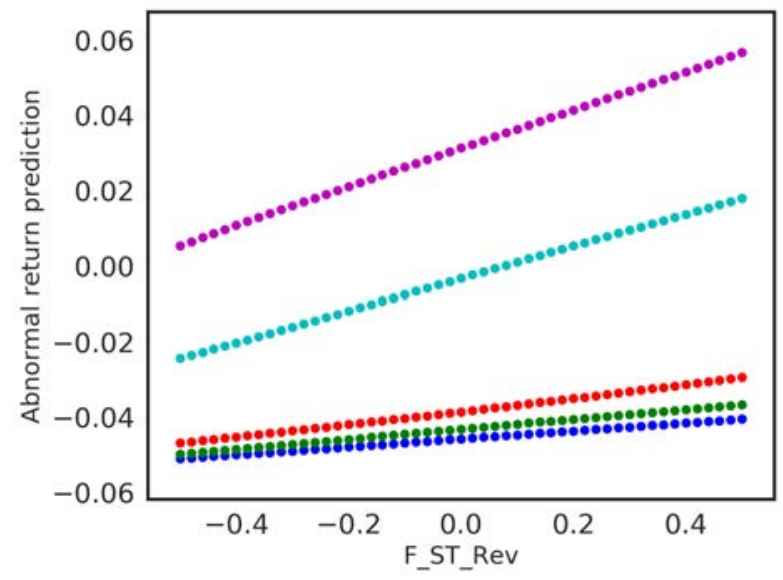

(c) Predicted abnormal returns as function of F_ST_Rev

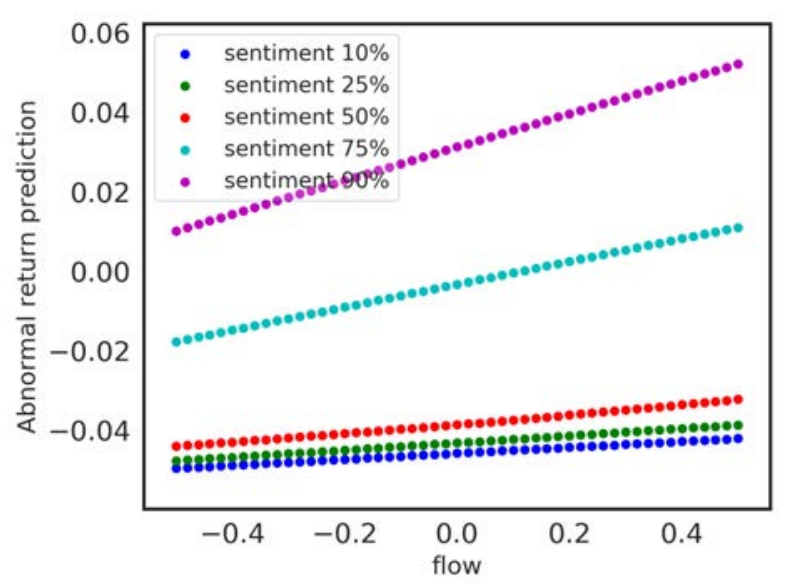

(b) Predicted abnormal returns as function of flow

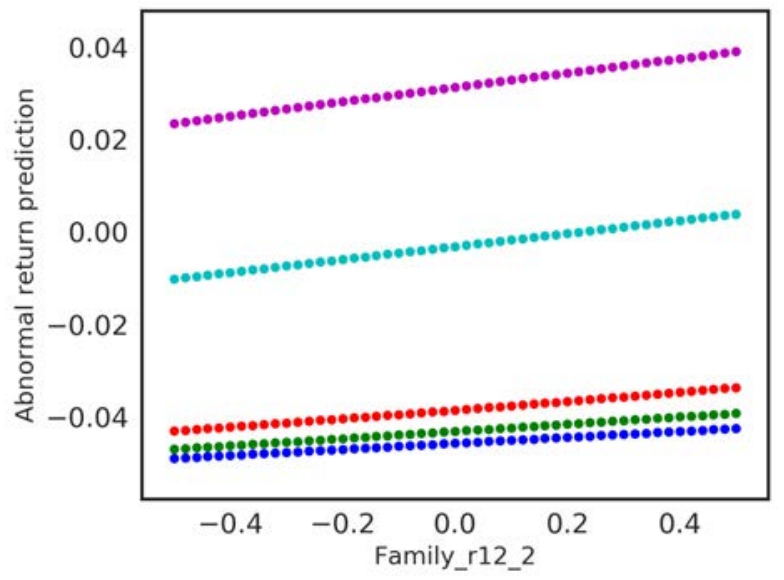

(d) Predicted abnormal returns as function of Family_r $12 \_2$

This figure shows the predicted abnormal returns (in percentages) as a function of one fund characteristic conditional on different sentiment quantiles. The other variables are set to their median. The neural network model is estimated with fund-specific characteristics and sentiment. The interaction effects are evaluated on the test data and averaged across three cross-out-of-sample folds. The high-minus-low portfolios have a higher mean conditional on high past sentiment. This is a non-linear interaction effect.

nal to sentiment, and sentiment plus CFNAI. ${ }^{16}$ Table 7 shows the results.

In terms of out-of-sample mutual fund return predictability, using CFNAI leads to equally strong results in terms of the mean and Sharpe Ratio of the long-short portfolio. This result is surprising at first in light of the low correlation between sentiment and CFNAI. However, the low (linear) correlation is misleading. Sorting the respective time series of sentiment, CFNAI, and orthogonalized sentiment into high, medium, and low states (terciles) results in large overlap between the states. High-sentiment and high-CFNAI periods are often the same periods. What

\footnotetext{
${ }^{16}$ We use a least-squares orthogonalization. The results are similar for a least absolute deviation orthogonalization. Sentiment and both orthogonalized sentiment series are all very similar because sentiment has a low $10 \%$ correlation with CFNAI.
} 
Table 7: Long-short abnormal return portfolios for different macro-economic information.

\begin{tabular}{rrrrrr}
\hline Weighting method & Information set & mean $(\%)$ & $\mathrm{t}$-stat & $\mathrm{SR}$ & $R_{F}^{2}(\%)$ \\
\hline \multirow{4}{*}{ Prediction-weighted } & Fund+sentiment & 0.40 & $5.4^{* * *}$ & 0.25 & 2.73 \\
& Fund+CFNAI & 0.39 & $6.0^{* * *}$ & 0.28 & 0.72 \\
& Fund+sentiment+CFNAI & 0.42 & $6.3^{* * *}$ & 0.29 & 2.48 \\
& Fund+sentiment_orth & 0.43 & $6.4^{* * *}$ & 0.29 & 1.22 \\
& Fund+CFNAI_orth & 0.38 & $5.4^{* * *}$ & 0.25 & 0.92 \\
Equally-weighted & Fund & 0.38 & $5.5^{* * *}$ & 0.25 & 0.19 \\
& Fund+sentiment & 0.33 & $5.9^{* * *}$ & 0.27 & 3.50 \\
& Fund+CFNAI & 0.33 & $6.5^{* * *}$ & 0.30 & 0.85 \\
& Fund+sentiment_orth & 0.32 & $6.0^{* * *}$ & 0.28 & 2.71 \\
& Fund+CFNAI_orth & 0.34 & $6.8^{* * *}$ & 0.31 & 1.58 \\
& Fund & 0.31 & $5.8^{* * *}$ & 0.27 & 1.11 \\
& Funt & 0.27 & 0.24 \\
\hline
\end{tabular}

This table reports the Sharpe ratio, mean and $R_{F}^{2}$ of long-short prediction-weighted and equally-weighted decile portfolios that use different macro-economic information sets for the prediction. We consider six different macroeconomic information sets: none, sentiment, CFNAI, sentiment orthogonal to CFNAI, CFNAI orthogonal to sentiment and sentiment+CFNAI. We use least-squares orthogonalization.

matters for mutual fund abnormal return predictability is to distinguish between the good and the bad states. This can be done equally effectively with sentiment and CFNAI. Put differently, different neural network models place very similar mutual funds into the same deciles. We calculate that $78 \%$ of mutual funds that are put in the bottom decile by the model that uses sentiment are also put in the bottom decile by the model that uses CFNAI. The corresponding number for the top decile is $74 \%$. These numbers are even higher for the orthogonalized sentiment measure and when using both sentiment and CFNAI as shown in Table B.11.

Figure 12 shows cumulative abnormal returns on the long-short portfolio, using predictionweighting and equally-weighted funds within the top and bottom deciles. It reinforces the result that the four different macro-economic information sets result in similarly strong out-performance. Consistent with our previous results, the prediction-weighting results in larger return spreads between the extreme deciles and hence a larger mean return.

Does that mean that the predictions with sentiment and CFNAI are equally good? No. The $R_{F}^{2}$ statistic is substantially higher when sentiment is used than when CFNAI is used. In other words, the actual outperformance of the best relative to the worst funds aligns better with the predicted outperformance when sentiment is used. The reason is that the model with sentiment does a better job predicting the actual (the cardinal and not just the ordinal) abnormal return of the funds in the top and bottom deciles than the model with CFNAI. In other words, while sentiment and CFNAI result in similar decile rankings of funds, the model with sentiment is substantial better in predicting the level of the performance. This can be exploited for timing the investments. Table 8 shows the out-of-sample performance based on sentiment terciles. The predictability of abnormal returns is the highest for medium and high sentiment states. An investor, who only invests into 
Figure 12: Cumulative abnormal returns of long-short portfolios for different macroeconomic information sets

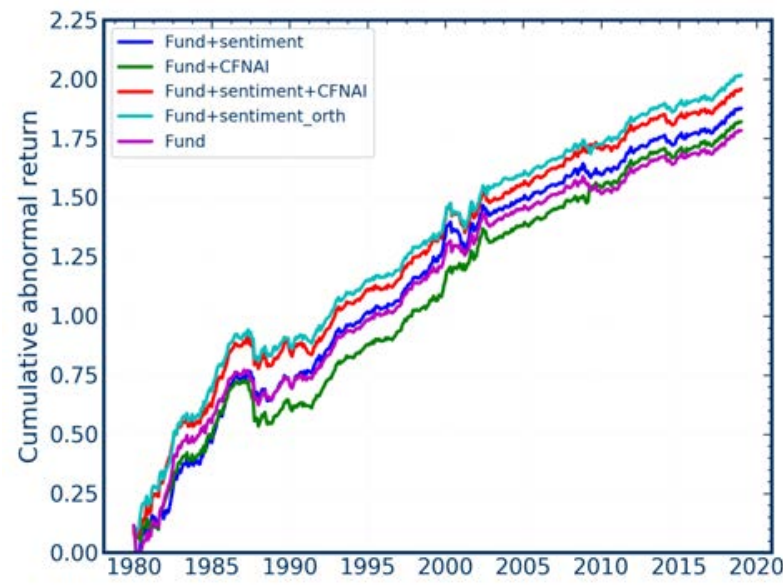

(a) Prediction-weighted long-short portfolio

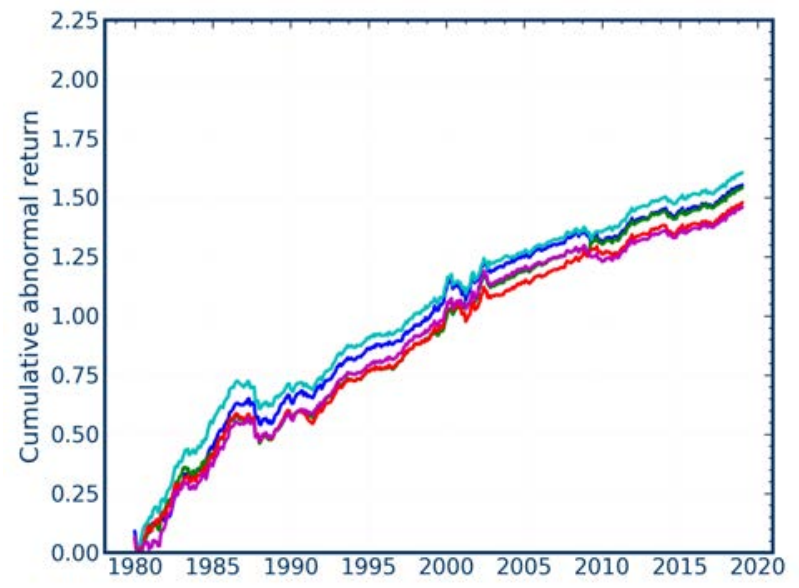

(b) Equally-weighted long-short portfolio

This figure plots the cumulative abnormal return returns of long-short prediction-weighted and equally-weighted decile portfolios that use different macroeconomic information and fund-specific characteristics to predict abnormal returns. We consider the following macro-economic information sets: none, sentiment, CFNAI, sentiment orthogonal to CFNAI and sentiment+CFNAI. We use least-squares orthogonalization.

the long-short strategy during periods of high predictability, earns more than twice the expected return compared to the low predictability state. The table also shows that even investors who can only take long positions can still achieve an average monthly abnormal return of $0.27 \%$ by investing into the top funds in high sentiment periods. Note that these results represent a valid out-of-sample performance as the strategy uses lagged sentiment and estimates the terciles cutoffs without the use of out-of-sample data.

To help understand the origin of the weaker performance of the model with CFNAI, appendix Figure B.7 revisits the interaction effects of fund-level characteristics with CFNAI. It shows no interaction effects: the predictive effect of a fund characteristic on abnormal returns in high CFNAI periods is a parallel shift from the relationship in low-CFNAI periods.

This is in contrast to the strong interaction effects for sentiment. It turns out the interaction effects of sentiment with fund-level variables is monotonic for all our variables. In order to assess the economic magnitude and the relative importance, we introduce a new interaction measure, which measures the differences in slopes for high and low macroeconomic states.

$$
\begin{aligned}
\operatorname{Interaction}(z, \text { macro })= & \left(\hat{R}^{a b n}(\text { high } z \text {, high macro })-\hat{R}^{a b n}(\text { low } z \text {, high macro })\right) \\
& -\left(\hat{R}^{a b n}(\text { high } z \text {, low macro })-\hat{R}^{a b n}(\text { low } z \text {, low macro })\right) .
\end{aligned}
$$

We evaluate the predicted abnormal return $\hat{R}^{a b n}$ for the highest and lowest value of the fund variable $z$ and the high (90\% quantile) and the low (10\% quantile) macroeconomic state. The other 
Table 8: Long-short abnormal return portfolios in different sentiment terciles.

\begin{tabular}{rrrrr|rrrr|rrrrr}
\hline \multicolumn{1}{c}{$T^{L}$} & \multicolumn{1}{c}{$T^{M}$} \\
Portfolio & SR & mean & t-stat & $R_{F}^{2}$ & SR & mean & t-stat & $R_{F}^{2}$ & SR & mean & t-stat & $R_{F}^{2}$ \\
\hline D10-D1 & 0.12 & 0.23 & 1.6 & 0.50 & 0.37 & 0.42 & $4.6^{* * *}$ & 3.39 & 0.32 & 0.55 & $4.0^{* * * *}$ & 4.83 \\
D1 & -0.11 & -0.18 & -1.4 & 0.71 & -0.25 & -0.23 & $-3.1^{* * *}$ & 3.65 & -0.23 & -0.29 & $-2.9^{* * *}$ & 1.35 \\
D2 & -0.19 & -0.16 & $-2.4^{* *}$ & 1.77 & -0.15 & -0.10 & $-1.8^{*}$ & 1.77 & -0.05 & -0.04 & -0.6 & -3.43 \\
D3 & -0.12 & -0.09 & -1.5 & 0.80 & -0.05 & -0.04 & -0.7 & 1.14 & 0.03 & 0.02 & 0.4 & -7.41 \\
D4 & -0.15 & -0.10 & $-1.9^{*}$ & 1.10 & 0.01 & 0.01 & 0.1 & -0.53 & -0.07 & -0.06 & -0.9 & -4.49 \\
D5 & -0.09 & -0.06 & -1.1 & 0.44 & 0.01 & 0.01 & 0.2 & 0.49 & 0.01 & 0.00 & 0.1 & -2.90 \\
D6 & -0.09 & -0.06 & -1.2 & 0.67 & 0.12 & 0.07 & 1.5 & -0.85 & 0.06 & 0.04 & 0.7 & -3.20 \\
D7 & -0.15 & -0.09 & $-1.8^{*}$ & 1.05 & 0.10 & 0.06 & 1.2 & -0.12 & 0.15 & 0.11 & $1.9^{*}$ & -0.43 \\
D8 & -0.10 & -0.06 & -1.2 & -0.55 & 0.15 & 0.10 & $1.8^{*}$ & -1.01 & 0.14 & 0.12 & $1.7^{*}$ & -1.69 \\
D9 & -0.06 & -0.05 & -0.8 & -0.80 & 0.19 & 0.24 & $2.3^{* *}$ & -0.32 & 0.07 & 0.08 & 0.9 & -0.12 \\
D10 & 0.05 & 0.04 & 0.6 & -0.86 & 0.22 & 0.19 & $2.7^{* * *}$ & 1.00 & 0.21 & 0.27 & $2.6^{* *}$ & 2.68 \\
\hline
\end{tabular}

This table reports the Sharpe ratio, mean, $\mathrm{t}$-statistic of mean and $R_{F}^{2}$ of prediction-weighted decile portfolios evaluated in different sentiment terciles. The mean and $R_{F}^{2}$ are reported in percentages. The low, medium and high tercile $\left(T^{L}\right.$, $T^{M}$ and $T^{H}$ ) splits for sentiment are based on the in-sample data of each of the three folds, and represent a valid out-of-sample performance. We use fund-specific characteristics and sentiment to predict abnormal returns.

variables are set to their median values. A high absolute value in this measure indicates a strong interaction effect and measures the difference in the return spread of characteristic $z$ in high and low sentiment states.

Figure 13 reports the interaction measure for sentiment and CFNAI with the fund characteristics. Return spreads due to fund momentum, turnover, flow and reversal are the most affected by sentiment. The predicted monthly spread in fund momentum is almost ten basis points higher in high sentiment states compared to low sentiment states. In contrast, CFNAI has virtually no interaction with the fund characteristics.

\section{Inspecting the Mechanism}

Having established that fund characteristics, and in particular fund momentum and flow, and their interaction with sentiment are key inputs for predicting mutual fund abnormal return, we now try to understand in more detail the mechanisms behind this prediction. To that end, we return to the univariate setting of Section 3. We decompose the mutual funds' abnormal return into a component that reflects trading between disclosure dates (between quarters) and a component that reflects trading within a disclosure period (within quarter).

$$
R_{i, t}^{a b n}=\underbrace{\tilde{R}_{i, t}-f_{t} \tilde{\beta}_{i}}_{\text {Between-disclosure abnormal return }}+\underbrace{R_{i, t}-f_{t} \beta_{i}-\left(\tilde{R}_{i, t}-f_{t} \tilde{\beta}_{i}\right)}_{\text {Within-disclosure abnormal return }}
$$


Figure 13: Interaction of fund variables with sentiment and CFNAI

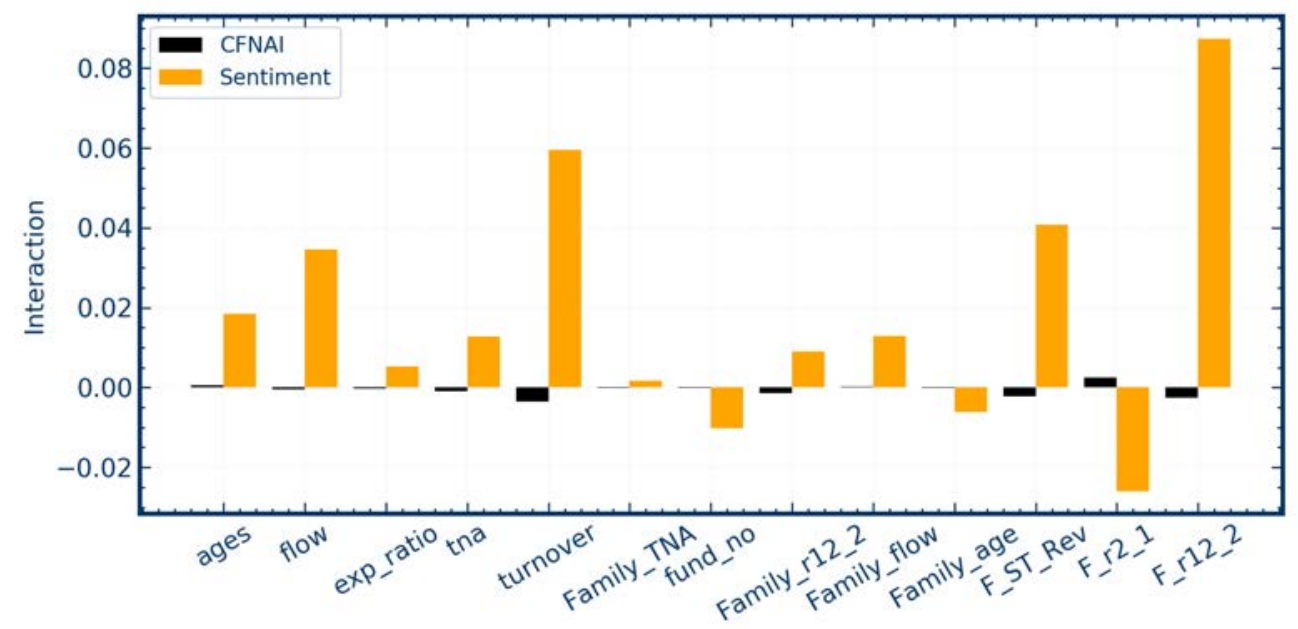

This figure reports the measure Interaction(z,macro) for fund characteristics and sentiment and CFNAI as macroeconomic variables. We evaluate the predicted abnormal return $\hat{R}^{a b n}$ for the highest and lowest value of the fund variable $z$ and the high ( $90 \%$ quantile) and the low (10\% quantile) macro-economic state. The other variables are set to their median values. The measure is reported in percentages.

$$
=\underbrace{\tilde{R}_{i, t}-f_{t} \tilde{\beta}_{i}}_{\text {Between-disclosure abnormal return }}+\underbrace{R_{i, t}-\tilde{R}_{i, t}}_{\text {Return gap }}+\underbrace{f_{t}\left(\tilde{\beta}_{i}-\beta_{i}\right)}_{\text {Risk exposure difference }}
$$

The between-disclosure abnormal return is the abnormal return of an investor who invests in the most recently disclosed stock positions of a fund and holds that portfolio until next fund disclosure. In the equation above, $\tilde{R}_{i, t}$ is the hypothetical return of a mutual fund $i$ that keeps its portfolio weights fixed at their last-disclosed levels (at $t-1), f_{t}$ is the contemporaneous return vector on the Carhart factors, and $\tilde{\beta}_{i}$ is the vector of exposures to the Carhart factors associated with this hypothetical fund return $\tilde{R}_{i, t}$. The exposures $\tilde{\beta}_{i}$ are estimated from a regression of $\tilde{R}_{i, t-h}$ on the Carhart factors in the previous 36 months $(h=1, \cdots, 36)$, where $\tilde{R}_{i, t-h}=\sum_{j} w_{i, j, t} R_{j, t-h}$. That is, $\tilde{R}_{i, t-h}$ is the return on a portfolio that holds the identity of the stocks $j$ and their portfolio weights $w_{i, j, t}$ fixed at the last-disclosed period $t$ for every $h$. The between-disclosure abnormal return is not simply the abnormal return of stocks with respect to the Carhart factors but captures the long-term stock-picking skills of mutual funds. A positive average between-disclosure abnormal return means that the mutual fund can pick stocks with positive alpha at disclosure dates (quarterly frequency).

A high value of within-disclosure abnormal returns indicates that the fund is adding value by actively trading between two adjacent disclosure dates. The within-disclosure abnormal return can be decomposed further into two parts: the return gap, as defined in Kacperczyk, Sialm, and Zheng (2008b), and the risk exposure differential, which is the difference between the risk exposure of the hypothetical fixed portfolio from the latest stock holding disclosure and the real risk 
Table 9: Decomposition of univariate long-short abnormal return factors

\begin{tabular}{r|rr|rrrr|rr|rrr}
\hline & \multicolumn{2}{|c}{ Total } & \multicolumn{2}{c}{ Between-disclosure } & \multicolumn{3}{c}{ Within-disclosure } & \multicolumn{2}{c}{ Risk difference } & \multicolumn{2}{c}{ Return gap } \\
& SR & mean & SR & mean & SR & mean & SR & mean & SR & mean \\
\hline F_r12_2 & 0.28 & $0.36^{* * *}$ & 0.14 & $0.20^{* * *}$ & 0.20 & $0.17^{* * *}$ & 0.14 & $0.11^{* * *}$ & 0.10 & $0.06^{* * *}$ \\
F_ST_Rev & 0.20 & $0.30^{* * *}$ & 0.14 & $0.16^{* * *}$ & 0.15 & $0.15^{* * *}$ & 0.12 & $0.08^{* *}$ & 0.12 & $0.06^{* * *}$ \\
Family_r12_2 & 0.19 & $0.13^{* * *}$ & 0.10 & $0.09^{* * *}$ & 0.09 & $0.04^{* *}$ & 0.12 & $0.07^{* *}$ & -0.06 & -0.03 \\
Beta & 0.15 & $0.18^{* * *}$ & 0.12 & $0.16^{* * *}$ & 0.03 & 0.03 & -0.01 & -0.00 & 0.05 & 0.03 \\
Rel2High & 0.14 & $0.20^{* * *}$ & 0.13 & $0.25^{* * *}$ & -0.05 & -0.05 & -0.03 & -0.03 & -0.03 & -0.03 \\
RNA & 0.13 & $0.13^{* * *}$ & 0.11 & $0.12^{* * *}$ & 0.01 & 0.01 & -0.03 & -0.02 & 0.04 & 0.02 \\
Family_TNA & 0.13 & $0.09^{* * *}$ & 0.09 & 0.07 & 0.05 & 0.03 & -0.12 & $-0.06^{* *}$ & 0.16 & $0.08^{* * *}$ \\
fund_no & 0.13 & $0.10^{* * *}$ & 0.10 & $0.07^{* *}$ & 0.06 & 0.03 & -0.12 & $-0.05^{* *}$ & 0.14 & $0.07^{* * *}$ \\
flow & 0.12 & $0.11^{* *}$ & 0.08 & $0.08^{* *}$ & 0.06 & 0.03 & -0.00 & -0.00 & 0.08 & $0.03^{* *}$ \\
Family_age & 0.11 & $0.09^{* *}$ & 0.08 & 0.07 & 0.03 & 0.02 & -0.13 & $-0.06^{* *}$ & 0.13 & $0.08^{* * *}$ \\
ROA & 0.10 & $0.10^{* *}$ & 0.11 & $0.13^{* * *}$ & -0.03 & -0.03 & -0.05 & -0.03 & 0.01 & 0.01 \\
PM & 0.10 & $0.10^{* *}$ & 0.10 & $0.11^{* *}$ & -0.01 & -0.01 & -0.03 & -0.02 & 0.02 & 0.01 \\
ROE & 0.10 & $0.11^{* *}$ & 0.09 & $0.12^{* *}$ & -0.01 & -0.01 & -0.02 & -0.01 & 0.00 & 0.00 \\
ST_Rev & 0.09 & $0.13^{* *}$ & 0.06 & 0.11 & 0.02 & 0.02 & 0.02 & 0.02 & 0.01 & 0.01 \\
CF & 0.09 & $0.09^{* *}$ & 0.11 & $0.16^{* *}$ & -0.07 & $-0.06^{* *}$ & -0.06 & -0.04 & -0.04 & -0.03 \\
\hline
\end{tabular}

This table reports mean and Sharpe ratio of the decomposition of univariate long-short abnormal return factors. Means of abnormal returns are reported in percentages. The results are sorted according to the Sharpe ratio of the long-short factors and show the first 15 factors. The full results are in Table B.4. For each of the 59 characteristics and each abnormal return, we construct decile-sorted portfolios. The long-short factors are the differences between the top decile and the bottom decile. Stars denote the significance levels.

exposure from the current (since rebalanced) portfolio.

We ask which characteristics best predict each of these three components of the fund abnormal return. Table 9 shows the results for the three-way decomposition. Columns 2 and 3 report the mean return and Sharpe ratio associated with an investment that goes long the $10 \%$ best funds and short the $10 \%$ worst funds based on a univariate prediction using the variable listed in the first column. These are the same results reported before. For brevity, we only report the first 15 rows of this table; the full table appears in the appendix (Table B.4). The next four sets of two columns predict one of the components of the abnormal fund return.

Momentum characteristics in the first few rows of the table are the most important characteristics for both between-disclosure and within-disclosure abnormal returns. A few stockspecific characteristics, and number of funds in the family, are useful for predicting betweendisclosure returns, while these momentum characteristics are the only significant predictors of within-disclosure abnormal returns. ${ }^{17}$ When it comes to understanding within-disclosure returns, we find that fund momentum and reversal are the only characteristics that predict both the return gap and the risk difference with the same sign. Other fund- and family variables predict the return gap significantly, but this effect is offset by an opposite-sign prediction for the risk difference. That is, while funds with these characteristics are trading in a way that increases the fund's return, they

\footnotetext{
${ }^{17}$ An exception being CF that is a significant negative predictor of within and positive predictor of between.
} 
Table 10: Decomposition of prediction long-short abnormal return portfolios

\begin{tabular}{r|rr|rr|rr|rr|rrr}
\hline & \multicolumn{2}{|c}{ Total } & \multicolumn{3}{c}{ Between-disclosure } & \multicolumn{3}{c}{ Within-disclosure } & \multicolumn{2}{c}{ Risk difference } & \multicolumn{2}{c}{ Return gap } \\
& SR & mean & SR & mean & SR & mean & SR & mean & SR & mean \\
\hline Stock+fund & 0.15 & $0.28^{* * *}$ & 0.05 & 0.13 & 0.14 & $0.15^{* * *}$ & 0.06 & 0.06 & 0.11 & $0.09^{* * *}$ \\
Stock+ fund+ sentiment & 0.21 & $0.41^{* * *}$ & 0.10 & $0.28^{* *}$ & 0.13 & $0.13^{* * *}$ & 0.07 & 0.06 & 0.09 & $0.06^{* *}$ \\
Stock & -0.01 & -0.02 & -0.01 & -0.03 & 0.01 & 0.01 & -0.01 & -0.01 & 0.03 & 0.02 \\
Stock+ sentiment & 0.07 & 0.15 & 0.04 & 0.12 & 0.02 & 0.02 & 0.00 & 0.00 & 0.02 & 0.02 \\
Fund & 0.25 & $0.38^{* * *}$ & 0.15 & $0.20^{* * *}$ & 0.17 & $0.18^{* * *}$ & 0.15 & $0.12^{* * *}$ & 0.08 & $0.06^{* *}$ \\
Fund+ sentiment & 0.25 & $0.40^{* * *}$ & 0.15 & $0.24^{* * *}$ & 0.16 & $0.16^{* * *}$ & 0.16 & $0.13^{* * *}$ & 0.03 & 0.03 \\
Flow+fund momentum+ sentiment & 0.24 & $0.48^{* * *}$ & 0.14 & $0.26^{* * *}$ & 0.17 & $0.22^{* * *}$ & 0.13 & $0.12^{* * *}$ & 0.11 & $0.10^{* * *}$ \\
\hline
\end{tabular}

This table reports the mean and Sharpe ratio for the decomposition of the prediction-weighted long-short decile portfolios. We use different information sets to predict abnormal returns. Means of abnormal returns are reported in percentages. Stars denote the significance levels.

do so by taking on more systematic risk. Funds with high fund momentum and reversal characteristics, in contrast, trade within the quarter in ways that both increase the return gap and reduce the systematic risk of the portfolio.

The same insights carry over to the neural network prediction model as shown in Table 10. The decomposition is a complex average of the univariate results. A prediction model that is only based on fund momentum, flow, and sentiment (the last row of the table) has the strongest withindisclosure effects, which is driven by the significant positive risk difference and return gap. When adding more fund characteristics, they lower the within-disclosure mean return.

\section{Conclusion}

In this paper, we revisit the question of predicting mutual fund performance. While predictability has been difficult to establish thus far, modern neural network techniques find strong evidence of predictability. An important advantage of non-linear neural network methods is that they can reliably estimate a complex functional relationship among a large set of variables. This turns out especially advantageous in predicting returns of actively managed mutual funds. The predictability we identify is real-time, out-of-sample, long-lived, and economically meaningful. It holds both before and after fees. Most of the benefits accrue from avoiding funds that the model predicts to be the worst performers. However, the prediction model is also able to identify about $10-20 \%$ of funds that generate positive abnormal returns even after fees.

We identify two fund characteristics, fund flow and fund momentum, as the key predictors of mutual fund out-performance. Characteristics of the stocks that funds hold do not play a significant role in predicting future abnormal performance. Moreover, these two fund characteristics matter much more when investor sentiment is high. That is, there are important interaction effects, which linear models fail to pick up. While including sentiment or CFNAI, a proxy for macro-economic activity, both improve predictability, there are no discernible interaction effects associated with CFNAI. These results should prove useful for improving theories of delegation in 
the mutual fund market.

Methodologically, we show that abnormal returns, obtained as local residuals to a factor model, are not only an economically motivated, but also the statistically better target for prediction. We demonstrate how to measure dependencies on macro-economic states. We suggest that instead of the typical horse race of model specifications it may be better to compare the prediction and trading benefits by varying the information set available to the same flexible machine learning algorithm. Finally, we introduce a novel measure for interaction effects in machine learning algorithms, which does not only measure a local slope, but a more informative global slope. These methodological contributions will help advance future asset pricing and investment research using machine learning, a growing area of research.

This paper focused on actively-managed equity mutual funds. Natural next steps are to consider bond mutual funds, as well as portfolios managed by hedge funds, pension funds, and endowments. 


\section{References}

Aminud, Y., And G. Ruslan (2013): “Mutual Fund's R2 as Predictor of Performance," Review of Financial Studies, 26(3), 667-694.

BAKER, M., AND J. WURGLER (2006): “Investor sentiment and the cross-section of stock returns," Journal of Finance, 61(4), 1645-1680.

BARber, B. M., X. HuANG, AND T. OdeAn (2016): “Which factors matter to investors? Evidence from mutual fund flows," Review of Financial Studies, 29(10), 2600-2642.

BERK, J. B., AND R. C. GReEN (2004): “Mutual fund flows and performance in rational markets," Journal of Political Economy, 112(6), 1269-1295.

BERK, J. B., AND J. H. VAN Binsbergen (2015): “Measuring skill in the mutual fund industry," Journal of Financial Economics, 118(1), 1-20.

- (2016): "Assessing asset pricing models using revealed preference," Journal of Financial Economics, 119(1), 1-23.

Bianchi, D., M. BüChner, T. Hoogteijling, And A. TAMoni (2021): “Corrigendum: Bond risk premiums with machine learning," Review of Financial Studies, 34(2), 1090-1103.

BIANCHI, D., M. BÜCHNER, AND A. TAMONI (2021): “Bond risk premiums with machine learning," Review of Financial Studies, 34(2), 1046-1089.

Bollen, N., AND B. JefFrey (2005): "Short-Term Persistence in Mutual Fund Performance," Review of Financial Studies, 18(2), 569-597.

BROWN, D. P., AND Y. WU (2016): "Mutual fund flows and cross-fund learning within families," Journal of Finance, 71(1), 383-424.

Bryzgalova, S., M. Lettau, S. Lerner, and M. Pelger (2021): “Asset Pricing with Missing Data," Working Paper.

Bryzgalova, S., M. Pelger, And J. ZHu (2021): "Forest through the Trees: Building CrossSections of Stock Returns," Working paper.

CARHART, M. M. (1997): “On persistence in mutual fund performance.,” Journal of Finance, 52(1), 57-82.

Chen, L., M. Pelger, And J. Zhu (2020): “Deep learning in asset pricing,” Working Paper.

COVAL, J., AND E. STAFFORD (2007): “Asset fire sales (and purchases) in equity markets," Journal of Financial Economics, 86(2), 479-512. 
Cremers, M., And A. Petajisto (2009): "How Active Is Your Fund Manager? A New Measure That Predicts Performance," Review of Financial Studies, 22(9), 3329-3365.

DeMiguel, V., J. Gil-Bazo, F. J. Nogales, and A. A. P. Santos (2022): “Machine Learning and Fund Characteristics Help to Select Mutual Funds with Positive Alpha," Working paper.

Doshi, H., R. ElKamhi, And M. Simutin (2015): “Managerial activeness and mutual fund performance," Review of Asset Pricing Studies, 5(2), 156-184.

FAMA, E. F., AND K. R. French (1996): “Multifactor Explanations of Asset Pricing Anomalies," Journal of Finance, 51(1), 55-84.

- (2010): "Luck versus Skill in the Cross-Section of Mutual Fund Returns," Journal of Finance, 65(5), 1915-1947.

FEnG, G., S. Giglio, AND D. XIU (2020): “Taming the Factor Zoo: A Test of New Factors," Journal of Finance, forthcoming.

Filippou, I., D. RAPACH, M. P. TAYlOR, AND G. ZHOU (2021): “Exchange Rate Prediction with Machine Learning and a Smart Carry Portfolio," Working Paper.

Freyberger, J., A. Neuhierl, AND M. Weber (2020): “Dissecting Characteristics Nonparametrically," Review of Financial Studies, forthcoming.

GABAiX, X., AND R. S. KOIJEN (2021): "In search of the origins of financial fluctuations: The inelastic markets hypothesis," Working Paper.

Goodfellow, I., Y. Bengio, And A. Courville (2016): Deep Learning. MIT Press.

Gruber, M. (1996): “Another Puzzle: The Growth of Actively Managed Mutual Funds,” Journal of Finance, 51(3), 783-810.

GU, S., B. T. Kelly, And D. XIU (2020): “Empirical Asset Pricing Via Machine Learning," Review of Financial Studies, 33(5), 2223-2273.

HAdDAD, V., S. KOZAK, AND S. SANTOSH (2020): "Factor timing," Review of Financial Studies, 33(5), 1980-2018.

Horel, E., AND K. Giesecke (2020): “Towards Explainable AI: Significance Tests for Neural Networks," Journal of Machine Learning Research, forthcoming.

Ibert, M., R. Kaniel, S. VAn Nieuwerburgh, and R. Vestman (2018): “Are mutual fund managers paid for investment skill?," Review of Financial Studies, 31(2), 715-772. 
JEGADEesh, N., AND C. S. MANGiPUdi (2021): "What do fund flows reveal about asset pricing models and investor sophistication?," Review of Financial Studies, 34(1), 108-148.

JEGAdeEsh, N., AND S. TitMAn (1993): "Returns to Buying Winners and Selling Losers: Implications for Stock Market Efficiency," Journal of Finance, 48(1), 65-91.

KACPERCZYK, M., S. V. NieUWERburgh, AND L. VeldKAMP (2014): “Time-varying fund manager skill," Journal of Finance, 69(4), 1455-1484.

KACPERCZYK, M., C. SiAlM, AND L. Zheng (2005): “On the Industry Concentration of Actively Managed Equity Mutual Funds," Journal of Finance, 60(4), 1983-2011.

_ (2008a): "Unobserved actions of mutual funds," Review of Financial Studies, 21(6), 2379_ 2416.

_ (2008b): "Unobserved actions of mutual funds," Review of Financial Studies, 21(6), 2379_ 2416.

KACPERCZyK, M., S. VAN NieuWerburgh, and L. VeldKAmp (2016): “A rational theory of mutual funds' attention allocation," Econometrica, 84(2), 571-626.

Karolyi, G. A., AND S. VAn NieuWerburgh (2020): "New methods for the cross-section of returns," Review of Financial Studies, 33(5), 1879-1890.

Kelly, B. T., S. PRUitT, AND Y. SU (2019): “Characteristics are covariances: A unified model of risk and return," Journal of Financial Economics, 134(3), 501-524.

Koljen, R. S., And M. Yogo (2019): “A demand system approach to asset pricing," Journal of Political Economy, 127(4), 1475-1515.

KosowsKI, R. (2011): “Do Mutual Funds Perform When It Matters Most to Investors? US Mutual Fund Performance and Risk in Recessions and Expansions," Quarterly Journal of Finance, 1(3), 607-664.

KOZAK, S., S. NAGEL, AND S. SANTOSH (2020): "Shrinking the Cross Section," Journal of Financial Economics, 135(2), 271-292.

Lettau, M., And M. Pelger (2020): “Factors that Fit the Time-Series and Cross-Section of Stock Returns," Review of Financial Studies, 33(5), 2274-2325.

LI, B., AND A. G. Rossi (2020): “Selecting mutual funds from the stocks they hold: A machine learning approach," Working Paper. 
MASSA, M., AND V. YADAV (2015): "Investor Sentiment and Mutual Fund Strategies," Journal of Financial and Quantitative Analysis, 50(4), 699-727.

Moskowitz, T. J. (2000): "Mutual fund performance: an empirical decomposition into stockpicking talent, style, transactions costs, and expenses. Discussion," Journal of Finance, 55, 16951703.

Roussanov, N., H. RuAN, And Y. Wei (2021): “Marketing mutual funds," Review of Financial Studies, 34(6), 3045-3094.

SadhWAni, A., K. Giesecke, And J. SiRignAno (2020): “Deep Learning for Mortgage Risk*," Journal of Financial Econometrics, 19(2), 313-368.

SAPP, T., AND A. TiWARI (2004): “Does Stock Return Momentum Explain the "Smart Money" Effect?," Journal of Finance, 59(6), 2605-2622.

StAMBAUGH, R. F. (2014): "Presidential address: Investment noise and trends," Journal of Finance, 69(4), 1415-1453.

StAMBAUGH, R. F., J. YU, AND Y. YUAN (2012): “The short of it: Investor sentiment and anomalies," Journal of Financial Economics, 104(2), 288-302.

Wu, W., J. Chen, Z. YANG, And M. L. Tindall (2021): “A cross-sectional machine learning approach for hedge fund return prediction and selection," Management Science, 67(7), 4577-4601.

XIONG, R., AND M. Pelger (2021): “Large dimensional latent factor modeling with missing observations and applications to causal inference," Working paper.

ZHENG, L. (1999): “Is Money Smart? A Study of Mutual Fund investors' Fund Selection Ability,” Journal of Finance, 54, 901-933. 


\section{A Data Cleaning and Imputation}

\section{A.1 Data Cleaning}

We make use of the code of Doshi, Elkamhi, and Simutin (2015) for processing mutual fund data. The fund returns, expenses, total net assets (TNA), investment objectives and other fund characteristics are from the Center for Research in Security Prices (CRSP) Survivor Bias-Free Mutual Fund Database. Our analysis requires fund holdings, which we obtain by linking the database to the Thomson Financial Mutual Fund Holdings. The stock characteristics are from Chen, Pelger, and Zhu (2020) and cover 46 characteristics that have been shown to have predictive power for the cross section of expected returns.

We restrict the analysis to diversified domestic active managed equity mutual funds. We use the newly introduced CRSP funds' investment objectives, crsp_obj_cd to define our sample and funds' style categories. The final sample selected with crsp_obj_cd is nearly identical to the one obtained when including funds with AGG, GMC, GRI, GRO, ING, and SCG Strategic Insight codes, EIEI, G, LCCE, LCGE, LCVE, MCCE, MCGE, MCVE, MLCE, MLGE, MLVE, SCCE, SCGE, and SCVE Lipper codes, and G, G-I, AGG, GCI, GRI, GRO, LTG, MCG, and SCG Wiesenberger codes. We screen styles and fund names to exclude international, balanced, sector, bond, money market, and index funds. There are eleven (mutual fund, time) observations for which the raw return is larger than 1 , which we also remove.

A fund's total net asset value (TNA) is summed across share classes, and its return, expense ratio, turnover and flow are averages weighted by the lagged asset value of each share class. Fund age is defined as the number of years since the inception of the oldest share class. The fund momentum characteristics are constructed as defined in Table 2.

Following Brown and $\mathrm{Wu}$ (2016), fund family is identified by the management company code. For the quarters with a missing company code, we use the mapping between the company name and company code identified in other quarters. For a given fund and month, Family_r12_2 and Family_flow are the averages of F_r12 2 and flow weighted by tha of all funds in the family, ex-

cluding the fund itself. Family_age is the age of the oldest fund in the family, excluding the fund itself. Fund_no is the number of funds in the family and Family_tna is the sum of TNAs of all funds in the family excluding the fund itself. 
Table A.1: Summary statistics of fund characteristics

\begin{tabular}{lcccc}
\hline Statistic & $\mathrm{N}$ & Mean & St. Dev. & Median \\
\hline turnover & 358,303 & 0.826 & 1.015 & 0.620 \\
ages & 407,139 & 13.669 & 10.200 & 11.000 \\
flow (\%) & 406,661 & 1.601 & 419.975 & -0.392 \\
r12_2 & 407,158 & 0.108 & 0.173 & 0.107 \\
LME & 407,158 & -0.385 & 0.108 & -0.424 \\
BEME & 407,158 & -0.153 & 0.376 & -0.161 \\
abnormal return (\%) & 407,158 & -0.028 & 2.000 & -0.028 \\
exp_ratio (\%) & 407,043 & 0.097 & 0.086 & 0.095 \\
TNA & 406,802 & $1,153.180$ & $4,833.920$ & 214.700 \\
Family_TNA & 398,655 & $19,834.410$ & $60,108.400$ & $1,584.700$ \\
Family_age & 399,011 & 22.657 & 19.512 & 18.000 \\
fund_no & 399,011 & 13.017 & 18.165 & 6.000 \\
\hline
\end{tabular}

This table reports summary statistics of the fund characteristics. The sample period is from 1980/01 to 2019/01.

\section{A.2 Data Imputation}

We use a panel of monthly firm returns and characteristics from 1963/01 to 2019/12. The data set has in total 30,000 different stocks with around 5,000-9,000 stocks available in each month. However, in each month only around 2,000-3,000 stocks have all 46 characteristics available. In order to use almost all stocks in our sample, we impute the missing characteristic information. This is important as a large number of funds' holdings include stocks that have missing characteristics. We follow the insights of Bryzgalova, Lettau, Lerner, and Pelger (2021) to impute the missing characteristics. More specifically, we the cross-sectional factor model advocated by Bryzgalova, Lettau, Lerner, and Pelger (2021), which is a modification of the method developed in Xiong and Pelger (2021) applied to characteristics. Intuitively, each month we estimate a latent factor model with principal components analysis (PCA) in the characteristic space and impute the missing observations as the common components of the factor model. For special cases this approach is equivalent to the expectation maximization (EM) algorithm, but this estimation approach is more general. This approach has the advantage that it takes into account the dependency between characteristics, which is not the case with a simple mean or median imputation. Importantly, the method of Xiong and Pelger (2021) allows the missing pattern to depend on the latent factor model or characteristic specific features, which is crucial as the data is not missing at random as shown by Bryzgalova, Lettau, Lerner, and Pelger (2021).

We have a three dimensional array of firm-characteristics $C_{t, l, i}$ which denotes the characteristics $l$ of firm $i$ at time $t$. We have in total $L$ firm characteristics which we report as cross-sectional quantiles from -0.5 to 0.5 . The number of total time periods is $T$ and at time $t$ there are $N_{t}$ stocks available. We denote by $C^{t}$ the $L \times N_{t}$ matrix of $L$ characteristics for the $N_{t}$ stocks in month $t$. We 
assume that the characteristics can be modeled by an approximate $K$-factor model as in Xiong and Pelger (2021):

$$
C_{i, l}^{t}=F_{i}^{t} \Lambda_{l}^{t^{\top}}+e_{i, l}^{t}
$$

Without missing values the latent factors and loadings can be estimated by PCA from the "characteristics covariance matrix" $\Sigma^{t}=\frac{1}{N_{t}} C^{t} C^{t^{\top}}$. In the presence of missing values, we use the method of Xiong and Pelger (2021) to estimate the latent factors. More specifically, we estimate the $L \times L$ matrix $\Sigma_{t}$ as

$$
\Sigma_{l, r}^{t}=\frac{1}{\left|Q_{l, r}\right|} \sum_{i \in Q_{l, r}} C_{l, i}^{t} C_{r, i}^{t}
$$

where $Q_{l, r}$ are the indices of all the stocks that have characteristics $l$ and $r$ in common at time $t$ and $\left|Q_{l, r}\right|$ is the cardinality of this set. The $\Lambda^{t}$ are estimated with PCA as the normalized eigenvectors of $\Sigma^{t}$. Last but not least, we estimate the "characteristic factors" with a weighted regression

$$
\underbrace{\hat{F}_{i}^{t}}_{K \times 1}=\left(\sum_{l \in Q_{i, t}} \hat{\Lambda}_{l}^{t} \hat{\Lambda}_{l}^{\dagger \top}\right)^{-1} \sum_{l \in Q_{i, t}} \hat{\Lambda}_{l}^{t} C_{l, i}^{t} .
$$

Given the estimated factors and loadings, the missing values are imputed with $\hat{C}_{l, i}^{t}=\hat{F}_{i}^{t} \hat{\Lambda}_{l}^{t \top}$.

The factor imputation depends on two parameters. First, we select the number $L_{\min }$ of characteristics that a stock needs to have in order to be included in the sample. By construction this is an upper bound on the number of latent factors. Second, we select the number of latent factors $K$. Based on an extensive analysis we have set $L_{\text {min }}=10$ and $K=10$ as the benchmark model. The results are robust to this choice, while it allows us to include almost all stocks in the sample.

We assess the accuracy of the data imputation method based on how well the characteristic factor model approximates the observed characteristic entries. We measure the amount of explained variation by the following $R^{2}$ using only the observed entries:

$$
R^{2}=1-\frac{\sum_{t, l, i} e_{t, l, i}^{2}}{\sum_{t, l, i} C_{t, l, i}^{2}}
$$

Table A. 2 shows that a model with $K=10$ factors explains around $75 \%$ of the cross-sectional variation in characteristics. Note that the first latent factor is very close to a cross-sectional average for each characteristic. Hence, a one-factor model is essentially imputation with a cross-sectional median, which is strongly suboptimal.

Table A.3 shows that after the data imputation we have full characteristic information for almost $99 \%$ of the stocks held by mutual funds. Without the data imputation, we could only observe 
the characteristics for around $57 \%$ of the stocks held by mutual funds. The choice of $L_{\min }$ trades off the accuracy of the imputation and the goal of keeping as many stocks as possible. The extensive empirical study in Bryzgalova, Lettau, Lerner, and Pelger (2021) provides further support for this imputation model.

Table A.2: $R^{2}$ of Factor Model

\begin{tabular}{cccccc}
\hline$K$ & 2 & 4 & 6 & 8 & 10 \\
\hline$R^{2}$ & $34.7 \%$ & $50.7 \%$ & $60.6 \%$ & $68.4 \%$ & $74.5 \%$ \\
\hline
\end{tabular}

This table shows the time average of $R^{2}$ of the characteristics imputation for different number of factors $K$. We require at least $L_{\min }=10$ observed characteristics for each stock.

Table A.3: Proportion of Missing Characteristics for Different $L_{\min }$

\begin{tabular}{ccc}
\hline$L_{\min }$ & Missing $(i, j, t)$ No. & Proportion of total observations \\
\hline 8 & 565,663 & $0.98 \%$ \\
10 & 744,087 & $1.29 \%$ \\
12 & $1,794,131$ & $3.12 \%$ \\
14 & $2,025,437$ & $3.52 \%$ \\
46, original characteristic data & $24,596,754$ & $42.80 \%$ \\
\hline
\end{tabular}

This table shows the number of missing characteristics observations and the corresponding proportion relative to the total number of entries. The results are summed over mutual funds, stocks and time.

\section{B Robustness Results}

\section{B.1 More univariate sorting results}

Table B.1: Group characteristic long-short factors from abnormal returns

\begin{tabular}{rrrrr}
\hline & mean $(\%)$ & std $(\%)$ & SR & t-stat \\
\hline fund momentum & 0.33 & 1.45 & 0.22 & $4.9^{* * *}$ \\
family & 0.12 & 0.74 & 0.16 & $3.5^{* * *}$ \\
value & 0.18 & 1.11 & 0.16 & $3.4^{* * *}$ \\
fund & 0.09 & 0.71 & 0.13 & $2.8^{* * *}$ \\
profitability & 0.13 & 1.02 & 0.13 & $2.7^{* * *}$ \\
friction & 0.17 & 1.72 & 0.10 & $2.1^{* *}$ \\
intangile & 0.08 & 0.88 & 0.09 & $1.9^{*}$ \\
past & 0.11 & 1.39 & 0.08 & $1.7^{*}$ \\
investment & 0.06 & 0.93 & 0.06 & 1.3 \\
\hline
\end{tabular}

This table reports the summary statistics for univariate long-short factors based on group-averaged abnormal returns and sorted according to their Sharpe ratios. For each of the 9 categories, we construct group characteristics as the equally-weighted average of the characteristics within each category. The long-short factors are the differences between the top decile and the bottom decile. "Mean", "std" and "Sharpe ratio" report the mean, standard deviation and Sharpe ratio of the factors and the fourth column, "t-stat" denotes the t-statistics for a test that the factor mean is different from 0 . 
Table B.2: First Principal Component within each Characteristic Group in Different Sentiment Terciles

\begin{tabular}{rrr|rr|rr}
\hline & \multicolumn{2}{c}{$T^{L}$} & \multicolumn{2}{c}{$T^{M}$} & \multicolumn{2}{c}{$T^{H}$} \\
Name & SR & t-stat & SR & t-stat & SR & t-stat \\
\hline fund momentum & 0.02 & 0.3 & 0.30 & $5.0^{* * *}$ & 0.23 & $4.6^{* * *}$ \\
family & 0.08 & 1.0 & 0.15 & $1.8^{*}$ & 0.16 & $2.5^{* *}$ \\
profitability & 0.01 & 0.1 & 0.20 & $1.9^{* *}$ & 0.17 & $2.5^{* *}$ \\
fund & 0.10 & 0.9 & 0.04 & 0.4 & 0.16 & $2.1^{* *}$ \\
past & -0.07 & -0.6 & 0.24 & $1.7^{* * *}$ & 0.12 & 1.3 \\
friction & 0.02 & 0.2 & 0.01 & 0.1 & 0.18 & $2.1^{* *}$ \\
value & 0.04 & 0.1 & 0.19 & $0.2^{* *}$ & -0.12 & -0.2 \\
intangile & -0.00 & -0.0 & -0.08 & -0.1 & 0.12 & 0.2 \\
investment & -0.02 & -0.0 & -0.10 & -0.1 & 0.12 & 0.1 \\
\hline
\end{tabular}

This table reports the mean, standard deviation and Sharpe ratio for different sentiment terciles. For each of the 9 categories, we apply PCA to the abnormal returns of all long-short factors within a group to obtain a group factor. We split the time-series into $T^{H}, T^{M}$ and $T^{L}$, which denotes the high, medium and low sentiment terciles based on the previous months. For each of these time periods we separately estimate the mean, standard deviation and Sharpe ratio of the factors conditional on a sentiment tercile. The column, "t-stat" denotes the t-statistics for factor mean different from 0 in each sentiment tercile. 
Table B.3: Spanning of univariate long-short portfolios with different factor models.

\begin{tabular}{|c|c|c|c|c|c|c|c|c|c|}
\hline & \multicolumn{2}{|c|}{4 factors } & \multicolumn{2}{|c|}{5 factors } & \multicolumn{2}{|c|}{6 factors } & \multicolumn{2}{|c|}{8 factors } & \multirow[b]{2}{*}{ mean } \\
\hline & $\alpha$ & $R^{2}$ & $\alpha$ & $R^{2}$ & $\alpha$ & $R^{2}$ & $\alpha$ & $R^{2}$ & \\
\hline F_ST_Rev & $\begin{array}{r}0.18^{* * *} \\
(0.04)\end{array}$ & 0.04 & $\begin{array}{r}0.19^{* * *} \\
(0.04)\end{array}$ & 0.02 & $\begin{array}{r}0.18^{* * *} \\
(0.04)\end{array}$ & 0.04 & $\begin{array}{r}0.23^{* * *} \\
(0.04)\end{array}$ & 0.31 & $\begin{array}{r}0.20^{* * * *} \\
(0.05)\end{array}$ \\
\hline F_r2_1 & $\begin{array}{r}0.01 \\
(0.05)\end{array}$ & 0.11 & $\begin{array}{r}0.03 \\
(0.05)\end{array}$ & 0.03 & $\begin{array}{r}-0.01 \\
(0.05)\end{array}$ & 0.12 & $\begin{array}{r}0.01 \\
(0.05)\end{array}$ & 0.17 & $\begin{array}{r}0.08 \\
(0.05)\end{array}$ \\
\hline F_r12_2 & $\begin{array}{r}0.17^{* * *} \\
(0.04)\end{array}$ & 0.23 & $\begin{array}{c}0.22^{* * *} \\
(0.04)\end{array}$ & 0.06 & $\begin{array}{c}0.16^{* * *} \\
(0.04)\end{array}$ & 0.23 & $\begin{array}{c}0.16^{* * *} \\
(0.04)\end{array}$ & 0.23 & $\begin{array}{r}0.28^{* * *} \\
(0.05)\end{array}$ \\
\hline ages & $\begin{array}{r}0.08 \\
(0.05)\end{array}$ & 0.02 & $\begin{array}{r}0.06 \\
(0.05)\end{array}$ & 0.03 & $\begin{array}{r}0.05 \\
(0.05)\end{array}$ & 0.03 & $\begin{array}{r}0.06 \\
(0.05)\end{array}$ & 0.03 & $\begin{array}{r}0.09 * \\
(0.05)\end{array}$ \\
\hline flow & $\begin{array}{l}0.10^{* *} \\
(0.05)\end{array}$ & 0.02 & $\begin{array}{r}0.08 \\
(0.05)\end{array}$ & 0.03 & $\begin{array}{r}0.08 \\
(0.05)\end{array}$ & 0.03 & $\begin{array}{r}0.07 \\
(0.05)\end{array}$ & 0.03 & $\begin{array}{l}0.12^{* *} \\
(0.05)\end{array}$ \\
\hline exp_ratio & $\begin{array}{l}0.11^{* *} \\
(0.05)\end{array}$ & 0.04 & $\begin{array}{r}0.14^{* * *} \\
(0.05)\end{array}$ & 0.07 & $\begin{array}{r}0.16^{* * *} \\
(0.05)\end{array}$ & 0.09 & $\begin{array}{r}0.16^{* * *} \\
(0.05)\end{array}$ & 0.11 & $\begin{array}{r}0.07 \\
(0.05)\end{array}$ \\
\hline tna & $\begin{array}{r}-0.05 \\
(0.05)\end{array}$ & 0.02 & $\begin{array}{r}-0.05 \\
(0.05)\end{array}$ & 0.02 & $\begin{array}{r}-0.06 \\
(0.05)\end{array}$ & 0.02 & $\begin{array}{r}-0.07 \\
(0.05)\end{array}$ & 0.04 & $\begin{array}{r}-0.06 \\
(0.05)\end{array}$ \\
\hline turnover & $\begin{array}{r}0.02 \\
(0.05)\end{array}$ & 0.01 & $\begin{array}{r}-0.05 \\
(0.05)\end{array}$ & 0.08 & $\begin{array}{r}-0.05 \\
(0.05)\end{array}$ & 0.08 & $\begin{array}{r}-0.07 \\
(0.05)\end{array}$ & 0.12 & $\begin{array}{r}0.03 \\
(0.05)\end{array}$ \\
\hline Family_TNA & $\begin{array}{r}0.13^{* * *} \\
(0.05)\end{array}$ & 0.02 & $\begin{array}{r}0.16^{* * * *} \\
(0.05)\end{array}$ & 0.05 & $\begin{array}{r}0.16^{* * *} \\
(0.05)\end{array}$ & 0.05 & $\begin{array}{r}0.18^{* * *} \\
(0.05)\end{array}$ & 0.07 & $\begin{array}{r}0.13^{* * *} \\
(0.05)\end{array}$ \\
\hline fund_no & $\begin{array}{c}0.09 * \\
(0.05)\end{array}$ & 0.03 & $\begin{array}{c}0.12^{* *} \\
(0.05)\end{array}$ & 0.03 & $\begin{array}{l}0.11^{* *} \\
(0.05)\end{array}$ & 0.04 & $\begin{array}{r}0.13^{* * *} \\
(0.05)\end{array}$ & 0.07 & $\begin{array}{r}0.13^{* * *} \\
(0.05)\end{array}$ \\
\hline Family_r12_2 & $\begin{array}{r}0.14^{* * *} \\
(0.05)\end{array}$ & 0.04 & $\begin{array}{r}0.17^{* * *} \\
(0.05)\end{array}$ & 0.01 & $\begin{array}{r}0.15^{* * *} \\
(0.05)\end{array}$ & 0.05 & $\begin{array}{r}0.14^{* * *} \\
(0.05)\end{array}$ & 0.05 & $\begin{array}{r}0.19^{* * *} \\
(0.05)\end{array}$ \\
\hline Family_age & $\begin{array}{r}0.08 \\
(0.05)\end{array}$ & 0.03 & $\begin{array}{c}0.11^{* *} \\
(0.05)\end{array}$ & 0.04 & $\begin{array}{l}0.10^{* *} \\
(0.05)\end{array}$ & 0.04 & $\begin{array}{l}0.11^{* *} \\
(0.05)\end{array}$ & 0.07 & $\begin{array}{l}0.11^{* *} \\
(0.05)\end{array}$ \\
\hline Family_flow & $\begin{array}{c}0.08^{*} \\
(0.05)\end{array}$ & 0.01 & $\begin{array}{r}0.07 \\
(0.05)\end{array}$ & 0.00 & $\begin{array}{r}0.08 \\
(0.05)\end{array}$ & 0.01 & $\begin{array}{r}0.07 \\
(0.05)\end{array}$ & 0.02 & $\begin{array}{r}0.07 \\
(0.05)\end{array}$ \\
\hline
\end{tabular}

This table reports the multivariate time-series regression results of univariate long-short abnormal return portfolios for different factor models. We consider the 4-factor Fama-French-Carhart model (market, size, value and momentum), the 5-factor Fama-French model (market, size, value, profitability and investment), a 6-factor model which adds the momentum factor to the Fama-French 5 factors, and an 8-factor model which adds the momentum, short-term reversal and long-term reversal factors to the Fama-French 5 factors. The $\alpha$ column reports the time-series pricing error and $R^{2}$ is the explained variation of the regression. Both the univariate long-short abnormal return portfolios and the factor models are normalized to have a standard deviation of 1 . Standard errors are in brackets and stars denote the significance levels. 
Table B.4: Decomposition of univariate long-short portfolios from mutual fund abnormal returns

\begin{tabular}{|c|c|c|c|c|c|c|c|c|c|c|}
\hline & \multicolumn{2}{|c|}{ Total } & \multicolumn{2}{|c|}{ Between-disclosure } & \multicolumn{2}{|c|}{ Within-disclosure } & \multicolumn{2}{|c|}{ Risk difference } & \multicolumn{2}{|c|}{ Return gap } \\
\hline & SR & mean & SR & mean & SR & mean & SR & mean & SR & mean \\
\hline F_r12_2 & 0.28 & $0.36^{* * *}$ & 0.14 & $0.20^{* * *}$ & 0.20 & $0.17^{* * *}$ & 0.14 & $0.11^{* * *}$ & 0.10 & $0.06^{* * *}$ \\
\hline F_ST_Rev & 0.20 & $0.30^{* * *}$ & 0.14 & $0.16^{* * *}$ & 0.15 & $0.15^{* * *}$ & 0.12 & $0.08^{* *}$ & 0.12 & $0.06^{* * *}$ \\
\hline Family_r12_2 & 0.19 & $0.13^{* * *}$ & 0.10 & $0.09^{* * *}$ & 0.09 & $0.04^{* *}$ & 0.12 & $0.07^{* *}$ & -0.06 & -0.03 \\
\hline Beta & 0.15 & $0.18^{* * *}$ & 0.12 & $0.16^{* * *}$ & 0.03 & 0.03 & -0.01 & -0.00 & 0.05 & 0.03 \\
\hline Rel2High & 0.14 & $0.20^{* * *}$ & 0.13 & $0.25^{* * *}$ & -0.05 & -0.05 & -0.03 & -0.03 & -0.03 & -0.03 \\
\hline RNA & 0.13 & $0.13^{* * *}$ & 0.11 & $0.12^{* * *}$ & 0.01 & 0.01 & -0.03 & -0.02 & 0.04 & 0.02 \\
\hline Family_TNA & 0.13 & $0.09^{* * *}$ & 0.09 & 0.07 & 0.05 & 0.03 & -0.12 & $-0.06^{* *}$ & 0.16 & $0.08^{* * *}$ \\
\hline fund no & 0.13 & $0.10^{* * *}$ & 0.10 & $0.07^{* *}$ & 0.06 & 0.03 & -0.12 & $-0.05^{* *}$ & 0.14 & $0.07^{* * *}$ \\
\hline flow & 0.12 & $0.11^{* *}$ & 0.08 & $0.08^{* *}$ & 0.06 & 0.03 & -0.00 & -0.00 & 0.08 & $0.03^{* *}$ \\
\hline Family_age & 0.11 & $0.09 * *$ & 0.08 & 0.07 & 0.03 & 0.02 & -0.13 & $-0.06^{* *}$ & 0.13 & $0.08^{* * *}$ \\
\hline ROA & 0.10 & $0.10^{* *}$ & 0.11 & $0.13^{* * *}$ & -0.03 & -0.03 & -0.05 & -0.03 & 0.01 & 0.01 \\
\hline PM & 0.10 & $0.10^{* *}$ & 0.10 & $0.11^{* *}$ & -0.01 & -0.01 & -0.03 & -0.02 & 0.02 & 0.01 \\
\hline ROE & 0.10 & $0.11^{* *}$ & 0.09 & $0.12^{* *}$ & -0.01 & -0.01 & -0.02 & -0.01 & 0.00 & 0.00 \\
\hline ST_Rev & 0.09 & $0.13^{* *}$ & 0.06 & 0.11 & 0.02 & 0.02 & 0.02 & 0.02 & 0.01 & 0.01 \\
\hline CF & 0.09 & $0.09^{* *}$ & 0.11 & $0.16^{* *}$ & -0.07 & $-0.06^{* *}$ & -0.06 & -0.04 & -0.04 & -0.03 \\
\hline Resid_Var & 0.09 & $0.14^{* *}$ & 0.08 & $0.17^{* *}$ & -0.03 & -0.03 & 0.03 & 0.03 & -0.06 & -0.06 \\
\hline ages & 0.09 & $0.05^{* *}$ & 0.01 & 0.01 & 0.06 & 0.04 & 0.07 & 0.04 & 0.02 & 0.01 \\
\hline MktBeta & 0.08 & $0.14^{* *}$ & 0.07 & 0.14 & 0.00 & 0.00 & 0.05 & 0.05 & -0.07 & $-0.05^{* *}$ \\
\hline r12_2 & 0.08 & $0.11^{* *}$ & 0.08 & $0.19^{* *}$ & -0.06 & $-0.08^{* *}$ & -0.08 & $-0.09^{* *}$ & 0.01 & 0.01 \\
\hline Spread & 0.08 & $0.13^{* *}$ & 0.07 & 0.14 & -0.01 & -0.01 & 0.04 & 0.04 & -0.04 & -0.04 \\
\hline D2P & 0.08 & $0.12^{* *}$ & 0.08 & $0.13^{* *}$ & -0.01 & -0.01 & 0.09 & $0.08^{* * *}$ & -0.16 & $-0.09^{* * *}$ \\
\hline r12_7 & 0.08 & $0.11^{* *}$ & 0.10 & $0.19^{* * *}$ & -0.07 & $-0.08^{* *}$ & -0.09 & $-0.09^{* *}$ & 0.02 & 0.02 \\
\hline F_r2_1 & 0.08 & 0.11 & -0.00 & -0.00 & 0.13 & $0.11^{* * *}$ & 0.12 & $0.08^{* *}$ & 0.07 & $0.04^{* *}$ \\
\hline LTurnover & 0.07 & 0.13 & 0.06 & 0.14 & -0.01 & -0.01 & 0.08 & $0.08^{* *}$ & -0.12 & $-0.09^{* * *}$ \\
\hline Variance & 0.07 & 0.13 & 0.07 & 0.17 & -0.04 & -0.04 & 0.04 & 0.04 & -0.09 & $-0.08^{* *}$ \\
\hline IdioVol & 0.07 & 0.12 & 0.07 & 0.15 & -0.04 & -0.04 & 0.03 & 0.03 & -0.07 & -0.06 \\
\hline C & 0.07 & 0.09 & 0.08 & $0.12^{* *}$ & -0.04 & -0.03 & -0.10 & $-0.08^{* * *}$ & 0.11 & $0.05^{* * *}$ \\
\hline Lev & 0.07 & 0.08 & 0.05 & 0.07 & 0.02 & 0.01 & -0.02 & -0.01 & 0.04 & 0.02 \\
\hline Family_flow & 0.07 & 0.04 & 0.05 & 0.03 & 0.02 & 0.01 & 0.04 & 0.02 & -0.03 & -0.01 \\
\hline ATO & 0.07 & 0.07 & 0.05 & 0.05 & 0.02 & 0.02 & -0.03 & -0.02 & 0.09 & $0.04^{* *}$ \\
\hline exp_ratio & 0.07 & 0.04 & -0.03 & -0.02 & 0.13 & $0.06^{* * *}$ & 0.08 & $0.04^{* *}$ & 0.05 & 0.03 \\
\hline CTO & 0.06 & 0.07 & 0.06 & 0.07 & -0.01 & -0.01 & -0.07 & -0.04 & 0.07 & 0.03 \\
\hline tna & -0.06 & -0.04 & -0.04 & -0.03 & -0.03 & -0.02 & 0.09 & $0.04^{* *}$ & -0.11 & $-0.06^{* * *}$ \\
\hline SUV & 0.06 & 0.06 & 0.06 & 0.07 & -0.03 & -0.02 & -0.04 & -0.02 & 0.01 & 0.01 \\
\hline SGA2S & 0.05 & 0.06 & 0.08 & $0.10^{* *}$ & -0.06 & -0.04 & -0.07 & $-0.05^{* *}$ & 0.02 & 0.01 \\
\hline OL & 0.05 & 0.05 & 0.03 & 0.04 & 0.01 & 0.01 & -0.01 & -0.00 & 0.03 & 0.01 \\
\hline PCM & 0.05 & 0.05 & 0.10 & $0.12^{* *}$ & -0.09 & $-0.07^{* *}$ & -0.06 & -0.04 & -0.06 & -0.03 \\
\hline r2_1 & 0.05 & 0.06 & 0.00 & 0.00 & 0.06 & 0.06 & 0.05 & 0.04 & 0.03 & 0.02 \\
\hline CF2P & 0.04 & 0.06 & 0.04 & 0.08 & -0.02 & -0.02 & -0.08 & $-0.06^{* *}$ & 0.08 & $0.04^{* *}$ \\
\hline NI & 0.04 & 0.05 & 0.04 & 0.05 & 0.01 & 0.01 & 0.12 & $0.09^{* *}$ & -0.16 & $-0.08^{* * *}$ \\
\hline $\mathrm{Q}$ & 0.04 & 0.05 & 0.02 & 0.04 & 0.01 & 0.01 & -0.07 & $-0.05^{* *}$ & 0.10 & $0.07^{* *}$ \\
\hline FC2Y & 0.04 & 0.05 & 0.07 & 0.09 & -0.06 & -0.05 & -0.06 & $-0.04^{* *}$ & -0.00 & -0.00 \\
\hline PROF & 0.04 & 0.04 & 0.05 & 0.08 & -0.06 & -0.05 & -0.06 & -0.03 & -0.02 & -0.01 \\
\hline LME & 0.04 & 0.03 & 0.04 & 0.04 & -0.01 & -0.00 & 0.03 & 0.03 & -0.03 & -0.03 \\
\hline D2A & 0.03 & 0.03 & 0.03 & 0.03 & 0.00 & 0.00 & -0.02 & -0.01 & 0.01 & 0.01 \\
\hline turnover & 0.03 & 0.03 & 0.04 & 0.04 & -0.02 & -0.01 & -0.01 & -0.01 & -0.02 & -0.01 \\
\hline AT & 0.03 & 0.04 & 0.01 & 0.02 & 0.02 & 0.02 & -0.04 & -0.02 & 0.05 & 0.04 \\
\hline OA & 0.03 & 0.03 & -0.01 & -0.00 & 0.05 & 0.03 & 0.07 & 0.04 & -0.01 & -0.00 \\
\hline r36_13 & -0.03 & -0.04 & -0.10 & $-0.13^{* *}$ & 0.12 & $0.09^{* * *}$ & 0.12 & $0.08^{* * *}$ & 0.02 & 0.01 \\
\hline AC & 0.03 & 0.02 & -0.00 & -0.00 & 0.04 & 0.02 & 0.06 & 0.03 & -0.02 & -0.01 \\
\hline E2P & -0.03 & -0.04 & -0.01 & -0.02 & -0.03 & -0.02 & 0.06 & 0.03 & -0.10 & $-0.05^{* *}$ \\
\hline OP & 0.02 & 0.03 & 0.02 & 0.03 & -0.00 & -0.00 & -0.02 & -0.01 & 0.01 & 0.01 \\
\hline NOA & 0.02 & 0.02 & 0.05 & 0.05 & -0.06 & -0.03 & -0.11 & $-0.06^{* *}$ & 0.05 & 0.03 \\
\hline DPI2A & 0.01 & 0.01 & 0.08 & $0.08^{* *}$ & -0.11 & $-0.07^{* * *}$ & -0.19 & $-0.09^{* * *}$ & 0.05 & 0.02 \\
\hline A2ME & 0.01 & 0.02 & 0.05 & 0.07 & -0.07 & $-0.06^{* *}$ & -0.15 & $-0.12^{* * *}$ & 0.12 & $0.06^{* * *}$ \\
\hline $\mathrm{S} 2 \mathrm{P}$ & -0.01 & -0.02 & -0.02 & -0.03 & 0.02 & 0.02 & 0.13 & $0.11^{* * *}$ & -0.18 & $-0.09^{* * *}$ \\
\hline Investment & 0.01 & 0.01 & 0.08 & $0.08^{* *}$ & -0.11 & $-0.07^{* * *}$ & -0.14 & $-0.09^{* * *}$ & 0.04 & 0.02 \\
\hline LT_Rev & 0.01 & 0.01 & -0.01 & -0.01 & 0.02 & 0.02 & 0.02 & 0.01 & 0.01 & 0.01 \\
\hline BEME & -0.00 & -0.00 & -0.03 & -0.04 & 0.05 & 0.04 & 0.13 & $0.11^{* * *}$ & -0.15 & $-0.07^{* * *}$ \\
\hline
\end{tabular}

This table reports the mean and Sharpe ratio for the decomposition of univariate long-short abnormal return factors. Means of abnormal returns are reported in percentages. The results are sorted according to the Sharpe ratio of univariate long-short factors. For each of the 59 characteristics and each abnormal return, we construct ten sorted decile portfolios. The long-short factors are the differences between the top decile and the bottom decile. 
Table B.5: Univariate long-short portfolios in different CFNAI terciles

\begin{tabular}{|c|c|c|c|c|c|c|}
\hline & \multicolumn{2}{|c|}{ Low CFNAI } & \multicolumn{2}{|c|}{ Medium CFNAI } & \multicolumn{2}{|c|}{ High CFNAI } \\
\hline & SR & mean $(\%)$ & SR & mean $(\%)$ & SR & mean $(\%)$ \\
\hline F_r12_2 & 0.26 & $0.39^{* * *}$ & 0.34 & $0.40^{* * *}$ & 0.25 & $0.30^{* * *}$ \\
\hline F_ST_Rev & 0.17 & $0.31^{* *}$ & 0.19 & $0.26^{* *}$ & 0.25 & $0.34^{* * *}$ \\
\hline Family_r12_2 & 0.28 & $0.23^{* * *}$ & 0.13 & $0.08^{*}$ & 0.13 & 0.08 \\
\hline Beta & 0.17 & $0.24^{* *}$ & 0.12 & 0.13 & 0.17 & $0.18^{* *}$ \\
\hline Rel2High & 0.07 & 0.14 & 0.22 & $0.25^{* * *}$ & 0.20 & $0.21^{* *}$ \\
\hline RNA & 0.18 & $0.21^{* *}$ & 0.17 & $0.12^{* *}$ & 0.05 & 0.05 \\
\hline Family_TNA & 0.04 & 0.04 & 0.26 & $0.16^{* * *}$ & 0.11 & 0.08 \\
\hline fund_no & 0.02 & 0.02 & 0.25 & $0.15^{* * *}$ & 0.16 & $0.12^{*}$ \\
\hline flow & 0.03 & 0.04 & 0.15 & $0.13^{*}$ & 0.18 & $0.15^{* *}$ \\
\hline Family_age & 0.04 & 0.04 & 0.27 & $0.15^{* * *}$ & 0.10 & 0.07 \\
\hline ROA & 0.17 & $0.20^{* *}$ & 0.09 & 0.07 & 0.04 & 0.04 \\
\hline PM & 0.21 & $0.24^{* *}$ & 0.13 & $0.11^{*}$ & -0.04 & -0.04 \\
\hline ROE & 0.19 & $0.23^{* *}$ & 0.08 & 0.07 & 0.02 & 0.02 \\
\hline ST_Rev & 0.09 & 0.16 & 0.15 & $0.18^{*}$ & 0.05 & 0.06 \\
\hline CF & 0.03 & 0.04 & 0.19 & $0.16^{* *}$ & 0.08 & 0.08 \\
\hline Resid_Var & 0.11 & 0.23 & 0.06 & 0.08 & 0.08 & 0.10 \\
\hline ages & -0.00 & -0.00 & 0.06 & 0.04 & 0.19 & $0.12^{* *}$ \\
\hline MktBeta & 0.12 & 0.25 & 0.06 & 0.09 & 0.06 & 0.09 \\
\hline r12_2 & -0.03 & -0.05 & 0.25 & $0.27^{* * *}$ & 0.09 & 0.12 \\
\hline Spread & 0.13 & 0.26 & 0.06 & 0.08 & 0.04 & 0.07 \\
\hline $\mathrm{D} 2 \mathrm{P}$ & 0.12 & 0.22 & 0.03 & 0.04 & 0.08 & 0.10 \\
\hline r12_7 & -0.05 & -0.10 & 0.20 & $0.23^{* *}$ & 0.14 & $0.19^{*}$ \\
\hline F_r2_1 & -0.01 & -0.03 & 0.19 & $0.23^{* *}$ & 0.09 & 0.12 \\
\hline LTurnover & 0.12 & 0.25 & -0.01 & -0.01 & 0.10 & 0.17 \\
\hline Variance & 0.10 & 0.20 & 0.03 & 0.05 & 0.09 & 0.13 \\
\hline IdioVol & 0.11 & 0.22 & 0.04 & 0.05 & 0.06 & 0.08 \\
\hline C & 0.02 & 0.04 & 0.24 & $0.27^{* * *}$ & -0.04 & -0.04 \\
\hline Lev & 0.07 & 0.11 & 0.03 & 0.03 & 0.11 & 0.11 \\
\hline Family_flow & 0.09 & 0.05 & 0.06 & 0.03 & 0.06 & 0.04 \\
\hline ATO & -0.01 & -0.02 & 0.07 & 0.08 & 0.17 & $0.14^{* *}$ \\
\hline exp_ratio & 0.06 & 0.04 & 0.16 & $0.09^{* *}$ & -0.00 & -0.00 \\
\hline CTO & -0.01 & -0.02 & 0.07 & 0.07 & 0.16 & $0.14^{*}$ \\
\hline tna & -0.06 & -0.05 & -0.06 & -0.03 & -0.06 & -0.05 \\
\hline SUV & 0.01 & 0.01 & 0.12 & 0.12 & 0.04 & 0.04 \\
\hline SGA2S & 0.01 & 0.02 & 0.18 & $0.18^{* *}$ & -0.02 & -0.02 \\
\hline $\mathrm{OL}$ & 0.02 & 0.02 & 0.08 & 0.07 & 0.05 & 0.04 \\
\hline PCM & -0.02 & -0.02 & 0.15 & $0.13^{*}$ & 0.03 & 0.03 \\
\hline r2_1 & 0.02 & 0.03 & 0.12 & 0.13 & 0.03 & 0.03 \\
\hline CF2P & 0.05 & 0.08 & 0.06 & 0.08 & 0.02 & 0.02 \\
\hline NI & 0.09 & 0.13 & -0.09 & -0.11 & 0.14 & $0.15^{*}$ \\
\hline Q & 0.04 & 0.07 & 0.04 & 0.04 & 0.05 & 0.05 \\
\hline FC2Y & 0.01 & 0.01 & 0.14 & $0.15^{*}$ & -0.01 & -0.02 \\
\hline PROF & 0.00 & 0.00 & 0.09 & 0.06 & 0.06 & 0.05 \\
\hline LME & 0.11 & 0.12 & 0.00 & 0.00 & -0.03 & -0.02 \\
\hline D2A & 0.06 & 0.05 & -0.00 & -0.00 & 0.05 & 0.04 \\
\hline turnover & 0.03 & 0.03 & 0.04 & 0.02 & 0.03 & 0.03 \\
\hline $\mathrm{AT}$ & 0.06 & 0.09 & 0.02 & 0.01 & 0.01 & 0.01 \\
\hline OA & 0.14 & $0.14^{*}$ & 0.11 & 0.08 & -0.16 & $-0.13^{* *}$ \\
\hline r36_13 & 0.08 & 0.12 & -0.18 & $-0.19^{* *}$ & -0.04 & -0.04 \\
\hline AC & 0.12 & 0.12 & 0.12 & 0.08 & -0.16 & $-0.12^{* *}$ \\
\hline E2P & -0.03 & -0.04 & -0.04 & -0.05 & -0.01 & -0.02 \\
\hline $\mathrm{OP}$ & -0.01 & -0.01 & -0.02 & -0.02 & 0.13 & 0.11 \\
\hline NOA & -0.02 & -0.02 & 0.12 & 0.09 & -0.02 & -0.01 \\
\hline DPI2A & -0.01 & -0.01 & 0.13 & $0.11^{*}$ & -0.06 & -0.06 \\
\hline A2ME & -0.07 & -0.12 & 0.09 & 0.10 & 0.05 & 0.06 \\
\hline $\mathrm{S} 2 \mathrm{P}$ & 0.05 & 0.09 & -0.08 & -0.10 & -0.02 & -0.03 \\
\hline Investment & -0.05 & -0.07 & 0.10 & 0.09 & 0.00 & 0.01 \\
\hline LT_Rev & 0.09 & 0.13 & -0.13 & -0.11 & 0.02 & 0.02 \\
\hline BEME & 0.11 & 0.14 & -0.10 & -0.11 & -0.03 & -0.04 \\
\hline
\end{tabular}

This table reports summary statistics for univariate long-short factors in different CFNAI terciles. The results are sorted according to the Sharpe ratio of univariate long-short factors. For each of the 59 characteristics, we construct ten sorted decile portfolios. The long-short factors are the differences between the top decile and the bottom decile. We split the time-series into $T^{H}, T^{M}$ and $T^{L}$, which denotes the high, medium and low CFNAI terciles based on the previous months. For each of these time periods we separately estimate "Mean" and "Sharpe ratio", which report the mean and Sharpe ratio of this factor conditional on a CFYAI tercile. The stars are the signifance of t-statistics for the test that factor mean is different from 0 . 


\section{B.2 Spanning}

Table B.6: Spanning of long-short abnormal prediction portfolios with different factor models.

\begin{tabular}{|c|c|c|c|c|c|c|c|c|c|}
\hline & \multicolumn{2}{|c|}{ FF 4 factors } & \multicolumn{2}{|c|}{ FF 5 factors } & \multicolumn{2}{|c|}{ FF 6 factors } & \multicolumn{2}{|c|}{ FF 8 factors } & \multirow[b]{2}{*}{ mean $\mu$} \\
\hline & $\alpha$ & $R^{2}$ & $\alpha$ & $R^{2}$ & $\alpha$ & $R^{2}$ & $\alpha$ & $R^{2}$ & \\
\hline \multirow[b]{2}{*}{ Stock + fund + sentiment } & $\begin{array}{r}0.07 \\
(0.05)\end{array}$ & 0.14 & $\begin{array}{c}0.08^{*} \\
(0.05)\end{array}$ & 0.13 & $\begin{array}{r}0.06 \\
(0.05)\end{array}$ & 0.15 & $\begin{array}{r}0.04 \\
(0.05)\end{array}$ & 0.19 & $\begin{array}{r}0.04 \\
(0.05)\end{array}$ \\
\hline & $\begin{array}{r}0.13^{* * *} \\
(0.04)\end{array}$ & 0.29 & $\begin{array}{l}0.10^{* *} \\
(0.04)\end{array}$ & 0.33 & $\begin{array}{l}0.08^{* *} \\
(0.04)\end{array}$ & 0.36 & $\begin{array}{c}0.07^{*} \\
(0.04)\end{array}$ & 0.37 & $\begin{array}{r}0.13^{* * * *} \\
(0.05)\end{array}$ \\
\hline \multirow[b]{2}{*}{ Stock+ sentiment } & $\begin{array}{r}0.05 \\
(0.04)\end{array}$ & 0.15 & $\begin{array}{r}0.04 \\
(0.04)\end{array}$ & 0.16 & $\begin{array}{r}0.03 \\
(0.04)\end{array}$ & 0.17 & $\begin{array}{r}0.01 \\
(0.04)\end{array}$ & 0.22 & $\begin{array}{r}0.01 \\
(0.05)\end{array}$ \\
\hline & $\begin{array}{c}0.09^{* *} \\
(0.04)\end{array}$ & 0.31 & $\begin{array}{r}0.04 \\
(0.04)\end{array}$ & 0.39 & $\begin{array}{r}0.03 \\
(0.04)\end{array}$ & 0.40 & $\begin{array}{r}0.02 \\
(0.04)\end{array}$ & 0.41 & $\begin{array}{c}0.08^{*} \\
(0.05)\end{array}$ \\
\hline \multirow[b]{3}{*}{ Flow + fund momentum + sentiment } & $\begin{array}{r}0.14^{* * *} \\
(0.05)\end{array}$ & 0.17 & $\begin{array}{r}0.20^{* * *} \\
(0.05)\end{array}$ & 0.04 & $\begin{array}{r}0.16^{* * *} \\
(0.05)\end{array}$ & 0.18 & $\begin{array}{r}0.16^{* * *} \\
(0.05)\end{array}$ & 0.18 & $\begin{array}{r}0.18^{* * * *} \\
(0.05)\end{array}$ \\
\hline & $\begin{array}{r}0.17^{* * *} \\
(0.05)\end{array}$ & 0.16 & $\begin{array}{r}0.22^{* * *} \\
(0.05)\end{array}$ & 0.04 & $\begin{array}{r}0.18^{* * *} \\
(0.05)\end{array}$ & 0.16 & $\begin{array}{r}0.19^{* * *} \\
(0.05)\end{array}$ & 0.18 & $\begin{array}{r}0.20^{* * * *} \\
(0.05)\end{array}$ \\
\hline & $\begin{array}{r}0.11^{* * *} \\
(0.04)\end{array}$ & 0.28 & $\begin{array}{r}0.22^{* * *} \\
(0.04)\end{array}$ & 0.13 & $\begin{array}{r}0.16^{* * *} \\
(0.04)\end{array}$ & 0.33 & $\begin{array}{r}0.18^{* * *} \\
(0.04)\end{array}$ & 0.37 & $\begin{array}{r}0.15^{\text {*** }} \\
(0.05)\end{array}$ \\
\hline F_r12_2+ sentiment & $\begin{array}{r}0.13^{* * *} \\
(0.04)\end{array}$ & 0.30 & $\begin{array}{r}0.25^{* * *} \\
(0.04)\end{array}$ & 0.11 & $\begin{array}{r}0.19^{* * *} \\
(0.04)\end{array}$ & 0.34 & $\begin{array}{r}0.19^{* * *} \\
(0.04)\end{array}$ & 0.34 & $\begin{array}{r}0.19^{* * * *} \\
(0.05)\end{array}$ \\
\hline
\end{tabular}

This table reports the time-series regression results of long-short prediction-weighted decile portfolios for different factor models. We compare different information sets to predict abnormal returns. We consider the 4-factor FamaFrench-Carhart model (market, size, value and momentum), the 5-factor Fama-French model (market, size, value, profitability and investment), a 6-factor model which adds the momentum factor to the Fama-French 5 factors, and an 8-factor model which adds the momentum, short-term reversal and long-term reversal factors to the Fama-French 5 factors. The $\alpha$ column reports the time-series pricing error and $R^{2}$ is the explained variation of the regression. Both the long-short abnormal return portfolios and the factor models are normalized to have a standard deviation of 1 . Standard errors are in brackets and stars denote the significance levels.

\section{B.3 Robustness to Holding Period}

We show that our main findings are robust to longer holding periods. This is relevant as funds are usually held for longer periods. We consider three different robustness tests: (1) we update characteristics annually, (2) we hold each fund investment for one year with overlapping returns and (3) we consider quarterly returns of quarterly updated positions.

First, we construct annually updated monthly abnormal return portfolios. Specifically, we sort funds into portfolios only once a year. We keep the weights constant in the sorting portfolios for 12 months. We use the December characteristics to obtain the decile sorting allocations and update these allocations each December. Then we compute the monthly abnormal returns as before. We report the univariate sorting results in panel (a) of table B.7. Second, we consider overlapping abnormal returns with one-year holding periods. At each time $t-1$, investors use the current month characteristics to form portfolios and hold the portfolio for one year. The overlapping holding results are in panel (b) of table B.7. Last but not least, we consider the abnormal return of investors who rebalance their portfolios every quarter. They rebalanced fund portfolios using the fund characteristics at the end of each quarter and hold the same portfolio for one quarter. These returns 
are not overlapping. For all three specifications, we observe that the Sharpe ratios and average abnormal returns are comparable to the results in Table 3. The fund-specific characteristics, in particular flow and fund momentum, have the highest Sharpe ratio and a statistically significant mean, while most stock-specific characteristics are not significant.

Table B.7: Univariate long-short portfolios from abnormal returns at different holding frequency

\begin{tabular}{|c|c|c|c|c|c|c|c|c|c|c|c|c|}
\hline & \multicolumn{4}{|c|}{ (a) Annually updated characteristics } & \multicolumn{4}{|c|}{ (b) Overlapping annual holdings } & \multicolumn{4}{|c|}{ (c) Quarterly } \\
\hline & mean & std & SR & t-stat & mean & std & SR & t-stat & mean & std & SR & t-stat \\
\hline F_r12_2 & 0.23 & 1.16 & 0.20 & $4.3^{* * *}$ & 0.32 & 2.35 & 0.24 & $5.1^{* * *}$ & 0.20 & 12.82 & 0.19 & $4.0^{* * *}$ \\
\hline F_ST_Rev & 0.18 & 1.18 & 0.16 & $3.4^{* * *}$ & 0.19 & 2.71 & 0.12 & $2.7^{* * *}$ & 0.17 & 8.86 & 0.23 & $4.9^{* * *}$ \\
\hline Family_r12_2 & 0.06 & 0.84 & 0.07 & 1.5 & 0.10 & 1.39 & 0.13 & $2.8^{* * *}$ & 0.05 & 8.29 & 0.07 & 1.4 \\
\hline Beta & 0.24 & 1.13 & 0.21 & $4.6^{* * *}$ & 0.20 & 1.98 & 0.18 & $3.8^{* * *}$ & 0.18 & 9.71 & 0.23 & $4.8^{* * *}$ \\
\hline Rel2High & 0.19 & 1.29 & 0.15 & $3.2^{* * *}$ & 0.26 & 2.29 & 0.20 & $4.2^{* * *}$ & 0.20 & 13.55 & 0.18 & $3.8^{* * *}$ \\
\hline RNA & 0.09 & 0.88 & 0.10 & $2.2^{* *}$ & 0.13 & 1.74 & 0.13 & $2.8^{* * *}$ & 0.07 & 7.36 & 0.12 & $2.6^{* *}$ \\
\hline Family_TNA & 0.08 & 0.73 & 0.12 & $2.5^{* *}$ & 0.10 & 1.23 & 0.14 & $3.0^{* * *}$ & 0.09 & 8.20 & 0.13 & $2.6^{* * *}$ \\
\hline fund_no & 0.07 & 0.73 & 0.10 & $2.2^{* *}$ & 0.10 & 1.24 & 0.14 & $3.0^{* * *}$ & 0.09 & 7.54 & 0.14 & $3.0^{* * *}$ \\
\hline flow & 0.16 & 0.93 & 0.17 & $3.6^{* * *}$ & 0.16 & 1.33 & 0.20 & $4.4^{* * *}$ & 0.05 & 4.71 & 0.12 & $2.6^{* * *}$ \\
\hline Family_age & 0.09 & 0.76 & 0.12 & $2.6^{* * *}$ & 0.10 & 1.26 & 0.14 & $3.0^{* * *}$ & 0.08 & 7.54 & 0.12 & $2.5^{* *}$ \\
\hline $\mathrm{ROA}$ & 0.07 & 0.92 & 0.08 & $1.7^{*}$ & 0.10 & 1.79 & 0.10 & $2.2^{* *}$ & 0.07 & 6.85 & 0.12 & $2.5^{* *}$ \\
\hline PM & 0.06 & 0.94 & 0.06 & 1.3 & 0.14 & 1.64 & 0.14 & $3.1^{* * *}$ & 0.08 & 6.48 & 0.14 & $2.9^{* * *}$ \\
\hline ROE & 0.06 & 0.97 & 0.06 & 1.4 & 0.09 & 1.73 & 0.09 & $2.0^{* *}$ & 0.07 & 7.56 & 0.11 & $2.3^{* *}$ \\
\hline ST_Rev & 0.08 & 1.31 & 0.06 & 1.3 & 0.11 & 2.59 & 0.07 & 1.6 & 0.09 & 7.46 & 0.15 & $3.1^{* * *}$ \\
\hline CF & 0.02 & 0.97 & 0.02 & 0.5 & 0.05 & 1.92 & 0.04 & 0.9 & 0.09 & 10.98 & 0.10 & $2.1^{* *}$ \\
\hline Resid_Var & 0.15 & 1.57 & 0.09 & $2.0^{* *}$ & 0.20 & 2.67 & 0.13 & $2.8^{* * *}$ & 0.18 & 18.18 & 0.12 & $2.4^{* *}$ \\
\hline ages & 0.05 & 0.60 & 0.08 & $1.7^{*}$ & 0.05 & 1.07 & 0.08 & 1.6 & 0.05 & 6.35 & 0.10 & $2.1^{* *}$ \\
\hline MktBeta & 0.12 & 1.65 & 0.07 & 1.5 & 0.13 & 2.79 & 0.08 & $1.7^{*}$ & 0.18 & 17.37 & 0.13 & $2.7^{* * *}$ \\
\hline r12_2 & 0.04 & 1.30 & 0.03 & 0.7 & 0.10 & 2.77 & 0.06 & 1.4 & 0.03 & 13.73 & 0.02 & 0.5 \\
\hline Spread & 0.14 & 1.58 & 0.09 & $1.9^{*}$ & 0.18 & 2.79 & 0.11 & $2.5^{* *}$ & 0.16 & 17.85 & 0.11 & $2.3^{* *}$ \\
\hline $\mathrm{D} 2 \mathrm{P}$ & 0.10 & 1.46 & 0.07 & 1.5 & 0.14 & 2.41 & 0.10 & $2.2^{* *}$ & 0.15 & 15.23 & 0.12 & $2.4^{* *}$ \\
\hline r12_7 & 0.04 & 1.40 & 0.03 & 0.6 & 0.09 & 2.64 & 0.06 & 1.3 & -0.01 & 12.64 & -0.01 & -0.2 \\
\hline F_r2_1 & 0.14 & 1.27 & 0.11 & $2.5^{* *}$ & 0.16 & 2.38 & 0.12 & $2.6^{* *}$ & 0.14 & 8.61 & 0.20 & $4.2^{* * *}$ \\
\hline LTurnover & 0.17 & 1.73 & 0.10 & $2.1^{* *}$ & 0.18 & 2.88 & 0.11 & $2.3^{* *}$ & 0.22 & 19.92 & 0.13 & $2.8^{* * *}$ \\
\hline Variance & 0.16 & 1.62 & 0.10 & $2.1^{* *}$ & 0.20 & 2.83 & 0.12 & $2.6^{* *}$ & 0.20 & 19.48 & 0.12 & $2.6^{* *}$ \\
\hline IdioVol & 0.13 & 1.59 & 0.08 & $1.7^{*}$ & 0.19 & 2.66 & 0.13 & $2.7^{* * *}$ & 0.17 & 18.21 & 0.11 & $2.4^{* *}$ \\
\hline C & -0.01 & 1.23 & -0.01 & -0.2 & 0.05 & 2.37 & 0.03 & 0.7 & -0.02 & 12.20 & -0.02 & -0.4 \\
\hline Lev & 0.10 & 1.20 & 0.08 & $1.7^{*}$ & 0.06 & 2.18 & 0.05 & 1.1 & 0.06 & 10.74 & 0.07 & 1.4 \\
\hline Family_flow & 0.04 & 0.66 & 0.07 & 1.4 & 0.01 & 1.10 & 0.02 & 0.4 & 0.01 & 3.54 & 0.04 & 0.8 \\
\hline ATO & 0.03 & 1.04 & 0.03 & 0.6 & 0.11 & 1.84 & 0.10 & $2.1^{* *}$ & 0.07 & 9.14 & 0.09 & $1.9^{*}$ \\
\hline exp_ratio & 0.04 & 0.73 & 0.05 & 1.1 & -0.01 & 1.17 & -0.01 & -0.2 & -0.04 & 6.50 & -0.07 & -1.5 \\
\hline CTO & 0.05 & 1.02 & 0.05 & 1.0 & 0.09 & 1.74 & 0.09 & $1.9^{*}$ & 0.07 & 7.71 & 0.11 & $2.4^{* *}$ \\
\hline tna & -0.02 & 0.77 & -0.03 & -0.7 & -0.06 & 1.14 & -0.09 & $-2.0^{*}$ & -0.01 & 6.70 & -0.01 & -0.3 \\
\hline SUV & 0.07 & 1.02 & 0.07 & 1.5 & 0.07 & 1.74 & 0.07 & 1.5 & 0.00 & 5.76 & 0.00 & 0.1 \\
\hline SGA2S & 0.04 & 0.95 & 0.04 & 0.9 & 0.06 & 2.13 & 0.05 & 1.0 & 0.04 & 11.44 & 0.05 & 1.0 \\
\hline $\mathrm{OL}$ & 0.05 & 0.97 & 0.05 & 1.1 & 0.09 & 1.71 & 0.09 & $1.9^{*}$ & 0.08 & 8.77 & 0.11 & $2.2^{* *}$ \\
\hline PCM & -0.01 & 0.90 & -0.01 & -0.2 & 0.01 & 1.88 & 0.01 & 0.3 & 0.02 & 7.48 & 0.03 & 0.6 \\
\hline r2_1 & 0.11 & 1.41 & 0.07 & 1.6 & 0.11 & 2.42 & 0.08 & 1.6 & 0.07 & 7.68 & 0.12 & $2.4^{* *}$ \\
\hline CF2P & 0.03 & 1.34 & 0.03 & 0.6 & 0.03 & 2.60 & 0.02 & 0.4 & -0.01 & 13.92 & -0.01 & -0.2 \\
\hline NI & 0.02 & 1.10 & 0.02 & 0.3 & 0.04 & 2.10 & 0.03 & 0.6 & 0.08 & 11.23 & 0.09 & $1.8^{*}$ \\
\hline Q & 0.06 & 1.22 & 0.05 & 1.0 & 0.07 & 2.42 & 0.05 & 1.0 & -0.01 & 11.26 & -0.01 & -0.1 \\
\hline FC2Y & 0.04 & 0.98 & 0.04 & 0.8 & 0.06 & 2.24 & 0.05 & 1.0 & 0.04 & 11.67 & 0.04 & 0.8 \\
\hline PROF & 0.07 & 0.86 & 0.08 & $1.7^{*}$ & 0.04 & 1.90 & 0.04 & 0.8 & 0.11 & 8.71 & 0.15 & $3.2^{* * *}$ \\
\hline LME & 0.05 & 0.87 & 0.06 & 1.2 & -0.01 & 1.21 & -0.01 & -0.2 & 0.01 & 5.89 & 0.01 & 0.2 \\
\hline $\mathrm{D} 2 \mathrm{~A}$ & -0.03 & 0.82 & -0.03 & -0.7 & -0.01 & 1.46 & -0.01 & -0.1 & -0.02 & 6.23 & -0.04 & -0.9 \\
\hline turnover & 0.05 & 0.92 & 0.05 & 1.2 & 0.03 & 1.73 & 0.03 & 0.6 & 0.07 & 12.73 & 0.07 & 1.4 \\
\hline $\mathrm{AT}$ & 0.07 & 1.11 & 0.06 & 1.4 & 0.00 & 1.82 & 0.00 & 0.1 & -0.01 & 8.89 & -0.02 & -0.4 \\
\hline $\mathrm{OA}$ & 0.00 & 0.73 & 0.00 & 0.1 & 0.02 & 1.48 & 0.02 & 0.5 & 0.01 & 5.30 & 0.02 & 0.5 \\
\hline r36_13 & -0.02 & 1.04 & -0.02 & -0.4 & -0.02 & 2.03 & -0.02 & -0.3 & 0.02 & 11.73 & 0.02 & 0.4 \\
\hline $\mathrm{AC}$ & 0.01 & 0.71 & 0.01 & 0.3 & 0.03 & 1.43 & 0.04 & 0.8 & 0.01 & 5.02 & 0.02 & 0.4 \\
\hline E2P & -0.03 & 1.33 & -0.02 & -0.5 & -0.00 & 2.47 & -0.00 & -0.0 & 0.06 & 14.70 & 0.05 & 0.9 \\
\hline $\mathrm{OP}$ & 0.04 & 0.96 & 0.04 & 0.8 & 0.03 & 1.91 & 0.03 & 0.6 & 0.08 & 9.40 & 0.10 & $2.2^{* *}$ \\
\hline NOA & -0.02 & 0.92 & -0.02 & -0.5 & -0.03 & 1.39 & -0.04 & -0.8 & -0.02 & 6.17 & -0.04 & -0.8 \\
\hline
\end{tabular}




\begin{tabular}{rrrrr|rrrrr|rrrr} 
& mean & std & SR & t-stat & mean & std & SR & t-stat & mean & std & SR & t-stat \\
\hline DPI2A & 0.04 & 0.93 & 0.04 & 0.8 & 0.08 & 1.83 & 0.07 & 1.6 & -0.01 & 6.27 & -0.02 & -0.4 \\
A2ME & -0.03 & 1.13 & -0.02 & -0.5 & 0.07 & 2.38 & 0.05 & 1.1 & 0.01 & 11.54 & 0.01 & 0.3 \\
S2P & 0.01 & 1.27 & 0.01 & 0.2 & -0.02 & 2.48 & -0.02 & -0.4 & 0.02 & 13.55 & 0.02 & 0.4 \\
Investment & 0.08 & 1.01 & 0.08 & 1.6 & 0.07 & 2.00 & 0.06 & 1.3 & 0.02 & 7.40 & 0.03 & 0.6 \\
LT_Rev & 0.02 & 0.98 & 0.02 & 0.5 & 0.04 & 1.71 & 0.04 & 0.9 & 0.04 & 9.41 & 0.05 & 1.1 \\
BEME & 0.05 & 1.11 & 0.05 & 1.1 & -0.03 & 2.34 & -0.02 & -0.5 & 0.00 & 11.50 & 0.00 & 0.1 \\
\hline
\end{tabular}

This table reports summary statistics for univariate long-short factors based on fund abnormal returns. Mean and std of abnormal returns are reported in percentages. The results are sorted according to the Sharpe ratio of univariate long-short factors based on abnormal returns, in the same order as in Table 3. In panel (a), the characteristics of mutual funds are updated in December of each year and kept constant throughout the year. Panel (b) reports the results for overlapping annual returns. The standard deviation and t-statistics are reported with Newey-West correction for time-series correlation with 12 lags. Panel (c) displays the results for non-overlapping quarterly abnormal return. For each of the 59 characteristics, we construct ten sorted decile portfolios based on fund abnormal returns. The long-short factors are the differences between the top decile and the bottom decile. The fourth column, " $t$ " reports the $t$-statistics for a test that the factor mean is different from 0 and stars denote the significance levels.

\section{B.4 Net Abnormal Returns}

Figure B.1: Cumulative abnormal net returns of prediction deciles.

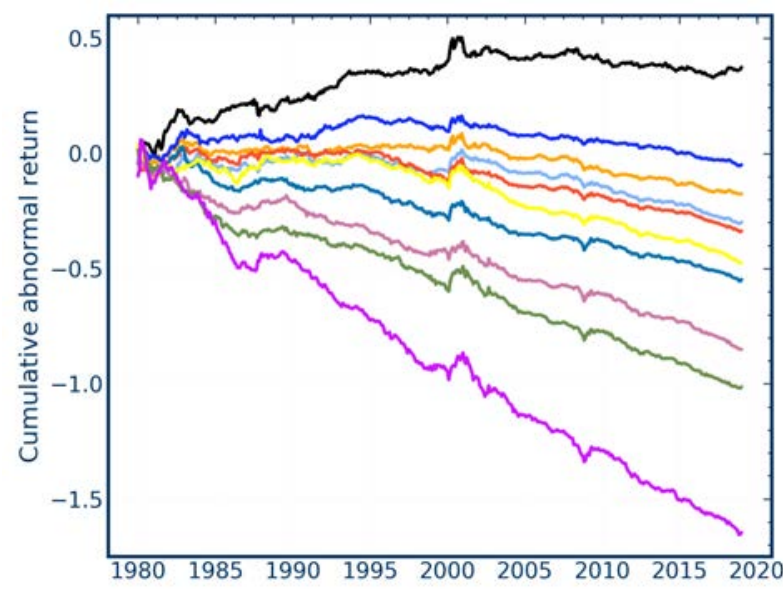

(a) Prediction-weighted abnormal net return

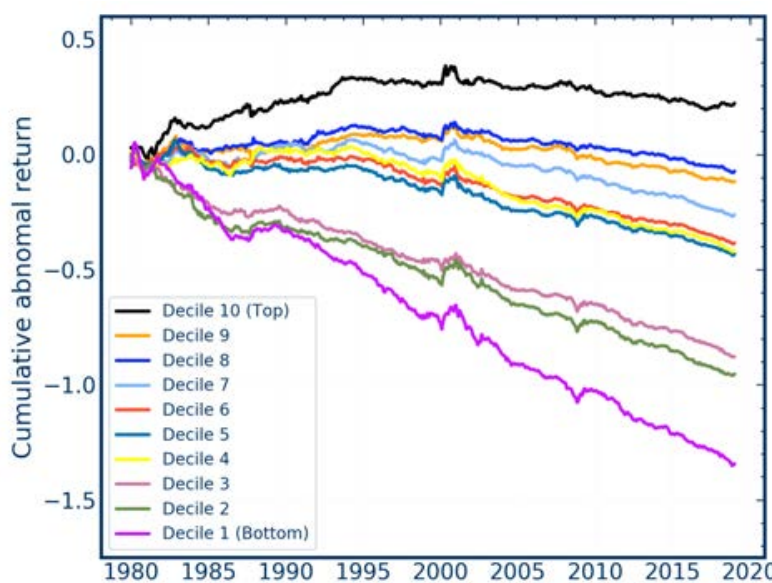

(b) Equally-weighted abnormal net return

These figures show the cumulative abnormal net returns for prediction sorted decile portfolios. We use fund-specific characteristics and sentiment to predict abnormal net returns. The left subfigure weights funds based on their prediction, while the right subfigure equally weights funds within the prediction deciles. 
Figure B.2: Cumulative expense ratios and abnormal net return for equally-weighted deciles.

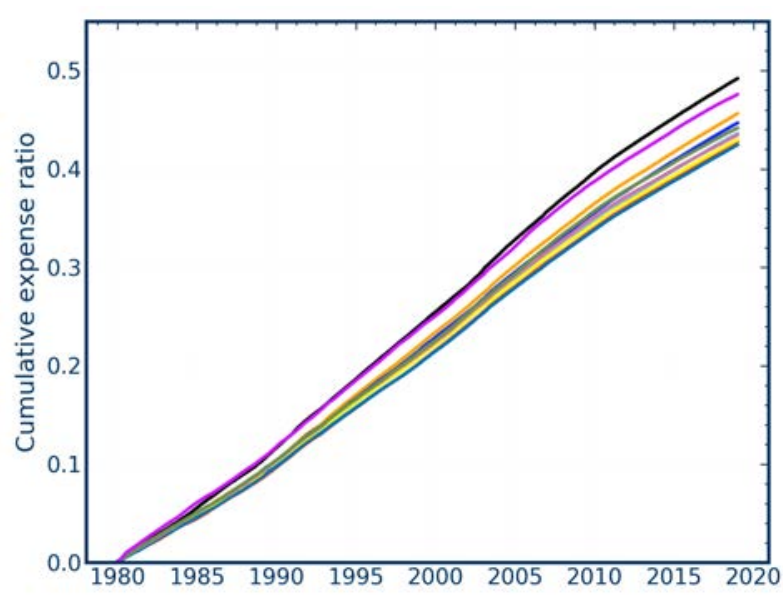

(a) Cumulative equally-weighted expense ratios

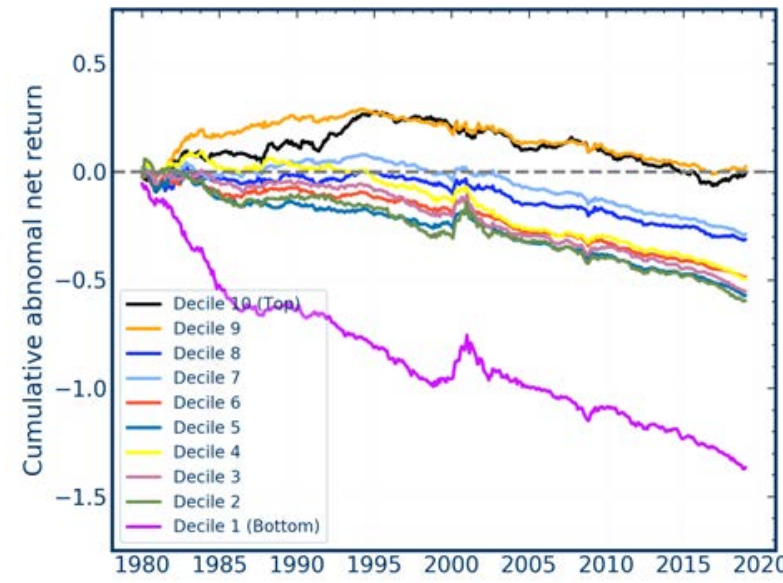

(b) Cumulative abnormal net returns

The left figure shows the cumulative expense ratios of equally-weighted prediction deciles. We use the full information set (fund-specific and stock-specific characteristics + sentiment) to predict abnormal returns. The right figures shows the abnormal net returns for the equally-weighted deciles, that is, the abnormal returns minus the fees.

\section{B.5 Equally-Weighted Prediction Portfolios}

Figure B.3: Cumulative abnormal returns of equally-weighted long-short prediction portfolios.

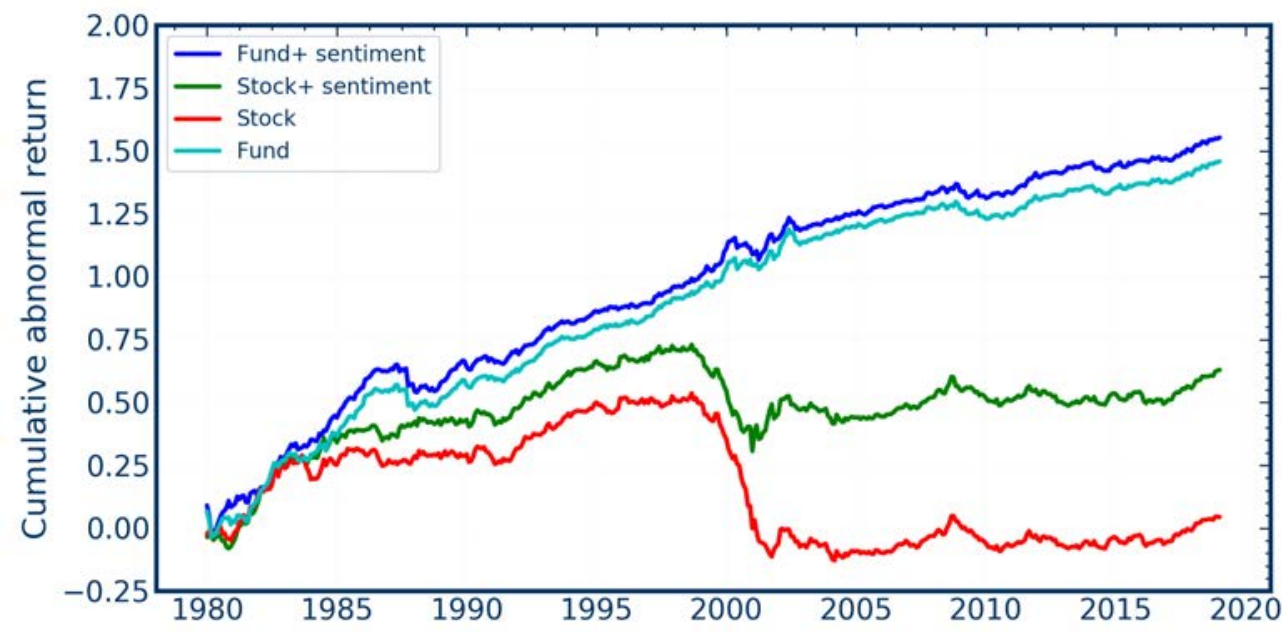

This figure plots the cumulative abnormal returns of equally-weighted long-short decile portfolios that use different information sets to predict abnormal returns. We consider fund-specific and stock-specific characteristics combined with sentiment. 
Figure B.4: Cumulative abnormal returns of equally-weighted deciles for different information sets.

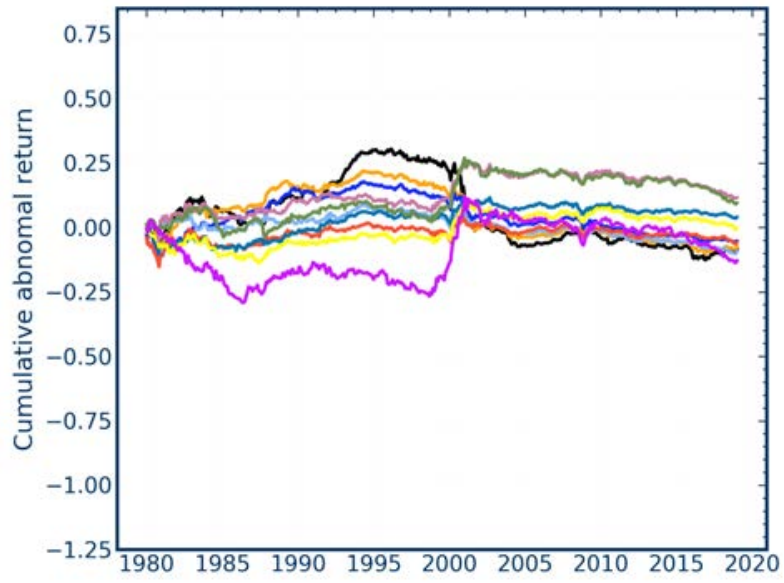

(a) Stock-specific characteristics

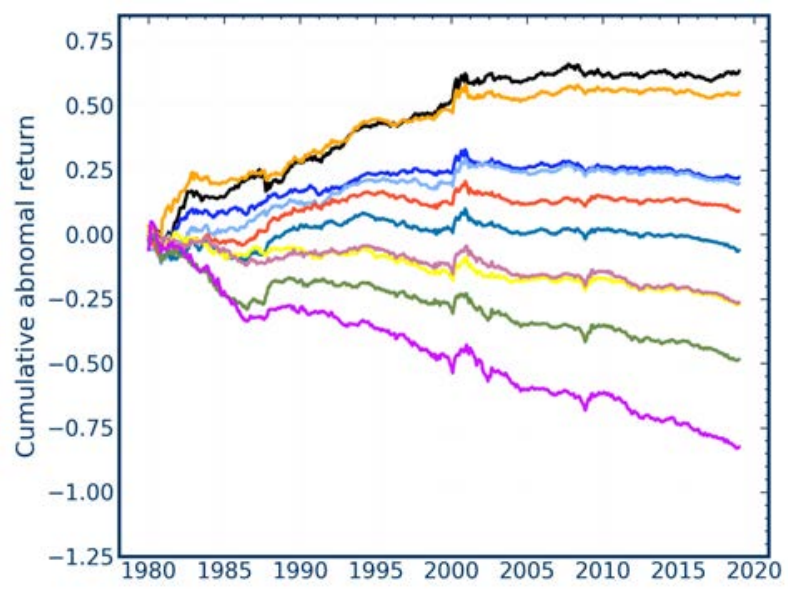

(c) Fund-specific characteristics

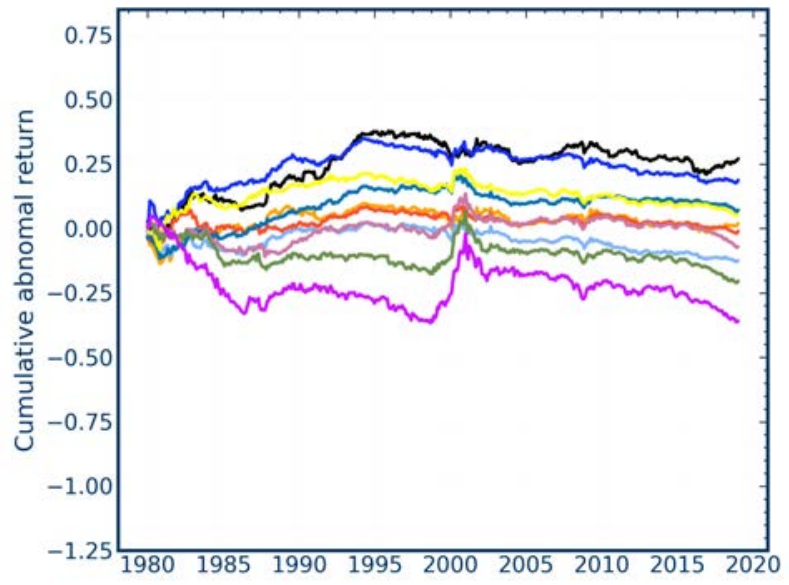

(b) Stocks-specific characteristics + sentiment

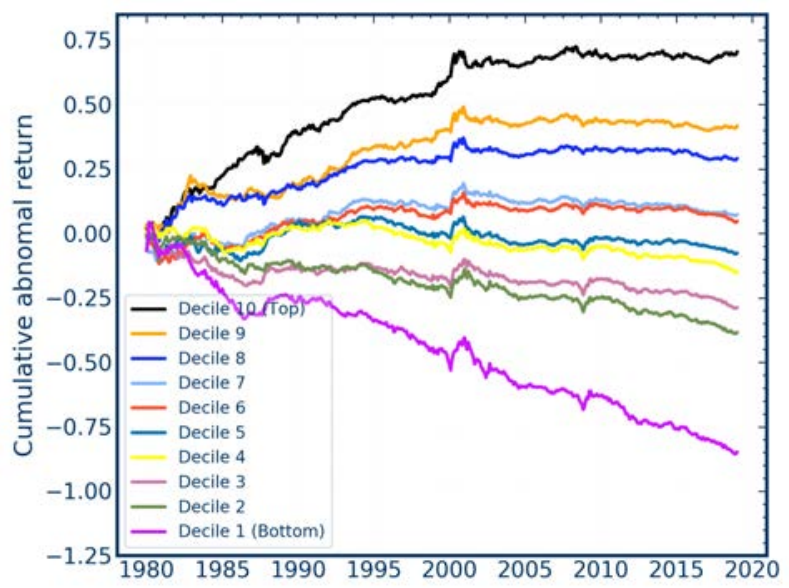

(d) Fund-specific characteristics + sentiment

This figure shows the cumulative abnormal returns sorted into prediction deciles for different information sets. The returns are equally-weighted within deciles. We consider fund-specific characteristics + sentiment, stock-specific characteristics+ sentiment, fund-specific characteristics or stock-specific characteristics to predict abnormal returns. 
Figure B.5: Cumulative abnormal returns of equally-weighted deciles for different information sets.

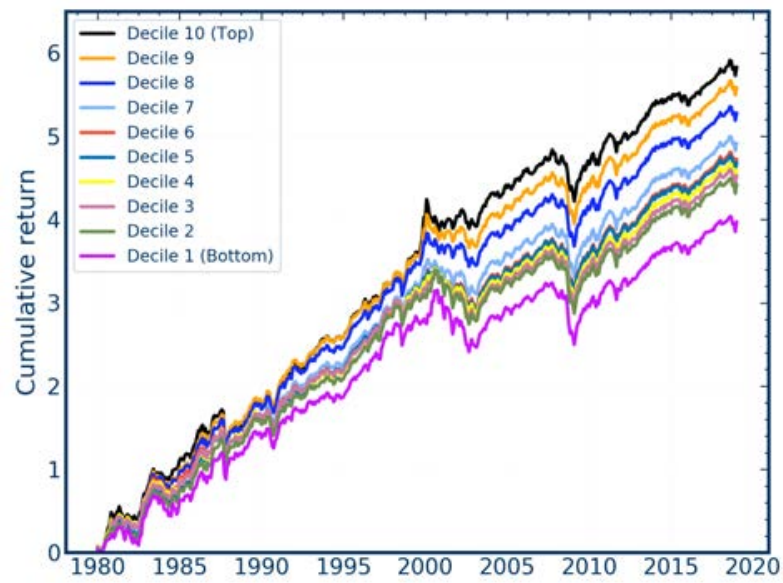

(a) Fund-specific characteristics+ sentiment

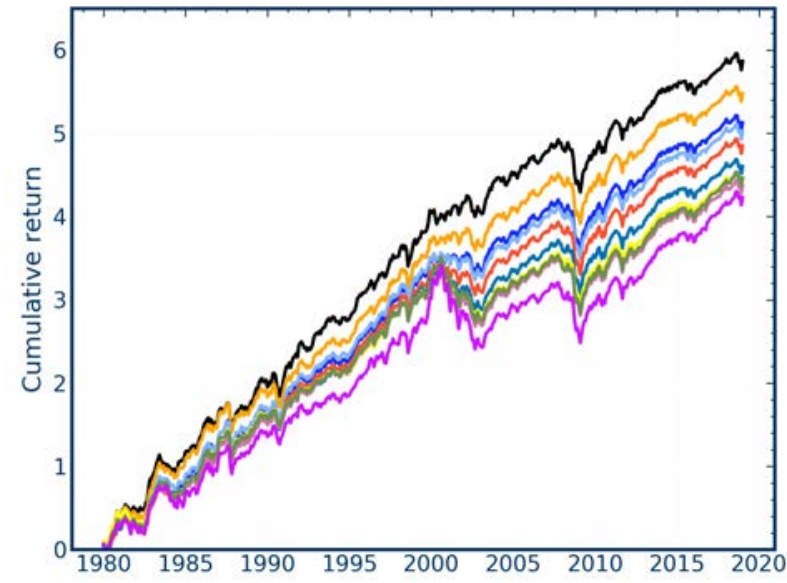

(b) Stock-specific characteristics+ sentiment

This figure plots the cumulative returns sorted into prediction deciles for different information sets. The returns are equally-weighted within deciles. We consider information sets which combine fund-specific and stock-specific characteristics and sentiment to predict returns instead of abnormal returns.

Figure B.6: Cumulative return of long-short portfolio with stock and fund-specific characteristics

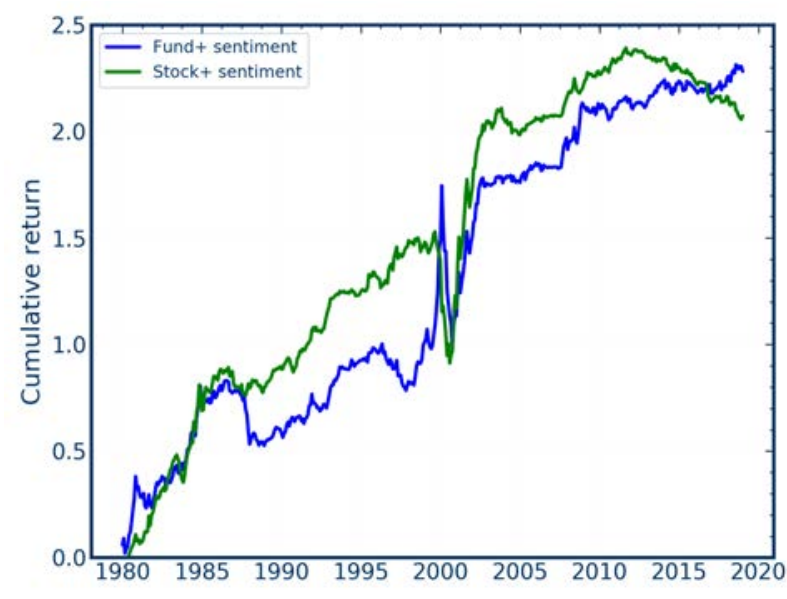

(a) Prediction-weighted

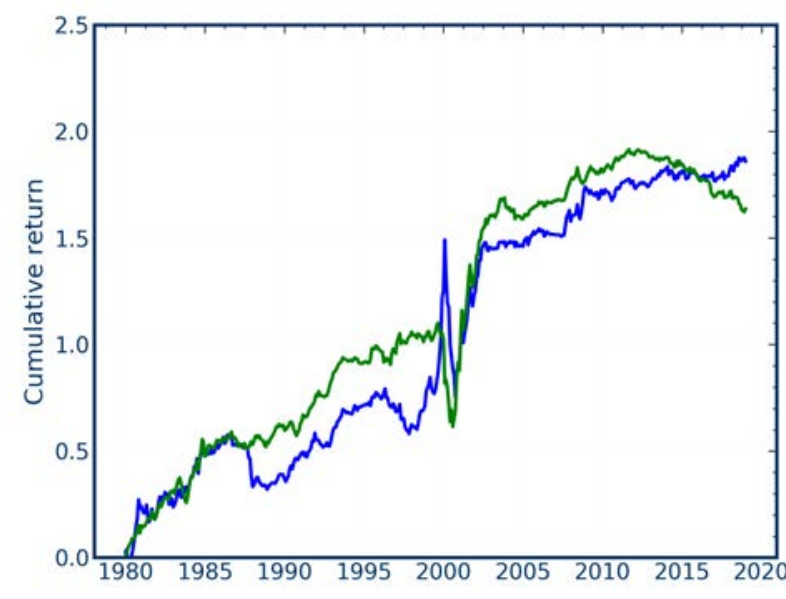

(b) Equally-weighted

This figure plots the cumulative return of long-short decile portfolios that use fund- or stock-specific characteristics and sentiment to predict returns instead of abnormal returns. 
Table B.8: Performance of equally-weighted long-short abnormal return portfolios for different information sets.

\begin{tabular}{rrrrr}
\hline Information set & mean $(\%)$ & t-stat & SR & $R_{F}^{2}(\%)$ \\
\hline Stock+ fund & 0.21 & $3.1^{* * *}$ & 0.14 & 2.03 \\
Stock+ fund+ sentiment & 0.30 & $4.3^{* * *}$ & 0.20 & 4.47 \\
Stock & 0.01 & 0.1 & 0.01 & -1.29 \\
Stock+ sentiment & 0.13 & $1.9^{*}$ & 0.09 & 0.18 \\
Fund & 0.31 & $5.8^{* * *}$ & 0.27 & 0.24 \\
Fund+ sentiment & 0.33 & $5.9^{* * *}$ & 0.27 & 3.50 \\
Flow+ fund momentum+ sentiment & 0.38 & $5.7^{* * *}$ & 0.26 & 1.26 \\
F_r12_2+ sentiment & 0.38 & $6.0^{* * *}$ & 0.28 & 0.43 \\
\hline
\end{tabular}

This table reports the Sharpe ratio, mean and $R_{F}^{2}$ of long-short equally-weighted decile portfolios that use different information sets to predict abnormal returns. We consider eight different information sets which combine fundspecific and stock-specific characteristics and sentiment. We also include flow and fund momentum individually.

Table B.9: Performance of equally-weighted long-short return portfolios for different information sets.

\begin{tabular}{rrrrr}
\hline Information set & mean (\%) & t-stat & SR & $R_{F}^{2}(\%)$ \\
\hline Fund+ sentiment & 0.40 & $2.7^{* * *}$ & 0.13 & 0.56 \\
Fund & 0.44 & $3.2^{* * *}$ & 0.15 & 0.84 \\
Stock+ sentiment & 0.35 & $2.9^{* * *}$ & 0.14 & -18.98 \\
Stock & 0.06 & 0.8 & 0.04 & -55.93 \\
Stock+ fund+ sentiment & 0.35 & $2.9^{* * *}$ & 0.14 & -25.20 \\
\hline
\end{tabular}

This table reports the Sharpe ratio, mean and $R_{F}^{2}$ of long-short equally-weighted decile portfolios based on predicting returns instead of abnormal returns with different information sets. We consider five different information sets which combine fund-specific and stock-specific characteristics and sentiment.

Table B.10: Decomposition of equally-weighted prediction long-short portfolios

\begin{tabular}{r|rr|rr|rr|rrr|rr}
\hline & \multicolumn{2}{|c}{ Total } & \multicolumn{3}{c}{ Between-disclosure } & \multicolumn{2}{c}{ Within-disclosure } & \multicolumn{3}{c}{ Risk difference } & \multicolumn{2}{c}{ Return gap } \\
& SR & mean & SR & mean & SR & mean & SR & mean & SR & mean \\
\hline Stock+fund & 0.14 & $0.21^{* * *}$ & 0.04 & 0.09 & 0.14 & $0.11^{* * *}$ & 0.08 & 0.05 & 0.10 & $0.06^{* *}$ \\
Stock+ fund+ sentiment & 0.20 & $0.30^{* * *}$ & 0.08 & $0.18^{* *}$ & 0.16 & $0.12^{* * *}$ & 0.10 & $0.08^{* *}$ & 0.09 & $0.05^{* *}$ \\
Stock & 0.01 & 0.01 & -0.01 & -0.01 & 0.03 & 0.02 & 0.01 & 0.01 & 0.03 & 0.02 \\
Stock+ sentiment & 0.09 & $0.13^{* *}$ & 0.05 & 0.11 & 0.03 & 0.03 & 0.03 & 0.03 & 0.00 & 0.00 \\
Fund & 0.27 & $0.31^{* * *}$ & 0.15 & $0.17^{* * *}$ & 0.18 & $0.14^{* * *}$ & 0.14 & $0.10^{* * *}$ & 0.07 & $0.04^{* *}$ \\
Fund+ sentiment & 0.27 & $0.33^{* * *}$ & 0.16 & $0.18^{* * *}$ & 0.20 & $0.15^{* * *}$ & 0.16 & $0.11^{* * *}$ & 0.07 & 0.04 \\
Flow+ fund momentum+ sentiment & 0.26 & $0.38^{* * *}$ & 0.13 & $0.20^{* * *}$ & 0.19 & $0.18^{* * *}$ & 0.16 & $0.11^{* * *}$ & 0.11 & $0.07^{* * *}$ \\
\hline
\end{tabular}

This table reports the mean and Sharpe ratio for the decomposition of equally-weighted long-short abnormal return portfolios. We use different information sets to predict abnormal returns. Means of abnormal returns are reported in percentages. The long-short portfolios are the differences between the top decile and the bottom decile. Stars denote the significance level. 


\section{B.6 Macroeconomic Conditioning Variables}

Table B.11: Prediction based classification relative to fund+ sentiment information.

\begin{tabular}{|c|c|c|c|c|c|c|c|c|}
\hline \multirow[b]{2}{*}{ Bin } & \multicolumn{2}{|c|}{$\#$ bin $=2$} & \multicolumn{2}{|c|}{$\#$ bin $=5$} & \multicolumn{2}{|c|}{$\#$ bin $=10$} & \multicolumn{2}{|c|}{$\#$ bin $=20$} \\
\hline & $1 \mathrm{st}$ & 2nd & 1st & 5 th & $1 \mathrm{st}$ & 10th & 1 st & 20th \\
\hline Fund + CFNAI & 0.91 & 0.91 & 0.84 & 0.82 & 0.78 & 0.74 & 0.70 & 0.61 \\
\hline Fund+ sentiment_orth & 0.95 & 0.95 & 0.89 & 0.89 & 0.85 & 0.81 & 0.79 & 0.70 \\
\hline Fund+CFNAI_orth & 0.91 & 0.91 & 0.83 & 0.83 & 0.78 & 0.74 & 0.70 & 0.61 \\
\hline Fund+ sentiment and CFNAI & 0.94 & 0.94 & 0.87 & 0.89 & 0.83 & 0.82 & 0.75 & 0.73 \\
\hline Fund & 0.93 & 0.93 & 0.87 & 0.86 & 0.81 & 0.78 & 0.73 & 0.67 \\
\hline Stock & 0.55 & 0.55 & 0.27 & 0.27 & 0.17 & 0.16 & 0.11 & 0.08 \\
\hline Stock+ sentiment & 0.55 & 0.55 & 0.27 & 0.27 & 0.17 & 0.15 & 0.11 & 0.08 \\
\hline
\end{tabular}

This figure shows the percentage of funds that overlap with the prediction quantiles based on fund+ sentiment information. We consider two, five, 10 or 20 quantiles and six different information sets for predicting abnormal returns. The reference classification is fund + sentiment. 
Figure B.7: Conditional mean as a function of fund characteristics and CFNAI

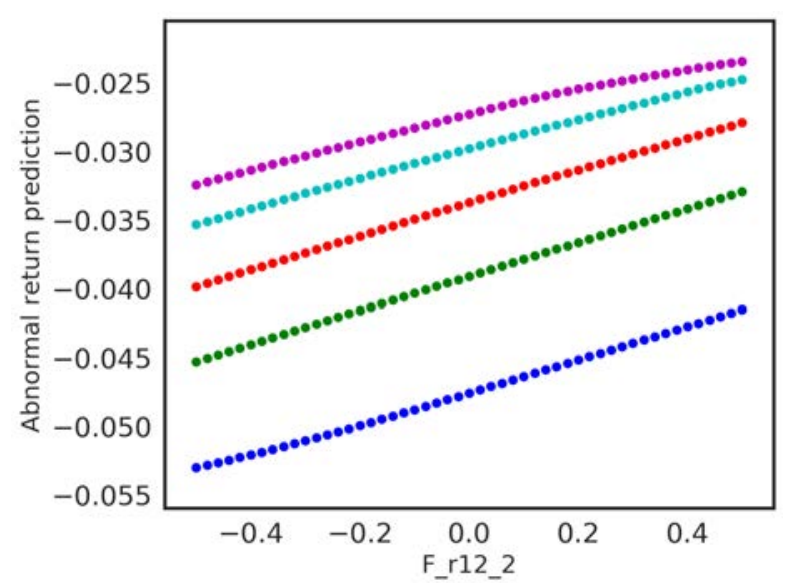

(a) Predicted abnormal returns as function of $F \_r 12 \_2$

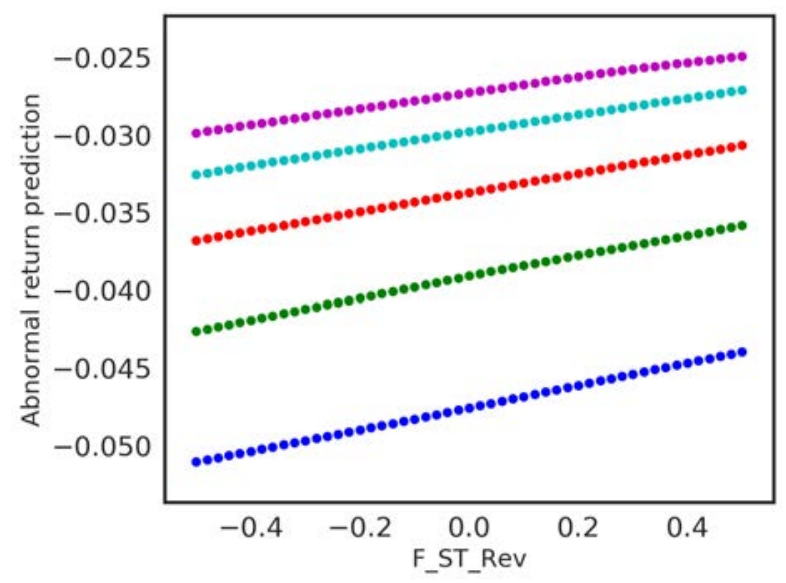

(c) Predicted abnormal returns as function of $F_{-} S T \_R e v$

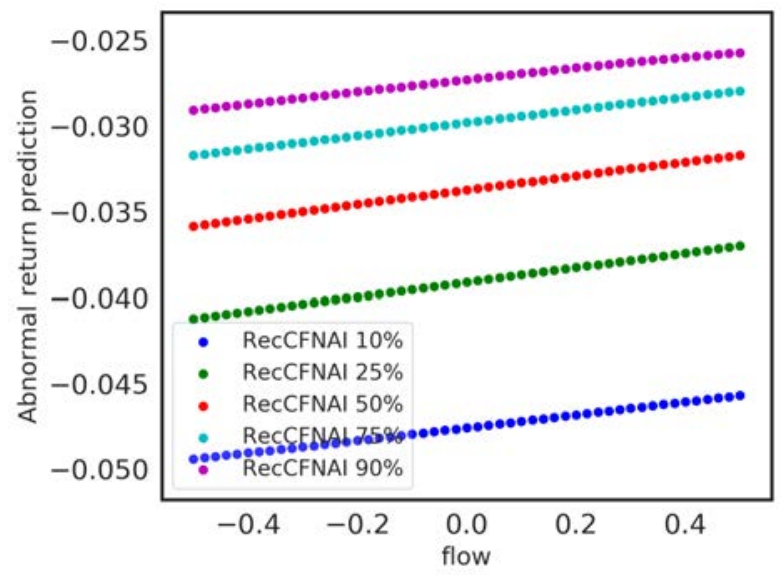

(b) Predicted abnormal returns as function of flow

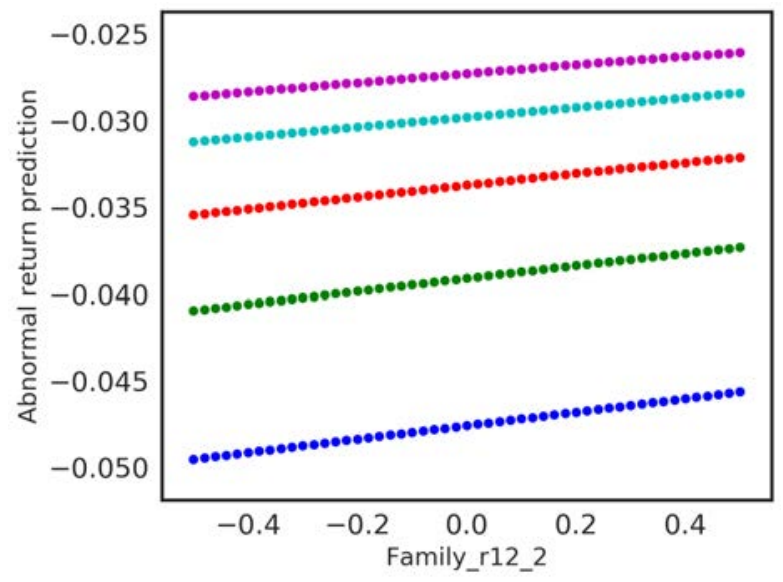

(d) Predicted abnormal returns as function of Family_r12_2

This figure shows the predicted abnormal returns (in percentages) as a function of one fund characteristic and different CFNAI quantiles. The other variables are set to their median values. The neural network model is estimated with fund-specific characteristics and CFNAI. The interaction effects are evaluated on test data and averaged across three cross-out-of-sample folds. The high-minus-low factors have almost the same mean conditional on different past CFNAI. There is essentially no interaction effect.

\section{B.7 Interaction Effects}

Lastly, we assess more general interactions between different fund characteristics. Here, we calculate the interactions between fund-specific characteristics. The interaction measure is defined similar to the main text as:

$$
\begin{aligned}
\operatorname{Interaction}\left(z_{i}, z_{j}\right)= & \left(\hat{R}^{a b n}\left(\text { high } z_{i}, \text { high } z_{j}\right)-\hat{R}^{a b n}\left(\text { low } z_{i} \text {, high } z_{j}\right)\right) \\
& -\left(\hat{R}^{a b n}\left(\text { high } z_{i}, \text { low } z_{j}\right)-\hat{R}^{a b n}\left(\text { low } z_{i} \text {, low } z_{j}\right)\right) .
\end{aligned}
$$


We set the high values of $z_{i}$ and $z_{j}$ to 0.5 , and the low value to -0.5 , which makes the measure symmetric with respect to $z_{i}$ and $z_{j}$, that is, Interaction $\left(z_{i}, z_{j}\right)=\operatorname{Interaction}\left(z_{j}, z_{i}\right)$. The other variables are set to their median values. The results are presented in Table B.12.

Table B.12: Interaction for fund-specific characteristics in the neural network model

\begin{tabular}{rccccc}
\hline & flow & F_r12_2 & F_ST_Rev & Family_r12_2 & turnover \\
\hline F_r12_2 & 0.251 & & & & \\
F_ST_Rev & 0.068 & 0.336 & & & \\
Family_r12_2 & 0.037 & 0.147 & 0.018 & & \\
turnover & 0.004 & 0.070 & 0.050 & -0.020 & \\
F_r2_1 & 0.080 & 0.284 & 0.049 & 0.048 & -0.007 \\
\hline
\end{tabular}

This table shows the interaction measure between the fund-specific characteristics. The results are presented in basis points. The neural networks use fund-specific characteristics and sentiment as input.

\section{Implementation}

Table C.1 summarizes the tuning parameters for the possible network structures. HU, the number of hidden units in each layer, deserves more explanation. The nodes of first layer are 64 or 32 and the number of nodes in each layer is half of the previous layer. For example, for a neural network with 3 layers the number of nodes are 32,16, 8 and 64,32,16. In mathematical terms the number of nodes in the $i$ th layer is $2^{7-i}$ or $2^{6-i}$.

Table C.1: Selection of tuning parameters

\begin{tabular}{r|l|c|c}
\hline Notation & Tuning Parameters & Candidates & Optimal \\
\hline HL & Number of layers in Neural Network & $1,2,3$ & 1 \\
HU & Number of hidden units in each layer & $2^{6-i}$ or $2^{7-i}, i=1$ to HL & 64 \\
DR & Dropout & $0.90,0.95$ & 0.95 \\
LR & Learning rate & $0.001,0.1$ & 0.001 \\
L1 & 11 regularization & $0,1 \mathrm{e}-5$ & 0 \\
L2 & 12 regularization & $0,1 \mathrm{e}-2,1 \mathrm{e}-3$ & 0.01 \\
\hline
\end{tabular}

This table shows the set of tuning parameters, which result in 144 candidate models. The optimal parameters are selected on the validation data.

We obtain robust and stable fits by ensemble averaging over several fits of the models. A distinguishing feature of neural networks is that the estimation results can depend on the starting value used in the optimization. The standard practice which has also been used by Chen, Pelger, and Zhu (2020) is to train the models separately with different initial values chosen from an optimal distribution. Averaging over multiple fits achieves two goals: First, it diminishes the effect of a local suboptimal fit. Second, it reduces the estimation variance of the estimated model. All our neural networks are averaged over eight model fits. 
We split the full time-series sample into three periods of the same length but select the dates randomly for each fold as shown in Figure C.1. We keep the same three randomly selected folds throughout our analysis. We use two of the periods to estimate the model and select the tuning parameters, and evaluate the prediction out-of-sample on the remaining third of the sample. We repeat the estimation on three different combinations of the three time periods and report the average results. The estimation and validation time period is split into $3 / 4$ used for training and $1 / 4$ used for validation to select the optimal tuning parameters from the candidate set in Table C.1. For each combination of candidate tuning parameters we train the network for 512 epochs. Our results are robust to the choice of tuning parameters. In particular, our results do not depend on the structure of the network and all models with good performance on the validation data provide essentially an identical model with the same relative performance on the test data.

Figure C.1: Sentiment time series for the different cross-out-of-sample folds

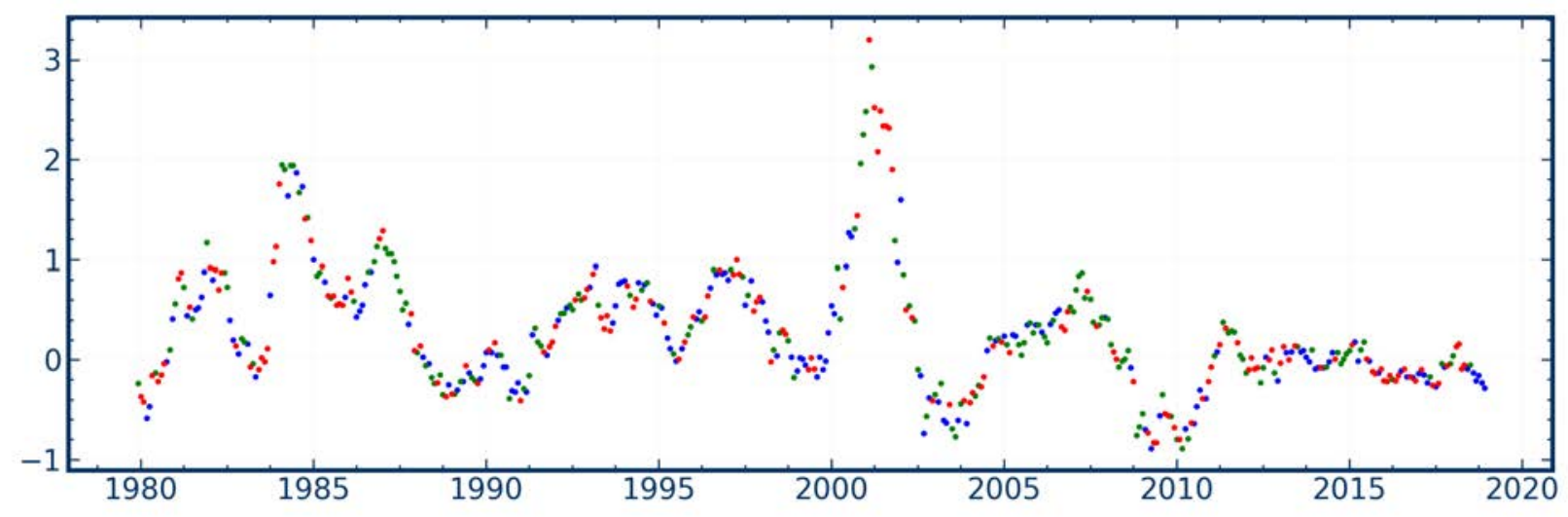

This figure plots the Baker and Wurgler (2006) sentiment measure from 1979/12 to 2018/12. Different colors denote the three different cross-out-of-sample folds, which we use throughout the paper. 